Portland State University

PDXScholar

Summer 8-8-2013

\title{
Academic Advising Structures that Support First- year Student Success and Retention
}

Brett Leland McFarlane

Portland State University

Follow this and additional works at: https://pdxscholar.library.pdx.edu/open_access_etds

Part of the Educational Leadership Commons, Higher Education Commons, and the Student Counseling and Personnel Services Commons

Let us know how access to this document benefits you.

\section{Recommended Citation}

McFarlane, Brett Leland, "Academic Advising Structures that Support First-year Student Success and Retention" (2013). Dissertations and Theses. Paper 1044.

https://doi.org/10.15760/etd.1044

This Dissertation is brought to you for free and open access. It has been accepted for inclusion in Dissertations and Theses by an authorized administrator of PDXScholar. Please contact us if we can make this document more accessible: pdxscholar@pdx.edu. 
Academic Advising Structures that Support First-year Student Success and Retention

\author{
by \\ Brett Leland McFarlane
}

\begin{abstract}
A dissertation submitted in partial fulfillment of the requirements for the degree of
\end{abstract}

\author{
Doctor of Education \\ in \\ Educational Leadership: Postsecondary Education
}

\author{
Dissertation Committee: \\ Janine Allen, Chair \\ Karen Haley \\ Susie Brubaker-Cole \\ Martha Works
}

Portland State University

2013 
(C) 2013 Brett Leland McFarlane 


\begin{abstract}
Academic advising has been touted as a key to student success and retention. Today’s academic advising delivery models vary considerably and little is known about the efficiency and effectiveness of these models. The purpose of this study was to determine if there is a relationship between how academic advising is delivered to firstyear students at a four-year public, high research activity university located on the west coast and the students' satisfaction with advising, advising learning outcomes, and retention. In the study, responses of 628 first-year students to a survey which asked them about their attitudes toward and experiences with academic advising were examined. Results indicated statistically significant relationships between student satisfaction ratings and advising learning outcomes and how advising is delivered, specifically, who advises students, where students are advised, how frequently students are required to see an advisor, how frequently students choose to see an advisor, and how “mandatory" advising is implemented. Furthermore results showed that student retention was related to who advises students and how "mandatory” advising is implemented with peer-led advising processes showing higher student attrition rates than other processes. The overall advising delivery variable effect size was small. Implications for practice and suggestions for future research are discussed.
\end{abstract}




\section{TABLE OF CONTENTS}

Page

ABSTRACT ......................................................................................... i

LIST OF TABLES ...................................................................................... vii

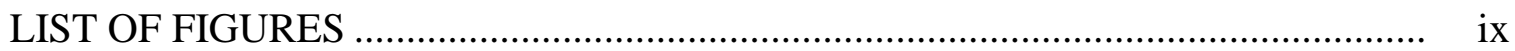

CHAPTER 1: INTRODUCTION TO THE RESEARCH ............................................. 1

Background of the Problem .................................................................................. 3

Statement of Research Problem .................................................................. 13

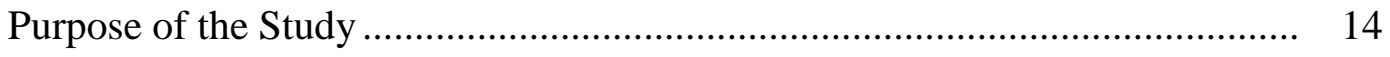

Research Questions ..................................................................................... 15

Research Methodology ……………………………..................................... 18

Organization of Study ………………........................................................ 21

CHAPTER 2: REVIEW OF THE LITERATURE …………………………............ 22

Key Institutional Factors Traditionally Associated with Student Retention ..... 23

Student and Faculty Interaction in Relation to Student Retention..................... 28

Associations Between Academic Advising and Retention ................................ 30

Studies claiming direct associations between advising and retention ... 30

Studies claiming indirect associations between advising and retention 33

Student Satisfaction in Relation to Academic Advising..................................... 35

Student Learning and Academic Advising .................................................... 39

Prescriptive and developmental models - Crookston ............................ 40

O’Banion's developmental advising model............................................ 44

Integrative approach........................................................................... 45 
Page

Recent models .............................................................................. 45

Collaborative approach ............................................................. 46

Praxis approach....................................................................... 47

Advising as problem based learning ........................................... 48

Learning constructs and academic advising .......................................... 48

Advising as learning …………………................................................ 49

Summary of Academic Advising Learning Constructs and Paradigms............. 51

Quality Academic Advising - A Synthesized Learning Paradigm.................... 54

History of Academic Advising in Relation to Advising Delivery Models........ 58

Academic Advising Organizational Models ....................................................... 61

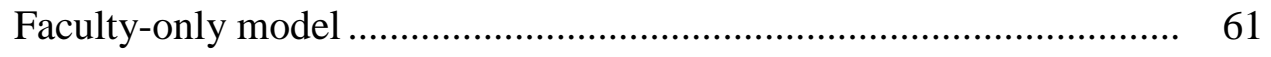

Supplementary advising model............................................................ 62

Split advising model .......................................................................... 62

Dual advising model ........................................................................... 63

Total intake model .......................................................................... 63

Satellite model ................................................................................ 64

Self-contained model ......................................................................... 64

Organizational Model Utilization ................................................................. 64

Advising Delivery Structures in Relation to Student Satisfaction, Learning, and

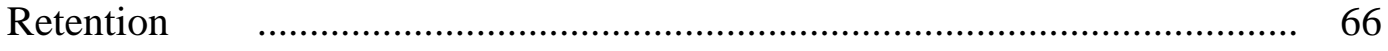

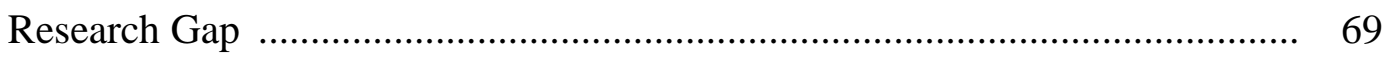

Summary and Conclusion ........................................................................... 70

CHAPTER 3: RESEARCH DESIGN AND PROCEDURES ………………………... 72

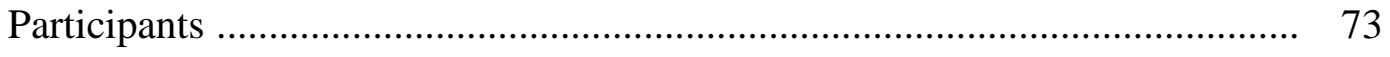

Instrument - Inventory of Academic Advising Functions (Student Version) ... 75 
Measures - Advising Delivery Models............................................................ $\quad 79$

Data Collection Procedures............................................................................. 82

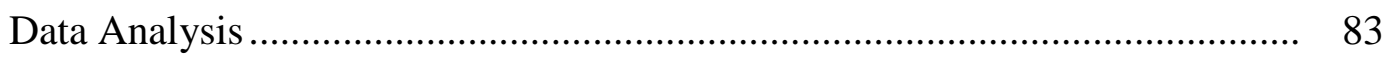

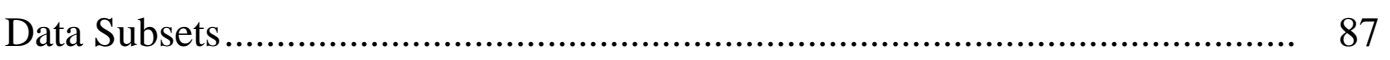

CHAPTER 4: RESULTS AND ANALYSIS OF DATA ………………………...... 89

Research Question One - Who Advises ........................................................ 89

In Relation to Student Satisfaction with Advising.................................. 90

In Relation to Academic Advising Learning Outcomes ........................ 94

In Relation to Student Retention (First-Year to Second-Year).............. 97

Research Question Two - Where Students are Advised ................................... 99

In Relation to Student Satisfaction with Advising................................. 99

In Relation to Advising Learning Outcomes ......................................... 104

In Relation to Retention (First-Year to Second-Year) ............................ 107

Research Question Three - Required Frequency of Advising........................... 109

In Relation to Student Satisfaction with Advising................................. 109

In Relation to Advising Learning Outcomes ............................................ 113

In Relation to Retention (First-Year to Second-Year) ............................ 116

Research Question Four - Self-Report Advising Frequency.............................. 118

In Relation to Student Satisfaction with Advising.................................. 118

In Relation to Advising Learning Outcomes ......................................... 124

In Relation to Retention (First-Year to Second-Year) ............................ 127

Research Question Five - How Mandatory Advising is Implemented............... 129

In Relation to Student Satisfaction with Advising................................. 129 
In Relation to Advising Learning Outcomes .......................................... 134

In Relation to Retention (First-Year to Second-Year) ........................... 137

CHAPTER 5: DISCUSSION OF RESULTS, LIMITATIONS OF RESEARCH, IMPLICATIONS FOR PRACTICE, SUGGESTIONS FOR FUTURE RESEARCH.. 139

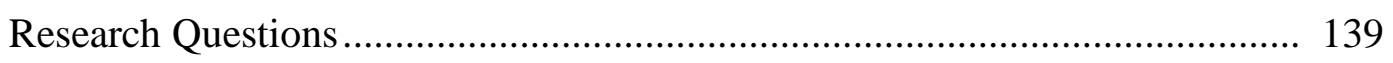

Who Advises Students - Discussion of Results ............................................... 141

Professional Advisors versus Faculty Advisors...................................... 141

Peer Advisors versus Faculty and Professional Advisors...................... 144

Where Advised - Discussion of Results ........................................................... 145

Central by College versus Decentralized................................................ 145

Central by Major versus Decentralized................................................... 146

Central by College versus Central by Major........................................... 146

Required Advising Frequency - Discussion of Results..................................... 147

Self-Report Advising Frequency - Discussion of Results................................. 150

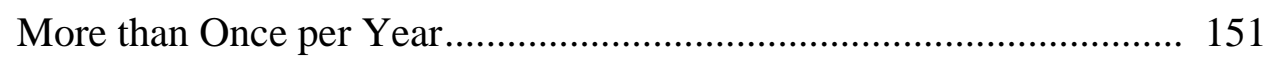

Once per Year versus Not Seeking Advising ........................................ 153

How Mandatory Advising is Implemented - Discussion of Results ................. 154

PIN from Advisor versus Group Led Process......................................... 154

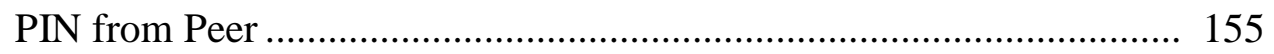

Implications for Practice and Recommendations for Future Research............... 156

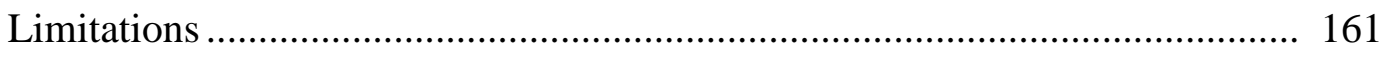

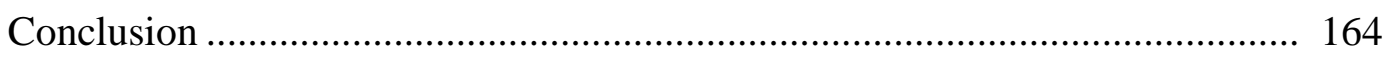

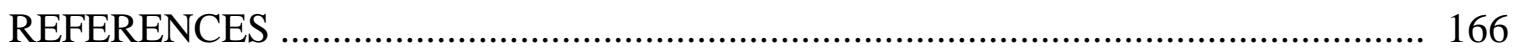


APPENDIX A: INVENTORY OF ACADEMIC ADVISING FUNCTIONS (STUDENT

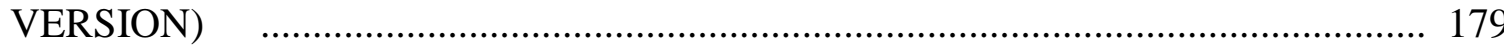

APPENDIX B: EMAILS TO STUDENTS REGARDING SURVEY ............................ 193

APPEDIX C: STUDENT DEMOGRAPHIC AND ENROLLMENT DATA AND DEFINITIONS FROM STUDENT INFORMATION SYSTEMS AND SURVEY .... 197 


\section{LIST OF TABLES}

\section{Page}

Table 1: Demographic Data of First-Year Freshman Surveyed ................................... 74

Table 2: Academic Advising Functions and Variable Names ........................................ 76

Table 3: Advising Learning Outcomes and Variable Names ........................................ 78

Table 4: Satisfaction Ratings on Advising Functions: By Who Advises - Numbers, Means, and Standard Deviations of Satisfaction Ratings for Each Group, and ANCOVA

Results.................................................................................................. 92

Table 5: Learning Outcomes: By Who Advises - Numbers, Means, and Standard Deviations of Learning Outcome Scores for Each Group, and ANCOVA Results ...... 96

Table 6: Retention First-Year to Second-Year: By Who Advises - Numbers, Means, and Standard Deviations of Retention Results for Each Group, and ANCOVA Results.... 98

Table 7: Satisfaction Ratings on Advising Functions: By Where Advised - Numbers, Means, and Standard Deviations of Satisfaction Ratings for Each Group, and ANCOVA

Results

Table 8: Learning Outcomes: By Where Advised - Numbers, Means, and Standard Deviations of Learning Outcome Scores for each Group, and ANCOVA Results ....... 106

Table 9: Retention First-Year to Second-Year: By Where Advised - Numbers, Means, and Standard Deviations of Retention Results for Each Group, and ANCOVA Results 108

Table 10: Satisfaction Ratings on Advising Functions: By Required Advising Frequency - Numbers, Means, and Standard Deviations of Satisfaction Ratings for Each Group, and

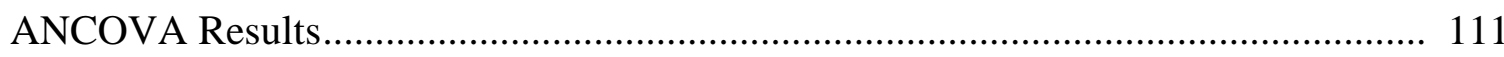

Table 11: Learning Outcomes: By Required Advising Frequency - Numbers, Means, and Standard Deviations of Learning Outcome Scores for Each Group, and ANCOVA Results

Table 12: Retention First-Year to Second-Year: By Required Advising Frequency Numbers, Means, and Standard Deviations of Retention Results for Each Group, and ANCOVA Results. 
Table 13: Satisfaction Ratings on Advising Functions: By Self-Report Advising Frequency - Numbers, Means, and Standard Deviations of Satisfaction Ratings for Each Group, and ANCOVA Results....

Table 14: Learning Outcomes: By Self-Report Advising Frequency - Numbers, Means, and Standard Deviations of Learning Outcome Scores for Each Group, and ANCOVA Results

Table 15: Retention First-Year to Second-Year: By Self-Report Advising Frequency Numbers, Means, and Standard Deviations of Retention Results for Each Group, and ANCOVA Results.

Table 16: Satisfaction Ratings on Advising Functions: By How PIN Delivered Numbers, Means, and Standard Deviations of Satisfaction Ratings for Each Group, and Group ANCOVA Results

Table 17: Learning Outcomes: By How PIN Delivered - Numbers, Means, and Standard Deviations of Learning Outcome Scores for Each Group, and ANCOVA Results ...... 136

Table 18: Retention First-Year to Second-Year: By How PIN Delivered - Numbers, Means, and Standard Deviations of Retention Results for Each Group, and ANCOVA Results

Table 19: Mandated Frequency of Advising at Study Institution versus Student SelfReport Frequency of Advising 


\section{LIST OF FIGURES}

Page

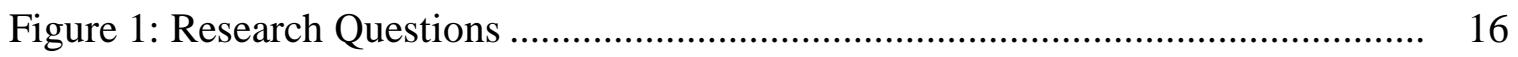




\section{Chapter 1}

\section{Introduction to the Research}

The long-term personal financial benefits of completing a four-year degree have been well documented throughout the last several decades. On average over a lifetime, a four-year college graduate will earn roughly twice that of someone without a college degree (Day, Newburger, \& Bureau, 2002; Pascarella \& Terenzini, 2005). In addition, research has shown that college graduates have significant gains in cognitive growth, psychosocial maturity, moral development, intellectual reasoning, and communication skills as well as a better understanding of cultural and racial diversity when compared to non-graduates (Pascarella \& Terenzini, 2005). Perhaps as important as the personal benefits is the impact college graduates have on the social and economic fabric in the United States. Statistically significant ties have been identified between college graduation and lower unemployment rates, higher tax generation rates, a decreased demand on public budgets, improved health, lower incarceration rates, higher levels of civic engagement and participation, and higher levels of volunteer work in general (Baum \& Payea, 2004). These educational advantages are clearly aligned with economic advantage in the world as well. Countries with the most educated populace also have the highest gross domestic product (GDP) and highest standards of living (World Bank, 2010). 
Along with the personal and societal benefits of a college education, there are significant personal and societal costs for students who begin a college career without graduating. Institutions spend millions of dollars on student recruitment, services, and education that do not propel students to graduation. Increases in college attendance over the last twenty five years has not been met with a proportional increase in college graduates (Bound, Lovenheim, \& Turner, 2010). A recent study found that over a five year period, state appropriations exceeding six billion dollars went to first-year college students who never made it to a second year (Schneider, 2010). Perhaps most devastating, students accumulate significant debt without the necessary earning power afforded by a college degree to pay back this debt (Dwyer, McCloud, \& Hodson, 2012). Without the earning power necessary to repay accumulated debt, students who would otherwise be net contributors to GDP instead become a drain to the economic system as a whole. Higher education may be doing a disservice to students and the community alike by not dedicating greater resources towards more effective student retention strategies.

Undergraduate student retention and graduation rates continue to lag throughout the United States. On average, only 55\% of students who start a four-year bachelor's degree at a public institution in this country will actually graduate within six years (Chapman, Laird, \& Kewal-Ramani, 2010). Even more discouraging, the percentage of students who complete baccalaureate degrees has only improved by two points over the last ten years despite a multitude of programs and interventions designed to improve student retention (Chapman et. al., 2010). National data indicate that most attrition occurs during the first year of a student's enrollment in four-year public institutions, with 
institutions losing an average of $25 \%$ of their students before the second year (ACT, 2010). These statistics are alarming, and highlight the need for an increased focus nationwide on public policy related to student retention at our institutions of higher education.

In response to these gloomy retention percentages, many institutions are creating new strategies for student retention as part of their institutional goals. The number of leadership positions in higher education with “retention” as a key charge is becoming more common as institutional leaders focus on which practices hold the most promise for retaining students on a consistent and long-term basis (ACT, 2010). One strategy that has regularly been identified by campus policy makers as important to improving retention rates is academic advising (Habley \& McClanahan, 2004).

\section{Background of the Problem}

While academic advising is often touted as a key factor in student retention, how advising is related to retention is not clear. Some studies suggests that the relationship between academic advising and retention is direct (Peterson, Wagner, \& Lamb, 2001;

Schertzer \& Schertzer, 2004). Other studies point to an indirect effect based upon factors such as relationships with faculty and staff (Allen \& Smith, 2008; Astin, 1993; Avants, 2004; Grosset, 1991; Kuh, Kinzie, Buckley, Bridges, Hayek, 2007; Smith, 2004; Yarbrough, 2010).

To better understand how academic advising might affect retention it is important to consider what constitutes quality academic advising. Historically, quality academic 
advising has been conceptualized as a form of teaching focused on student development (Smith \& Allen, 2006). This perspective, based on the original conceptualizations of Crookston (1972) and O’Banion (1972), is most commonly termed “developmental advising.” According to Smith and Allen, developmental advising is a student-centered process that

- acknowledges the individuality of students,

- $\quad$ assists students with integrating life, career, and educational goals,

- helps students connect curricular and co-curricular aspects of their educational experience, and

- provides scaffolding that gives students opportunities to practice decisionmaking and problem-solving skills in an atmosphere of shared responsibility (p. 56).

Developmental advising is often presented as the antithesis of prescriptive advising which, in contrast to developmental advising, is based on the authority and primary responsibility of the advisor. Prescriptive advising involves providing information and telling students what to do and what they need to know, rather than offering them choices and opportunities for decision-making (Smith \& Allen, 2006). As such, this kind of advising focuses on meeting academic requirements. The presumption of the recent conceptual dichotomy of developmental versus prescriptive advising is that developmental advising is what students need and what students want. 
Smith and Allen (2006) challenged the forced-choice distinction between prescriptive and developmental advising suggesting that it presents a false dichotomy. They argued that conceiving and measuring the two types of advising as a dichotomy does not allow students to tell researchers that both types of advising may be important and relevant. Indeed, Smith and Allen found that, while students see the importance of developmental advising, they also consider prescriptive advising that involves dispensing accurate information as highly important.

Smith and Allen (2006) examined the academic advising literature since 1972 and identified 12 crucial advising functions that cross both the prescriptive and developmental perspectives. These 12 advising functions operationalize five domains Smith and Allen identified as essential to the advising role: integration, referral, information, individuation, and shared responsibility. The authors describe the integration functions as involving holistic advising which assists students in connecting their curricular and co-curricular choices to academic, career, and life goals. The referral functions comprise referral to both academic and non-academic resources based on problems a student may encounter which may be detrimental to goal achievement. The information functions relate to advisors providing students with accurate information about degree requirements as well as helping students understand how things work, particularly with regard to policies and procedures at a given institution. The individuation functions focus on knowing the student as an individual based on the student's skills, interests, and abilities. The shared responsibility function involves 
helping students develop problem-solving, planning, and decision-making skills while students take greater responsibility for their success and progress in higher education.

Within the academic advising profession a new paradigm is emerging that focuses on what students learn when they receive quality academic advising. This learningcentered paradigm views advising as a teaching and learning function imbedded within the academy (Hemwall \& Trachte, 1999, 2005; Lowenstein, 2005). Learning-centered advising presumes that "it is through academic advising that students acquire the knowledge and learn the skills and predisposition to successfully navigate the educational environment and earn a degree” (Smith \& Allen, 2012, p. 1). Thus, from the perspective of the learning paradigm, it is through what students learn from quality academic advising that facilitates retention. Based largely on the 12 advising functions that operationalize their conception of the five domains of quality academic advising, Smith and Allen (2012) identified eight learning outcomes that represent "what students should be able to know, do, and value or appreciate” (p. 5) as a result of quality academic advising encounters. Smith and Allen posit that from advising encounters students know (1) what requirements they must fulfill in order to earn their degree, and (2) where they can go to get help with problems. They should also understand (3) how things work at their institution with regard to policies and procedures and (4) how their academic choices connect to their career and life goals. Furthermore, students should develop (5) a plan to achieve their educational goals and (6) at least one relationship with a faculty or staff member at their institution who has had a significant and positive influence on them. Finally, (7) students should appreciate the importance of establishing an advisor/advisee 
relationship with someone on campus and (8) that advising should be mandatory for all students. Smith and Allen found that where and how often students received advising was associated with all eight learning outcomes. Students who accessed advising and did so more often scored higher on all eight learning outcomes than those who were not receiving advising or who were receiving it less often. In addition, Smith and Allen found that students who got information about what classes to take to meet requirements from advisors rather than from advising materials (e.g., websites, handouts, bulletins) or from persons in their informal social support networks (i.e., friends, other students, family members) scored higher on all eight advising learning outcomes.

Unfortunately, despite the widely held belief that academic advising can contribute either directly or indirectly to student retention and learning, advising continues to be a college experience that is rated among the lowest in student satisfaction (Allen, Smith, \& Muehleck, 2012; Astin, Green, \& Korn, 1987; Astin, 1993; Keup \& Stolzenberg, 2004; Low, 2000; Lyons, 1991; Nordquist, 1993). In addition, students report discrepancies between what is important to them in academic advising and their level of satisfaction with the advising they are receiving (Smith \& Allen, 2006). Allen and Smith (2008) also found that what students deem as important in an advising relationship does not align with what faculty believe is their responsibility in an advising relationship. This dissonance may be an additional contributor to student dissatisfaction with advising. 
It is important to consider that students' satisfaction with their academic experience is no trivial matter. Alexander Astin (1993) states, “...it is difficult to argue that student satisfaction can be legitimately subordinated to any other education outcome” (p. 273) when he speaks of students' perceptions of their educational experience. Indeed, Schreiner (2009) found that for each class level, freshman year through senior year, satisfaction indicators almost "doubled the ability to predict retention beyond what demographic characteristics and institutional features could predict” (p. 3). And in a subsequent single institution study that looked specifically at advising satisfaction and degree completion time, Guillén (2010) found a statistically significant relationship between time to degree and student satisfaction specifically with advising. These research findings suggest that student satisfaction with advising may be an important factor in the advising/retention relationship.

Given the association between advising and retention, it behooves colleges and universities to deliver advising in a manner that maximizes student learning and satisfaction, and ultimately retention. It is important to consider the various ways students receive academic advising, where the advising is done, and who is doing the advising. Limited research has been done on the effectiveness of various advising models, and in particular, student satisfaction with particular advising models (Avants, 2004; Kennedy-Dudley, 2007; Smith, 2004). The research that has been done has focused on identifying how institutions deliver advising rather than the efficacy of the models used. This line of inquiry into the models used by institutions has been 
dominated by a taxonomy developed by Wes Habley in 1983. Habley’s taxonomy posits seven structures that represent how advising is delivered across all types of institutions.

- Faculty-Only Model: Instructional faculty complete all academic advising. There are no professional advising offices.

- Supplementary Model: All students are assigned a faculty advisor. Advising offices exist for general information and referral.

- Split Model: Specific groups of students are advised in an advising office, while others are assigned to faculty advisors or academic units.

- Dual Model: Each student has two advisors. Instructional faculty advise students on major requirements, while an advising office advises students on general requirements, procedures, and policies.

- Total Intake Model: Administrative units are responsible for all advising until a specific event or requirements have been met. At this point instructional faculty take over advising, for example, after a specified set of foundational courses have been completed.

- Satellite Model: Each school or college within the institution has established its own approach to advising.

- Self-contained Model: Staff in centralized units advise students from matriculation to graduation (pp. 535-540).

Based on his taxonomy of advising delivery models, Habley (2004) surveyed hundreds of institutions across the United States in 1987, 1992, 1998, and 2003. Habley 
specifically asked survey respondents to identify the one model that most closely represents advising on their campuses (Habley, 2004, p. 18). He then compiled these responses to show models that are most prevalent in each institutional type:

- Two-Year Public: the "self-contained" model is most prevalent

- Two-year Private: the "faculty-only" model is most prevalent

- Four-year Public: the "split" model continues to be most prevalent

- Four-year Private: the "faculty-only" model is most prevalent (p. 20).

Habley examined trends and changes in how institutions deliver advising over a two-decade period, and found an increase in the use of professional advisors, and a decrease in the use of teaching faculty to deliver advising (Habley, 2004). Although Habley's survey asks respondents to select one of his models to describe how advising is delivered on their campus, individual academic units within an institution may use a different model. For example, what Habley himself recognizes as his "satellite" model in reality may represent a combination of a "split" model, a "faculty-only" model, and a "total intake" model all present on the same campus.

Data from the most recent national survey on academic advising highlighted how Habley's models continue to be ineffective in describing how academic advising is structured for many institutions (Carlstrom, in press). Over 120 representatives from responding institutions commented that none of the advising models accurately represent how advising is structured at their institution (Miller, in press). While the models that Habley describes are helpful for broad categorization purposes, they are not helpful in 
creating an institutional snapshot of the structural diversity within individual institutions, nor do they address the "efficiency" of the various advising models that he identifies. Since 1983 when Habley developed these models, there have been dramatic changes in the diversity of students, in the use of technology in advising, in "who" delivers advising, and in the learning outcomes that educators hope students achieve through advising encounters. A more flexible and adaptive view of advising structures may be required; one that allows for the focused assessment of student learning outcomes and is adaptable across institutional types.

Miller (in press) posits shifting the conversation to a four dimensional focus on advising structures, namely "who is advised," "who advises,” "where is advising done,” and "how are advising responsibilities divided among advisors" (pp. 1-2). She believes that by simplifying the discussion on structures, we can have more meaningful conversations regarding how advising is delivered. The "who is advised" refers to certain student populations such as first-generation students, international students, students on probation, or first-year students. The "who advises" can represent faculty, professional advisors, peers, or counselors. The "where is advising done" component may be a faculty office, a major-centric advising center, online advising, or a university centralized advising center for all students. Finally, the "how are advising responsibilities divided" component would identify if students receive advising from one particular assigned advisor, a cadre of advisors, or a more individualized scenario. Miller's approach identifies individual variables that, when combined, purport to present a more accurate advising structural snapshot for a particular student or student population, at a particular 
point in time. An example might be first-year students at a four-year public urban university, studying pre-business, advised by a professional advisor in a centralized prebusiness advising office. Miller's approach also presents a structure that is more functional for use in individualized institutional assessment of learning outcomes, particularly regarding the "efficiency" of a particular advising model for a particular student population.

While Miller's (in press) four dimensional focus on advising structures provides a framework for assessment, it is lacking a variable that has been identified in the literature as a key to student retention and advising learning outcomes; that factor is the frequency with which a student sees an academic advisor (Astin, 1977; Beal \& Noel, 1980; Lowe \& Toney, 2000; Metzner, 1989; Pascarella \& Terenzini, 1977; Smith \& Allen, 2012). Some institutions do not require any of their students to ever see an academic advisor, while other institutions may require that a student meet with an academic advisor several times throughout the year. Foundational work by Pascarella and Terenzini (1977) identified faculty interaction with, and concern for, students as the greatest contributors to the identification of which students stay and which depart. Research has shown that students who meet with their advisor on a regular basis are more likely to also be involved in a range of educationally purposeful activities outside of the classroom (Kuh et al., 2006). Finally, Smith and Allen (2012) found that the frequency of advisor contact was directly related to the learning that occurs from academic advising. In their multi-institutional study involving over 22,000 students at nine institutions, Smith and Allen found that students who were advised "frequently” or even "occasionally” scored significantly 
higher in advising learning outcomes than those who were "not advised." Based on this past research, it is reasonable to assert that a fifth dimension, how frequently students receive advising, should be added to Miller's (in press) framework.

\section{Statement of Research Problem}

Over the last few decades, our public institutions have undergone dramatic change in how advising is delivered and in particular "who" advises students (Habley, 2004). In 1987 slightly over half the students in four-year public universities were advised under a faculty-only or faculty-supplementary advising model, meaning the student’s primary academic advising relationship was with a faculty member whose major responsibility was teaching. By 2003 the percentage of students advised under these models at fouryear public universities was down to just over $20 \%$, indicating a significant shift away from the involvement of teaching faculty in the academic advising process (Habley, 2004, p.20).

Today’s academic advising delivery models vary considerably, and little is known about the efficiency and effectiveness of these delivery models. Given the resource and financial constraints on our public institutions today, it is essential that we identify practices and organizational structures that facilitate learning and increase student satisfaction and, ultimately student retention and graduation. Miller (in press) posits examining advising delivery structures from a variable approach that involves (1) who is advised, (2) who advises, (3) where advising is done, and (4) how advising responsibilities are divided. Is there a relationship between these various academic 
advising delivery variables, academic advising learning outcomes, and student retention? In particular, how do these factors impact first-year students at our four-year public institutions, those at highest risk for attrition (ACT, 2010)? Prior research has shown student satisfaction to be a key factor in student retention, but little research has been done on quality academic advising related to how and where advising is delivered. Given the dramatic change in “who” delivers advising at our public institutions (Habley, 2004) it is essential that we know if quality academic advising is occurring and if that learning has a relationship to student retention.

\section{Purpose of the Study}

Academic advising has been touted as a key to student success and retention. In addition, claims have been made that students more satisfied with various key metrics related to their college career are retained at a higher rate than those who are less satisfied, independent of other factors (Schreiner, 2009). Therefore, student satisfaction with advising plays an integral role in identifying factors that may be impacting student retention. Limited research examined advising delivery models in relation to student satisfaction with advising, student academic advising learning outcomes, and student retention. Research completed to date has primarily focused on Habley’s (1983) initial taxonomy which is not very applicable today, especially for lower division students in four-year public institutions, because of the dramatic shift in "who" advises students (Habley, 2004). 
Given the over 13 million students enrolled in higher education institutions at the lower division level (NCES, 2012), the need for further research is essential to determine if there is a relationship between academic advising delivery models, student learning outcomes, student satisfaction with advising and ,ultimately, student retention. In particular, it is imperative that we identify what type of advising delivery models students are more satisfied with, learn more through, and are more likely to be associated with retention. Recent attrition data indicates that four-year public institutions are losing an average of $25 \%$ of their students before the second year of college (ACT, 2010). The same study indicates that students are far more likely to be retained if they return for a second year of college. It is essential that first-year student success and relationships with quality academic advising be explored in more detail.

\section{Research Questions}

This research addresses whether the manner in which advising is delivered to first year students is associated with advising learning outcomes, student satisfaction with advising, and/or student retention. Figure 1 represents a graphical representation of the research questions for this study. 


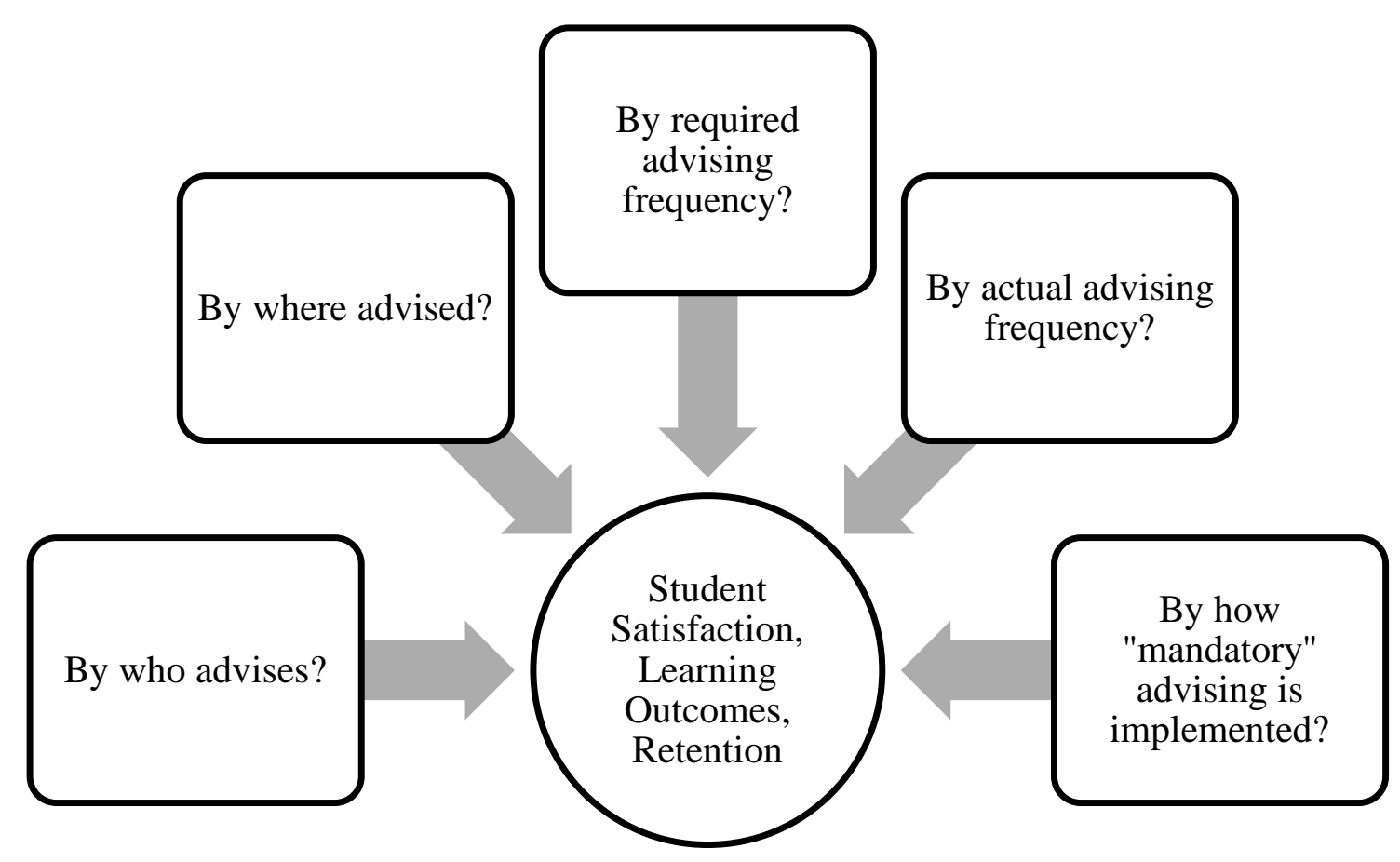

Figure 1 Graphic representation of research questions for this study

First year students, as defined for this study, are students who began their study at an institution of higher education without earning college credit after graduating from high school. Thus, students who have earned college credit while still in high school (through advanced placement credit, enrollment in their local community college, international baccalaureate, etc.) were considered first-time students in this study. Student retention, for this study, was defined as a student enrolled in spring quarter of year one, returning fall quarter of year two. 
The following research questions were explored in this study.

1. Is there a relationship between who advises first-year students and
a. Student satisfaction with advising?
b. Academic advising learning outcomes?
c. Student retention (first-year to second-year)?

2. Is there a relationship between where first-year students are advised and
a. Student satisfaction with advising?
b. Academic advising learning outcomes?
c. Student retention (first-year to second-year)?

3. Is there a relationship between how frequently first-year students are required to see an advisor and
a. Student satisfaction with advising?
b. Academic advising learning outcomes?
c. Student retention (first-year to second-year)?

4. Is there a relationship between how frequently first-year students actually see an advisor and
a. Student satisfaction with advising?
b. Academic advising learning outcomes?
c. Student retention (first-year to second-year)?

5. Is there a relationship between how "mandatory" advising is implemented and
a. Student satisfaction with advising?
b. Academic advising learning outcomes? 
c. Student retention (first-year to second-year)?

\section{Research Methodology}

This study was a non-experimental quantitative research design that utilized survey data collected in 2010 and 2011 by a multi-institutional research collaborative. The advising survey instrument, the Inventory of Academic Advising Functions-Student Version, was developed and originally administered in 2003 by Smith and Allen (2006). The survey asked students about the importance of and their satisfaction with academic advising functions, where and how often they get academic advising, and their advising learning. In addition, the survey included measures that have been linked to retention in the literature. Student demographic and enrollment data have been provided by each participating institution's office of institutional research.

Although the survey was administered to undergraduate students at five public four-year institutions, two private four-year institutions, and two community colleges in the State of Oregon, for this particular study, only student responses from one of the public four-year institutions were examined. This particular institution was chosen as it was the only four-year institution in the research collaborative where advising is mandated for all students, meaning that all students are required to participate in the academic advising process. Based on interview data from the original study, collected from advising personnel in academic units within the university, how first-year freshmen who have declared majors in each unit are advised were categorized using a modification of Miller's (in press) schemata of (1) who does advising, (2) where students are advised, 
(3) how frequently students are advised, and (4) how units implement mandatory advising. Students' identified academic major was used to identify how individual students are advised.

The "who" does advising component was based on the most common structures at the selected institution. With this particular institution, the following subcategories were examined:

(a) professional advisors where advising is a primary role ${ }^{1}$,

(b) faculty advisors with advising listed as one of several responsibilities within their job description, and

(c) advising provided by student peers.

The "where” students are advised was based on the most common structures at the selected institution. At this particular institution, the following subcategories were examined:

(a) advising center centralized by college within the institution,

(b) advising center centralized by major within the institution, or

(c) decentralized advising that occurs in individual staff or faculty offices.

\footnotetext{
${ }^{1}$ Senior instructors with advising as a primary role were categorized as professional advisors in this study.
} 
The frequency that students are required to see an advisor was based on the most common structure for first-year students at the selected institution. With this particular institution, the following subcategories were examined:

(a) required to be advised once per year, and

(c) required to be advised once per term.

The frequency in which students actually see an advisor, irrespective of what is mandated by their major, was based on the self-report data from the Inventory of Academic Advising Functions-Student Version (Smith \& Allen, 2006), and categorized as follows:

(a) Not currently seeking advising

(b) Seeking advising once per year, and

(c) Seeking advising more than once per year.

Finally, the manner in which academic units implement “mandatory” advising was examined. At the study institution all students are required to see an advisor at least once per year. The study institution enforces mandatory academic advising through a system where students are given a personal identification number (PIN) from their academic unit, presumably after receiving academic advising. However, the manner in which students receive this PIN varies by academic unit and was further examined as follows:

(a) PIN received directly from assigned academic advisor, or 
(b) PIN received by an advisor after attending a group process, or

(c) PIN received after participating in peer-led advising process.

The desired outcome of this research was to provide additional empirical research to the field of academic advising, specifically examining student satisfaction with advising, student advising learning outcomes, and student retention in relation to (1) who does advising, (2) where students are advised, (3) how frequently students are required to be advised, (4) how frequently students actually see an advisor, and (5) how units implement "mandatory" advising. With a better understanding of these relationships, perhaps institutions can be more effective and efficient when designing or refining academic advising delivery models.

\section{Organization of Study}

This study is divided into five chapters. Chapter One introduces the study, provides background information related to the study, presents the statement of problem and purpose for the research, and defines the research questions along with an overview of the methodology. Chapter Two reviews the literature most relevant to the study as it relates to student retention, student satisfaction measures including advising, student development theory related to advising, learning theory tied to academic advising, and academic advising delivery models, past and present. Chapter Three outlines the purpose of the study, the design of the study, research questions, research design, and detailed research methodology. Chapter Four presents the results of the study. Chapter Five discusses study results, implications, limitations, and suggestions for further research. 


\section{Chapter 2}

\section{Review of the Literature}

Chapter one posited a need for further research regarding academic advising delivery models in relation to student satisfaction with advising, student learning associated with academic advising, and ultimately student retention. With a better understanding of the relationships between academic advising delivery models, student satisfaction with academic advising, learning that occurs through advising encounters, and student retention, we have a better chance of creating advising structures that enhance the productivity and efficiency of, and satisfaction with academic advising.

This chapter will 1) review key institutional factors traditionally associated with student retention, 2) review literature exploring associations between academic advising and retention, 3) explore past research on student satisfaction and student satisfaction with advising, 4) identify historical and contemporary theories related to student learning and academic advising, 5) explore the historical background and current transitions related to academic advising delivery models, and 6) review past studies focused on the success of academic advising delivery models. Connected with the research questions in chapter one, the goal of this chapter is to review relationships that have been explored between academic advising and student satisfaction with advising, examine studies that explore the link between student retention and academic advising, review learning theory and learning outcomes that have developed over the years tied to academic advising, and review the various structures that define how academic advising is delivered. Finally, 
this chapter will identify a research gap that currently exists between student outcomes related to advising and how advising is delivered.

\section{Key Institutional Factors Traditionally Associated with Student Retention}

To better understand the relationship between academic advising and student retention, it is important to look at the overall factors identified through research as associated with student retention. In 1991, Pascarella and Terenzini reviewed a substantial body of literature and research indicating that completion of the baccalaureate degree is a central determinant of occupational status and income. Since 1991, both researchers have devoted more time to extending and expanding their work on factors related to educational attainment. In their pre-1990 literature review, Pascarella and Terenzini (2005) found several college experiences that seemed to promote educational attainment and student persistence independent of institutional and student characteristics. In other words, these experiences were consistent across institutional type and student demographics. One significant finding was that “...the degree of a student's integration into campus social systems had positive net effects on attainment” (p. 395). The more integrated a student is in campus social systems, the greater the chance that student will persist to graduation. The authors also found the following factors to be tied with educational attainment and persistence: living on campus instead of off-campus, being involved in a living-learning center on campus, participating in student orientation and first-year seminars, and working part-time on campus rather than off-campus, among others. 
Subsequent work in the 1990s focused on "conditions and student experiences that influence persistence and educational attainment independently of the characteristics of the institutions students attend” (Pascarella \& Terenzini, 2005, p. 396). Not surprisingly, the authors found college student grade performance to be the single best predictor of student persistence, degree completion, and graduate school enrollment; this finding was consistent regardless of precollege, academic, socioeconomic, demographic, and even within-college experiences. The authors also found that the first year of a student's academic performance is the most predictive when looking at first to second term progression, first-to-second year progression, and beyond the second year for both two year and four year institutions. Additional findings indicate that academic intervention programs, in general, do assist students in overcoming deficiencies related to academic preparation and help students to adjust socially to the institution ( Pascarella \& Terenzini, 2005). First year seminar courses were also identified as benefiting all categories of students and impacting student persistence for both male and female, majority and minority students. Unfortunately, with limited experimental design interventions, it is difficult to determine if these effects are direct or indirect. Some indirect factors such as improved time management or study skills that result from the first year seminar participation may be impacting the results (p. 403).

Increased financial aid in the form of grants and scholarships was identified as having a positive net effect on student persistence (Pascarella \& Terenzini, 2005, p. 439). The tuition rate, hours worked off-campus (over 15 hours), and unmet financial need were all identified as inversely related to both retention and graduation. The authors 
found that interactions with faculty and peers on campus also played an “...independent and positive role in student persistence and attainment” (p. 439). Interestingly, even student perceptions that faculty are accessible and concerned about student development was identified as having a positive influence on retention.

Academic field was also identified as playing a role in retention, graduation, and graduate school enrollment. While Pascarella and Terenzini’s initial review in 1990 did not find that academic field was a factor in retention or graduation, recent studies have found that students majoring in engineering, business, the sciences, and health-related professions are more likely to graduate than students in other majors (Pascarella \& Terenzini, 2005, p. 439). Students participating in intercollegiate sports also had much higher retention and graduation rates over those not participating in intercollegiate sports (p. 440). Academic and social involvement was identified as exerting a statistically significant and positive influence on retention and graduation, but the authors were less clear if this is a direct or indirect effect as the findings are inconsistent and the causal linkages at times are unclear.

In addition to specific research associated with student retention, several theorists are well known for their conceptions of college teaching, learning, and experiences in college that they posit are tied to student retention.

A theory developed by Chickering, Gamson, and Paulson (1987) focused on the importance of college teaching and learning and it's relation to student retention. The authors note seven principles for good practice in undergraduate education and conditions 
that should be met for effective student retention. The authors note that effective instruction must:

(1) encourage contact between students and faculty, (2) develop reciprocity and cooperation among students, (3) encourage active learning, (4) provide for prompt instructor feedback, (5) emphasize time on task, (6) communicate high expectations, and (7) respect various ways of learning and diverse talents (pp. 35).

Perhaps the most widely cited theory related to student retention, or in this case student departure, is that of Vincent Tinto (1975). Tinto's theory attempts to capture the unique and complex relationships that exist between the individual and the institution regarding student departure. Tinto's initial theory looked at the causes of student departure from three areas: (1) individual characteristics prior to entering college, (2) experiences of the individual while in college, and (3) the impact of external forces that interfere with the college experience. Within each of these three areas are specific factors that he posits contribute to student departure.

Tinto identifies two individual characteristics that he believes are associated with student departure, namely “intention” and “commitment” (Tinto, 1993, p. 37). Intention relates to how strongly an individual is fueled by an educational goal, essentially the higher the student's educational goal, the more likely the student is to persist. Commitment relates to a student's level of motivation; the higher a student's motivation to complete a program, the higher the chance of completion. 
Tinto identifies four interaction challenges students have with the institution that he posits impacts their decision to stay or depart. The first interaction challenge a student faces is living independently, away from the familiar world of family and friends. Some students find this adjustment difficult and as a result depart the institution. The second interaction challenge a student faces is the inability to meet the academic demands of the institution. This may manifest based on incomplete high school preparation, an increased demand in academic workload, or just being unprepared in general for the academic demands of college (Tinto, 1993). The third interaction challenge refers to a mismatch of student and institution. The student does not feel a sense of belonging with the institutional community. This may relate to incongruence between a student's values and interests and that of other students at the institution. The final interaction challenge can essentially be termed isolation. Students fail to make meaningful relationships with other students, faculty, and staff resulting in departure from the institution.

Finally, Tinto describes external factors that may influence a student's departure (Tinto, 1993). The influence of external factors may relate to multiple roles a student has, as well as competing obligations for employment, family or community demands, and other factors that are outside the control of the institution. He also posits that students in non-residential colleges are at higher risk from external factors due to more frequent outside demands. 


\section{Student and Faculty Interaction in Relation to Student Retention}

Several researchers have focused on the importance of student and faculty interaction when examining the reasons for student retention or departure (Kuh, Kinzie, Buckley, Bridges, \& Hayek, 2007; Nordquist, 1993; Pascarella \& Terenzini, 1977, 1980, 2005). In a preliminary study, Pascarella and Terenzini (1977) identified informal interaction with faculty outside of the classroom to be a factor that differed between departing and returning students. Later work by both researchers found that particular background characteristics made this interaction even more important for students identified as at-risk based on socioeconomic factors, first-generational status, and low aspiration towards college (Pascarella \& Terenzini, 1980). In fact, this interaction with faculty, and the level of concern that faculty had for students, was identified by Pascarella and Terenzini (2005) as a significant contributor to identifying departing and persisting students.

Nordquist (1993) further explored the student departure puzzle by conducting a qualitative approach to test some of the key elements identified by Tinto (1993), particularly related to what Tinto described as incongruence. Nordquist interviewed students who had withdrawn from institutions in Utah and asked questions that were designed to address specific college experiences, family background, personal goals related to college attendance, social interaction with peers and faculty, academic advising, and the overall circumstances that related to college departure. He noted that all but one student described overall best and worst college experiences in terms of 
positive or negative experiences involving interaction with a faculty member (Nordquist, 1993, p. 12). He highlights that students believed that faculty were trying to "weed out" students, that faculty didn't care if students attended class or actually learned anything, and that faculty were not interested in answering student questions. In relation to Tinto's (1993) explanation of isolation as another key factor in the departure puzzle, Nordquist (1993) specifically identified faculty mentoring relationships as having the most significant positive impact on social and academic integration as well as subsequent enrollment decisions.

Additional recent research by Kuh, Kinzie, Schuh, Whitt, and Associates (2010) focused exclusively on institutions that have both higher-than-predicted student engagement, and graduation rates. The research team examined 20 institutions that, based on past research, are engaging students and graduating students at rates much higher than expected given incoming student factors such as academic preparedness; factors that should preclude such graduation rates. Of the 20 institutions in this study, 9 were private and 11 were public. Kuh et al. (2005) found that the faculty/student relationships at these high engagement institutions were unique in that faculty and staff members were accessible to students both inside and outside the classroom, were interested in students' education needs and career interests, and were interested in helping students be independent thinkers and problem solvers (pp. 207-208). In addition, faculty and staff provided timely and extensive feedback on student homework and worked closely with students on scholarly projects. According to research on these institutions 
by Kuh and his research team, a student's relationship with faculty and staff at an institution can have a significant impact on the departure decision.

\section{Associations Between Academic Advising and Retention}

Academic advising is another factor frequently associated with student retention; the actual relationship may not be as clear as some other retention factors. This particular section will explore (1) studies that suggest a direct relationship between student retention and academic advising, (2) studies that indicate an indirect relationship between student retention and academic advising, and according to some studies, may actually be tied more closely to a student's relationship with faculty and staff, and (3) studies that suggest student satisfaction in general, and student satisfaction with academic advising may be important factors in student retention.

\section{Studies Claiming Direct Associations Between Advising and Retention}

A study by Patrick, Furlow, and Donovan (1988) measured the success of a comprehensive advising and orientation program focused on high-risk students at a regional campus of a large public research university. The program consisted of biweekly intensive academic advising visits as well as a first-year experience course that included career development, educational planning, personal adjustment and decision making, and an introduction to campus life. At-risk students were then invited to participate in the program administered by the director of Academic Affairs, two professional advisors and six faculty members, identified by peers as being competent advisors. A comparison of participants and non-participants noted that program 
participants were retained at a rate $9.5 \%$ above non-participants despite that fact that only at-risk students were invited to participate.

A study by Metzner (1989) was designed to examine the perceived quality of advising and related influences on student attrition for freshman students. The goal of the study was to determine if better advising could reduce student attrition using a retention model developed by Bean and Metzner (1985). The study was conducted at an urban Midwestern public university with enrollment of approximately 20,000 students, most with credit from previous institutions. The specific population examined in this study consisted of roughly 1,000 freshman students who were not living in the residence halls and were not international students (roughly 50\% of the freshman student body) (p. 426). Minority and part-time students were underrepresented in the sample. Students in a firstyear composition course were surveyed and asked to rate the quality of the academic advising they had received on a 5-point Likert-type scale where a "1" was defined as "very low” and a “5” was defined as "very high” (p. 427). Ratings from 1 to 3 were categorized as "poor advising" by the researcher, while a rating of either a 4 or a 5 was categorized as "good advising." There was also a specific category of students who did not receive advising at the university. An ordinary least squares multiple regression was completed with variables being introduced by simultaneous variable entry. Overall, the variables examined accounted for approximately $30 \%$ of the variance in dropout, with the most significant variables being (1) college grades, (2) intent to leave the university, and (3) high school academic performance (p. 429). Tests examining the quality of advising in relation to other variables found no statistically significant relationships. Neither good 
advising nor poor advising were found to have a significant or direct effect on dropout rates, but good advising did show a statistically significant indirect effect on dropout rates. Membership in the "good advising” group showed a 25\% less rate of attrition than “poor advising,” and “poor advising” showed a 40\% less rate of attrition when compared to "no advising" (p. 433). Limitations from this study are due to the sample being from just one institution and the limited number of minority students who were included in the analysis, as well as a reliance on the students' judgment of what determines “good advising.”

Seidman (1991) randomly assigned 278 incoming community college students to either a control group or a treatment group that received pre- and post-admissions advising. The treatment group met with advisors to discuss course schedules, involvement opportunities, and general progress during the first term of college. The results indicated that students in the experimental group were more likely to persist to the second year than those in the control group.

Studies by Patrick, Furlow, and Donovan (1988) and by Seidman (1991) both involved a small number of students who were given fairly intrusive treatments, which questions whether the improved retention identified in these studies was due to the actual advising students received or attributable instead to the faculty/staff interaction that was part of these studies. The work by Metzner (1989) did not find any direct relationship between academic advising and retention. 


\section{Studies Claiming Indirect Associations Between Advising and Retention}

A second grouping of studies is associated with indirect associations between academic advising and retention. The academic advising was not the primary focus of the study; instead a by-product commonly associated with the academic advising was examined. An interesting subset of studies indirectly tied to the relationship between academic advising and student retention involves faculty, staff, and administrators. How do faculty and administrators perceive academic advising? A study by Beal and Noel (1980) reviewed roughly 900 institutional retention programs and reported that institutional administrators rated inadequate academic advising as a primary factor associated with student attrition. In a survey of more than 1,000 college faculty and administrators, Habley and McClanahan (2004) found that academic advising was noted to be among the campus interventions that survey respondents identified as having the greatest impact on student retention across all institutional types. A study by Getzlaf, Sedlacek, Kearney and Blackwell (1984) included advisor satisfaction as one variable assessing academic integration. The results of the study failed to isolate advisor satisfaction as a contributing factor to future enrollment behavior.

Creamer (1980) examined past retention research and proposed an explanation for how academic advising may contribute to factors predicting student success. Creamer identified frequent student/faculty interaction, targeted recruitment, quality advising, improved academic performance, and integration into the campus environment as areas 
where advising impacts retention. Creamer believed that the quality of advising might be as basic to goal achievement in college as the quality of teaching (p. 11).

In 1981, Wes Habley developed an advisement-retention model as a way to better understand factors within institutions that may impact a student's decision to leave or stay. Habley believed that for the advising relationship to impact retention, it must move beyond prescriptive and clerical activities traditionally associated with advising and involve a more student-centered and developmental approach. Habley's (1981) model had three main components: the educational environment, reasons for staying, and reasons for leaving. He put these components on a continuum in relation to student effort (E), student ability (A), and reward (R) positing that the advisor is responsible for helping a student move from a place of low E, low A, and low R, to a place of high E, high A, and high R. Although sound in reasoning, Habley's model was never empirically tested.

A study by Grosset (1991) specifically examined the number of times that students met with faculty or other college staff outside of the classroom. This particular study did show that the quality of interactions with faculty and advisors was related to retention. In addition, the study noted that interactions identified as contributing to student growth did impact student retention decisions. This particular study did not distinguish if these meetings outside of class were advising related, or if the meetings were with faculty advisors or professional advisors.

Nordquist (1993) conducted a qualitative survey and interviews designed to identify institutional experiences related to retention. One of the interview questions 
specifically asked students if they sought assistance from academic advisors, and to describe that experience. Many students described their decision to depart from the institution in terms associated with negative experiences and interactions with faculty and staff. Again, advisors were not specifically singled out in this study.

The majority of the studies claiming indirect relationships with student retention as a by-product of academic advising focus on the actual components of the faculty/staff relationship, or highlight perceptions by faculty and administrators of the impact advising has on retention. Very few studies actually examine the advising/retention relationship.

\section{Student Satisfaction in Relation to Academic Advising}

In 2006, Noel-Levitz compiled data from a three-year survey of over 53,000 students from 170 institutions of higher education in the United States; approximately 30,000 of these students were undergraduates. The study examined what the authors term a "performance gap" (Noel-Levitz, Inc., 2006, p. 3) which is the difference between an importance rating and a satisfaction rating on eight functional areas identified in the literature as being important to students. These eight functional areas are "instructional effectiveness, academic advising, campus climate, registration effectiveness, service excellence, admissions and financial aid, safety and security, and academic services” (p. 4). The study found that the two most important functional areas for students were instructional effectiveness and academic advising, in that order, while student satisfaction with academic advising in particular was rated mediocre. Given the relative importance student place on academic advising, these relatively low satisfaction rates imply that this 
"performance gap” may be problematic. One significant limitation of this study was the assumption that importance and satisfaction ratings were comparable on the same scale. Because these two types of ratings measure significantly different phenomena, the use of one scale to evaluate these ratings is a concern.

A study of 20 students was conducted by Beasley-Fielstein (1986) and examined student perceptions of the academic advising relationship. This phone survey was split between students who expressed satisfaction with academic advising and those who expressed dissatisfaction. Each student was asked to describe and rate advisor qualities and characteristics, experiences, delivery methods, behaviors, perceptions of the advising relationship, and ideas for improvement. Dissatisfied students described advisors as inaccessible, intimidating, indifferent, and even unpredictable. Students who were satisfied with advising believed advisors were interested in their program, a reliable source of information, generous with their time, and accessible. Several themes of "effective advising” emerged from this study regarding the importance of taking a personal interest in students, focusing on both academic and career advising, showing genuine concern for students, and being efficient in helping to solve student issues.

A study conducted at Kent State University (1993) asked students to assess academic services, programs, and institutional climate. Students rated and made comments on many campus services including registration, advising, student records, student activities, program curriculum, teaching quality, career planning, and course availability among others. Among all of the items listed, academic advising received the 
lowest ratings score as well as the majority of the negative comments. Students were not satisfied with errors made by advisors, appointments that were not kept, advisor incompetence, and a general lack of appreciation of student needs by advisors.

Schreiner (2009) conducted a survey of over 27,000 students at 65 four-year institutions in an effort to empirically determine if there is a positive relationship between student satisfaction and retention beyond what can be predicted based on student and institutional characteristics. Nearly $75 \%$ of the institutions in this survey were private, $40 \%$ were baccalaureate only, $38 \%$ from master's only institutions, and $15 \%$ from doctoral institutions. A large number of the institutions were located in the Midwest, but all regions in the United States were represented. A student satisfaction inventory instrument was used with a seven point scale asking students to rate item importance from $1=$ not at all important to $7=$ very important. In addition, students rated satisfaction from $1=$ very dissatisfied to $7=$ very satisfied. The reliability of the instrument was high with an alpha of .98 and a 3-week retest $\mathrm{r}$ of .87 . This study utilized a logistic regression analysis allowing the researchers to predict actual retention 4 to 12 months later, after accounting for students' demographic characteristics as well as institutional characteristics. The study found that across all models and class levels, satisfaction indicators added significantly to the ability to predict student retention, in fact, for each class level satisfaction indicators almost doubled the ability to predict retention beyond what demographic characteristics and institutional features could predict (Schreiner, 2009, p. 3). This study also found that campus climate was the most important factor related to student satisfaction. Regarding academic advising and satisfaction, several 
items are noteworthy. Advisor availability and approachability were identified as key items for first-year students. Those first-year students who rated their advisor as approachable and available persisted at a rate higher than those who did not have this same belief. For sophomores, satisfaction with advising overall increased their chances of persisting to year three, and for juniors, having knowledgeable advisors who can guide students effectively through the curriculum was a key factor. This study is particularly important given the strength of findings related to student satisfaction and persistence. Based on the findings of this study, the more satisfied lower division students are with their advising experiences, the higher the chance of retaining those students through the upper division years towards graduation.

In 2009, Roberts and Styron conducted a study at a research-intensive public university in the south looking at the experiences of education and psychology students. While examining satisfaction, the researchers found that students who did not persist had a "statistically significant lower perception of faculty/staff approachability than those students who did persist” (p. 9). In addition, the perception of social connectedness was identified as a key factor in student persistence.

A study conducted at the University of Wisconsin-Madison School of Business (Schroeder, 2012) examined undergraduate academic advising satisfaction as well as the level of expectation and importance that students place on specific advising functions. The study utilized an adaptation of a survey instrument developed by Smith and Allen (2006), the Inventory of Academic Advising Functions-Student Version. The adaptation 
involved in this study was adding a scale of student expectation to scales in the instrument that involve student importance and satisfaction ratings. Approximately 1,900 students were surveyed with a $38 \%$ response rate. A variety of statistical analysis methods were applied to the data with student satisfaction used as the dependent variable. Several conditioning variables were included such as age, gender, race, ethnicity, year in school, and GPA to control for demographic characteristics (p. 27). The study findings concluded that both student importance and expectation ratings were an important determinant of student satisfaction with advising. The study did not specifically examine student-learning outcomes in relation to academic advising and the study population was limited to business students within one institution.

A common thread throughout these studies, similar to the retention and advising studies, is a primary focus on satisfaction with a faculty or staff relationship. In addition, it should be noted that several of these studies are doctoral dissertations and are not peer reviewed, published articles. Overall, academic advising continues to be a field that remains largely unexamined in relation to the amount of work that exists related to classroom learning and student success.

\section{Student Learning and Academic Advising}

Learning associated with the academic advising process has been a topic of discussion among academics for decades. Academic advising as an "examined activity" has only existed for the last four decades (Frost, 2000, p. 4), and the debate over what constitutes learning in an academic advising setting continues to the present day. The 
following section will review the most prevalent models and paradigms that contribute to the current discussion of which learning outcomes are most consistently tied to academic advising.

\section{Prescriptive and Development Models - Crookston}

Burns Crookston is well known for developing the first two models of academic advising in 1972 which he differentiated as “prescriptive” and “developmental”(Hemwall \& Trachte, 1999). According to Crookston, prescriptive advising can be best compared to that of a doctor/patient relationship. The student or "patient" has an ailment or problem and the advisor or “doctor” makes a diagnosis, prescribes something, or gives advice (Crookston, 1994). In contrast, the developmental model is "concerned not only with a specific personal or vocational decision but also with facilitating the student's rational processes, environmental and interpersonal interactions, behavioral awareness, and problem-solving, decision making, and evaluation skills” (Crookston, 1994, p. 15). Crookston believes that higher education and the advising process, as a result of the advisor and student engaging in a series of developmental tasks, can lead to students creating a plan for personal growth and self-fulfillment within their lives. For Crookston, advising or any other experience within the educational environment can be regarded as teaching if it results in growth and development of the individual, group, or community (Crookston, 1994).

It is important to note that as the developmental model has roots in a variety of theories: student development theory, cognitive development theory, career development 
theory, learning theory, moral theory, adult development theory, personality theory, retention, multiculturalism, typology, decision-making, and several others (Creamer, 2000). Within theory clusters, the primary categories typically associated with academic advising, and particularly developmental advising, are psychosocial theory and cognitive development theory.

There are two psychosocial theories that play a pivotal role in the developmental advising model. One of these pivotal theories was Erikson's Developmental Theory which explored the relationship between an individual's development and his or her social context (Erikson, 1963). Based originally on the work of Freud, Erikson developed eight stages of development in which there is a developmental "crisis" that is to be resolved at each respective developmental stage. He encouraged others to understand behavior through physiological processes, social context, and ego processes. At each stage there is an opportunity for a positive or a negative resolution to the described development crises and this impacts the development and progress of later stages (Erikson, 1963). Erikson's work has been foundational in subsequent student development theories, including academic advising.

A second influential psychosocial theory is Arthur Chickering's (1969) seven vectors of identity development, grounded in the work of Erikson and originally developed in 1969 and revised in 1993 (Chickering \& Reisser, 1993). Chickering identifies particular vectors as: developing competence, managing emotions, moving through autonomy towards interdependence, developing mature interpersonal 
relationships, establishing identity, developing purpose, and developing integrity. Although not as linear as the stages Erikson defines in his theory, Chickering's vectors build on each other and lead to greater complexity, stability and integration (Chickering, 1969).

Several cognitive development theories were foundational in influencing initial academic advising models. Cognitive development theories, in general, are focused on how people think. Similar to psychosocial theories, they follow a series of steps or stages, but unlike psychosocial theories, most cognitive development theorists believe that these steps or stages cannot be “skipped,” nor can one move backwards through these steps or stages. Cognitive theorists focus on describing the nature and process of change, while psychosocial theorists focus on content development (Pascarella \& Terenzini, 2005). The majority of cognitive-structural theories are based on the work of Jean Piaget in the early 1960s. Piaget studied the role of maturation in children and at what age and level children are able to understand new concepts (Hemwall \& Trachte, 1999). Piaget's work forms the basis of four well-known cognitive-structural theorists focused on college student development, namely William Perry, Lawrence Kohlberg, Marcia Baxter-Magolda and Carol Gilligan. The two cognitive-structural models that influenced the first developmental advising models were those of William Perry and Lawrence Kohlberg.

William Perry was fascinated by the way in which so many of his student's failed to learn the concepts that he was teaching them at Harvard University. He began to 
collect data from student essays and interviews which served as the basis for his nine-step model of intellectual development as students move from typical black and white thinking to complex and integrated thoughts and actions. He later went on to publish ways in which faculty can identify which "stage” a student is at and how to help students move along the continuum. Perry's nine positions are clustered into the following four groupings (as cited in Pascarella \& Terenzini, 2005):

- Dualism - Individuals order their worlds in absolute categories.

- Multiplicity - Multiple perspectives are recognized. Others are seen as “entitled to their views.”

- Relativism - Multiple perspectives are recognized and analytical thinking skills begin to emerge identifying some validity to others’ positions.

- Commitments in relativism - Students test various claims eventually making a commitment to ideas and value and establishing identity in the process. (pp. 3435)

Lawrence Kohlberg’s (1972) focused more on moral cognitive development, the cognitive processes and modes of reasoning used when making moral choices. Kohlberg identified three general levels of moral reasoning with two stages at each level. He notes progression through these levels to a refined set of principles and maturing sense of justice.

Crookston highlights the key relationship in a developmental advising setting to be one between the advisor and advisee where the advisor relates to the advisee in a holistic 
way, integrating academic, career, and personal goals into advisement, rather than focusing only on academic or career goals (Crookston, 1972). Essentially, Crookston sees advising as a tool with the goal to go beyond providing information; it should be broader, long lasting, and more profound than a prescription of advice. Although Crookston does not say so directly, it should be noted that both the prescriptive and developmental models are his constructs and were presented jointly as a way to highlight the advantages of developmental advising.

\section{O’Banion's Developmental Advising Model}

At the same time Crookston was presenting his concept of development and prescriptive advising, Terry O’Banion was presenting a developmental model of advising that "described the academic advising process with five dimensions: exploration of life goals, exploration of vocational goals, program choice, course choice, and course schedules” as cited in Huggett (2004, p. 79). O’Banion’s model was essentially a more focused alternative to Crookston's broad reaching model, targeting conversations that he believed belonged in the realm of academic advising and the advisor/advisee relationship. These two models of developmental advising are essentially the dominant paradigm in the literature of the field (Pardee, 2000). As such, these models have prompted the most recent debate and discussion as others are examining the goals and philosophy of academic advising, as well as advising structures. 


\section{Integrative Approach}

Based on the work of O’Banion, Burton and Wellington (1998) offered a variation of the developmental model that they refer to as the "integrative advising model” (pp. 14-19). The integrated approach to advising essentially takes O’Banion’s five dimensions and integrates them into a circular, overlapping pattern. In the integrated model, the student maintains the majority of the control over how much self-analysis occurs in any given advising session and how much influence the student is choosing to give the advisor in any given interaction. Although the integrative model allows for a more flexible interaction between the student and the advisor, it has not held the popularity of O’Banion’s (1972) original model.

\section{Recent Models}

Over the last decade, several researchers began questioning the foundation of developmental advising models (Hemwall \& Trachte, 1999; Kelley, 2008; Kirk-Kuwaye \& Libarios, 2003; Laff, 2006; Lowenstein, 2005; Smith \& Allen, 2006). Although each research team acknowledges the merits of developmental advising, they each question if psychosocial and student development theories are the most relevant base to draw on for the field of academic advising. Each researcher essentially debates the paradigm of counseling versus the paradigm of teaching and learning within the profession. This next section will discuss models that approach academic advising from a teaching and learning paradigm, a paradigm that has only taken shape within the last decade. 
Collaborative approach. In 1999, Marc Lowenstein was the first researcher to posit a new teaching and learning paradigm for the field of academic advising (Lowenstein, 2005). Lowenstein initially argued against the model of prescriptive advising, agreeing with Crookston that "advising should always have a goal that goes beyond providing information” (Lowenstein, 2005, p. 67). He goes on to argue that the developmental advising approach does not present a compelling view of the goal of academic advising. Key to his argument is that focusing on a student's personal development is counter to an instructor’s primary academic goals and responsibilities. He essentially sees the advisor as focused on facilitating student learning across the curriculum. Where an instructor focuses on learning related to a specific course or content area, the advisor facilitates learning across the student's entire curriculum. Lowenstein states “...learning transpires when a student makes sense of his or her overall curriculum just as it does when a person understands an individual course, and the former is every bit as important as the latter” (Lowenstein, 2005, p. 69). The domain of the professor is the individual course while the domain of the academic advisor is the overall curriculum. Lowenstein sees advisors teaching the overall logic of education, how disconnected pieces of the curriculum fit together, how to base educational choice, and how to continually enhance learning by relating new learning to experiences that have already occurred. Lowenstein notes that the developmental paradigm has helped define advising for 30 years but it "fails to illuminate the most important areas of the profession's possible impact” namely the relationship between advising and teaching (Lowenstein, 2005, p. 73). 
Praxis approach. Related to Lowenstein's collaborative approach, the praxis approach to academic advising also questions the foundation of advising theory being based on student developmental theory versus teaching and learning theory (Hemwall \& Trachte, 1999). The authors argue that

...proponents of student development as both a theory and a movement have lost sight of the principle mission of higher education: to introduce students to liberal learning, to the world of ideas, to the life of the mind, and to cultivate in them the habit of life-long learning (Hemwall \& Trachte, 1999, p. 7.)

The authors (Hemwall \& Trachte, 1999) continue, noting that the literature on academic advising regards the holistic development of individual students as the defining mission of the field. They maintain that the developmental underpinnings of academic advising contribute to the strained relationship that exists between faculty and professional advisors and believe that these same theoretical conflicts result in faculty reluctance to participate in workshops and conferences centered on academic advising. Hemwall and Trachte (1999), utilizing critical theory, particularly that of Pablo Freire (1970), present the idea of praxis and define it as reflection and action upon the world to transform it. They believe that advisors should engage students in a dialogue about the purpose and meaning of course requirements and that ultimately these discussions should prompt changes in goals and values; making meaning of the world to transform it rather than focusing on student self-development. It should be noted that both Hemwall and Trachte 
are faculty in small liberal arts colleges where faculty are responsible for all advising, and as such probably approach their analysis from the lens of a particular institutional type.

Advising as problem-based learning. The theory of problem-based learning is grounded in how students resolve “...ill-structured and logically fuzzy problems” (Laff, 2006, p. 38). Advising is seen as process where advisors challenge students to think about what they know, reflect on what they do not know and need to understand, and help them to contextualize learning for future applications (Laff, 2006). Rather than providing answers to students, advisors help to apply research-type questions to advising situations and allow students to think through the problem and develop processes which help the student with subsequent learning. It is essentially equipping students to intentionally engage their learning and help them to understand how their learning in turn engages their lives.

\section{Learning Constructs and Academic Advising}

This developing focus on academic advising as a teaching and learning function begins to question the student development theory that has been the foundation of academic advising for the last 30 years. Given the reporting structure shifts that are now placing the function of academic advising under academic affairs at a much more rapid pace (Habley, 2004), it should not be surprising to see the proliferation of teaching and learning theory beginning to inform practice. Barr and Tagg (1995) in their seminal article describe the shift that is taking place in higher education from traditional instruction to a newer learning-centered paradigm. They see the mission of higher 
education as "not instruction but rather that of producing learning with every student by whatever means work best” (Barr \& Tagg, 1995, p. 13). They also note that under this new learning paradigm specific roles begin to blur on our campuses as it is no longer just teaching faculty responsible for helping students to construct knowledge. The knowledge, skills, and characteristics displayed by effective instructors are essentially the same as those exhibited by effective advisors under the learning model. Hemwell and Trachte (2005) note that

When educators focus on advising as learning, they can examine what and how the student learns rather than the role or duties of the advisor, the advising administrator, and the advising system. This perspective should also reveal ways of maximizing the learning potential of academic advising. (p. 75)

The authors also pose two questions: what should students learn through advising, and how might that learning take place?

\section{Advising as Learning}

Kelley (2008) addresses one idea for applying the learning paradigm more effectively to academic advising. Identifying Bloom’s taxonomy (Bloom, 1956) as a useful cognitive and content-centered learning foundation, Kelly builds on the work of Fink (2003) who examined students' abilities to manipulate and restate learned content, moving beyond content-centered application to include leadership, the ability to teach oneself, and other functions that are shared with developmental theory. Content becomes just one of the six major categories of learning which include application, integration, 
human dimension, caring, and learning how to learn (Kelley, 2008, p. 21). Just as traditional lecture courses can overly focus on foundational knowledge, so can academic advising. Kelley believes that synergies in Fink’s model can create an environment where significant advising can occur, defining significant as advising that causes change in the advisee. He also notes how the work of Hemwall and Trachte (2005) in defining ten principles of academic advising resonates directly with the work of Fink (2003). Kelley (2008) begins with Fink’s three-stage model for course design and applies these stages to the world of academic advising defining the 12-step process:

- Identify the situational factors - What limitations are present based on staffing, needs, etc.?

- Formulate significant learning goals - What is most important? What do students need to know?

- Design measures of feedback and assessment - How will you measure if advisees learned the material the advisor set out for them to master?

- Generate teaching and learning activities - How do you design the opportunity for change to occur in advisees?

- Integrate the primary components - Do steps 2,3, and 4 support and reflect each other? If not, what needs to be reshaped and refined?

- Create an integrated plan - How will you introduce learning opportunities to students and when? 
- Select an effective advising strategy - Place the individual learning activities into a particular sequence, making sure activities are in relation to each other.

- Integrate the intermediate components - Again review the micro and macro plan for learning opportunities for congruence.

- Put together the grading system - A difficult concept for advising, but how do advisees get feedback on their progress?

- Identify and proactively address problems - Are there any operational problems that can be addressed ahead of time?

- Write the syllabus

- Evaluate the advising process and skills - Feedback from students on if this is working (pp. 23-27).

Given the relative complexity of this process, some would question if this model is realistically implementable, especially at larger public institutions. It is difficult to argue with the need to actively design opportunities for learning and change to occur, what Kelley (2008) and Fink (2003) define as “significant learning.”

\section{Summary of Academic Advising Learning Constructs and Paradigms}

This review has focused on the foundational theories and models behind the two primary paradigms in academic advising. The first paradigm being the development of the "whole" person, also known as developmental advising and based primarily on work by Burns Crookston (1972). Grounded in psychosocial and student development theory, with some influence from cognitive development theory and typology theory, this 
paradigm has been dominant in the field of academic advising for the last 30 years. Supporters point to the flexibility of the model and how adaptable it can be in varying institutional and structural settings. Critics point to the need for a paradigm that is more aligned with the teaching and learning mission of our institutions of higher education.

The second paradigm presents academic advising as a teaching and learning function, and as such focuses more on the concepts of praxis and traditional contentcentered learning taxonomies, such as those identified by Bloom and Fink (Kelley, 2008). Supporters see the need to infuse academic advising with intentional learning outcomes that are properly structured, delivered, and assessed within the confines of the discipline, and aligned directly with the educational missions of our institutions rather than focused on the individual development of our students.

It can be argued that the learning paradigm is the most pragmatic approach moving forward based on the 1995 article from Barr and Tagg that focused on the new learning paradigm of higher education, and given the movement towards aligning academic advising within academic affairs (Habley, 2004). As Kelley (2008) states "the acknowledgement that advisees are learners and advisors are teachers may be the most powerful philosophical change in advising in 30 years” (p. 19).

In addition to the theoretical and philosophical rationale for the "advising as learning” paradigm, a further justification for this disciplinary paradigm shift is to address the current rift between faculty advisors and professional advisors which several researchers believe is rooted in fundamental differences in how faculty see student 
development versus teaching and learning (Habley, 1994; Hemwall \& Trachte, 1999; Kelley, 2008; Lowenstein, 2005). Habley notes, “...our role must be to further engage faculty, not to alienate them. A failure to engage faculty will result in NACADA becoming an association of professional advisors rather than a professional association for advisors” (Habley, 1994, p. 30). NACADA is the global community for academic advising and represents the premier association tied with the practice of academic advising. Faculty are engaged in teaching and learning activities in all institutions; not all faculty are engaged in individual student development, and do not see their role as being engaged in individual student development. As Lowenstein (2005, p. 65) states “...for advising to be perceived as similar to teaching in a significant way it needs to be perceived differently than proponents of the developmental paradigm see it.” In other words, faculty advisors and professional advisors need to be aligned regarding advising outcomes to successfully influence change in the field of academic advising.

In reality, much of what is defined as "developmental” in the advising world could easily be adapted to contain appropriate and measurable learning outcomes. Individual student development, if properly focused, can be aligned with the teaching and learning function, the core of our higher education system. Aligning the mission of our institutions with the mission of academic advising will only serve to strengthen ties, improve relationships, target assessment, and allow for further growth as our institutions continue to focus on "student learning" as their primary function. 


\section{Quality Academic Advising - A Synthesized Learning Paradigm}

There has been significant debate recently regarding what constitutes quality academic advising, and what specifically students should learn in relationship to academic advising. The global community for academic advising (NACADA) has published a Concept of Academic Advising which claims advising as having its own pedagogy, learning outcomes, and curriculum (NACADA, 2006). NACADA considers these learning outcomes critical to the teaching and learning mission of higher education stating “Academic advising synthesizes and contextualizes students’ educational experiences within the frameworks of their aspirations, abilities, and lives to extend learning beyond campus boundaries and timeframes” (p. 524).

Lowenstein (2005) has provided the most descriptive account of learning-centered advising noting that advisors should be focusing on student academic learning and not be concerned with student interpersonal growth and development. The "logic" of the curriculum becomes the primary focus and discussion point in an advising session (Lowenstein, 2000, p. 2). Advisors help students make sense of the curriculum and guide students through a process of active learning, identifying key relationships between courses and disciplines with a focus on logical reasoning. Hemwall and Trachte (1999) when addressing the concept of praxis with academic advising believe that advisors should be engaging students in a dialogue about the purpose and meaning of course requirements and that ultimately these discussions should prompt changes in goals and 
values; making meaning of the world to transform it rather than focusing on student selfdevelopment.

Lowenstein (2005) along with Hemwall and Trachte (1999) argue that learningcentered approaches focused primarily on the curriculum and the meaning of the curriculum are superior to what has traditionally been identified as developmental or prescriptive advising (Crookston, 1972). They believe that these two traditional approaches to academic advising have ignored the crucial link between learning and the curriculum and believe a correction is necessary to bring advising practices back in line with curricular and liberal learning.

Smith and Allen (2012) suggest that the learning-centered approach is a welcome addition to development and prescription advising approaches, but warn that neither developmental nor prescriptive advising should be abandoned in light of this renewed focus on curricular or structural "learning”. In fact, their examination of advising literature over the last 30 years (Smith \& Allen, 2006; Allen \& Smith, 2008) suggests that quality academic advising is a multidimensional approach that involves five domains encompassing 12 advising functions, and actually utilizes approaches and components that are prescriptive, developmental, and learning-centered across many of the academic advising roles.

The authors describe the integration domain, the first of five domains, as one involving holistic advising which assists students in connecting their curricular and cocurricular choices to academic, career, and life goals. The referral domain comprises 
referral to both academic and non-academic problems a student may encounter which may be detrimental to goal achievement. The information domain relates to advisors providing students with accurate information about degree requirements as well as helping students understand how things work, particularly with policies and procedures at a given institution. The individuation domain focuses on knowing the student as in individual, based on the student's skills, interests, and abilities. The shared responsibility domain involves helping students to problem-solve, plan, and improve decision-making skills; allowing students to take greater responsibility for their success and progress in higher education.

Interestingly, the specific domain that students uniformly believe is to be the most important is the information domain, which is prescriptive in nature (Smith \& Allen, 2006). Students across institutional type indicated that receiving accurate information from advisors about degree requirements was more important than any of the other 11 functions (Allen, Smith, Muehleck, 2012). This particular study involved two public community colleges and five four-year public institutions in a northwest state. Students at the community college were all enrolled in credit-bearing classes at the community college in anticipation of transfer to four-year universities. Over 100,000 students were invited to participate with an overall response rate of $25 \%$. Second in importance to receiving accurate information about degree requirements was advising that helps students to choose among courses in their program of study, a function that can be seen as partially prescriptive in nature. 
Smith and Allen (2012) in later work sought to empirically assess if learning occurs in an advising encounter, namely is there an association between student learning and academic advising? The researchers closely examined the literature on academic advising in relation to student success and developed eight learning outcomes that represent knowledge, skills, and values, that are important to navigate the educational landscape. In a study at nine institutions consisting of 22,000 students, researchers asked two questions; (1) do scores on eight specific learning outcomes vary as a function of frequency of contact with advisors in the formal advising setting, and (2) among students who have contacted advisors, are scores higher for those who have more contacts than for those with fewer contacts (pp. 10-11)? This study included two community colleges, two private not-for-profit institutions, and five public universities. The study used an analysis of covariance (ANCOVA) to control for outside variables that could be hypothesized to affect advising learning. The results indicated a consistent pattern across learning outcomes, namely students who were advised frequently scored highest on learning outcomes, followed by those students advised occasionally, followed by those students who were not advised (pp. 15-16). Although institution was a variable examined in this study, under a non-mandatory advising system it is possible that other factors such as motivation may be influencing some of these learning outcomes.

Smith and Allen (2012) have identified quality academic advising as incorporating concepts from both prescriptive and developmental advising (Crookston, 1972; O’Banion, 1972), as well as learning-centered advising (Lowenstein, 1999,2005; Hemwall \& Trachte, 1999). They have identified that these concepts actually work in 
tandem in advising encounters and combine to form an integrated whole that can be assessed by looking at specific advising functions.

\section{History of Academic Advising in Relation to Advising Delivery Models}

It is important to review how advising has been delivered throughout history to understand how modern academic advising delivery models developed. This section will explore the three main periods defined in the literature related to academic advising as a precursor to a discussion of the history of academic advising delivery models.

Frost (2000) identified three main periods within the history of academic advising: "Higher education before academic advising was defined, academic advising as a defined and unexamined activity, and academic advising as a defined and examined activity” (p. 4). The first period, roughly 1636-1900 coincides directly with the founding of Harvard. Students during this colonial period followed a standard curriculum and had no variability in the courses they could take. These earliest universities were primarily focused on training selected young men for the clergy and public service; much of the coursework was steeped in religious studies (Gordon, Habley, \& Grites, 2008). The principle of in loco parentis was followed with faculty serving the role of parents. Frost (2000) identifies three primary educational ideals that emerged during this period as utility, liberal culture, and research; as institutions grew during this first period, utility referred to expanded curricular choices for students. Harvard has traditionally been identified as the first institution to institute elective coursework for students. This introduction of elective coursework is also tied to the first need for "academic advisors" 
as guides to help students select appropriate coursework for their chosen paths (Gordon et al., 2008). Princeton and Yale were identified by Frost (2000) as two institutions that were steeped in liberal culture. Liberal culture at the time was typically defined as involving the fine arts, language, and literature as key themes. Finally, the research emphasis is typically associated with a genesis in European universities, particularly those within Germany. Frost notes "Professors who advocated a research philosophy devoted their energy to research and scholarship and tended to ignore their students” (p. $6)$.

The second era traditionally identified within the history of academic advising ran from 1870 until roughly 1970; Frost labels this period “Academic Advising as a Defined and Unexamined Activity” (2000, p. 4). This era initiated more conflict between faculty wanting to preserve the traditional curriculum and those wanting a more robust elective system. John Hopkins University is credited as the first institution to create what we know today as "majors" and was the first institution to formally identify the word “adviser” (Gordon et al., 2008). In fact, the President of John Hopkins at that time, Daniel Gilman, saw the role of advising as one in which the adviser would listen to student difficulties, act as a representative of the institution if action was required, and see the a student's course of study was given adequate attention (Hawkins, 1960, p. 565). Unfortunately, Gilman's vision of advising did not become reality for many institutions such as Harvard where the Board of Freshman Advisers did little more than approve study cards and hold occasional student luncheons (Veysey, 1965). As the decades progressed, particularly in the 1930s and 1940s several universities created support 
systems designed to consider a student's overall well-being that encompassed the physical, social, emotional, spiritual, and intellectual components. In 1949, the American Council on Education issued a statement defining the essential components of a student personnel program that some consider to be the foundation of developmental advising as it is known today (Kuhn, 2008). While definitions and roles related to academic advising were beginning to emerge during this period, the profession as a whole remained unexamined.

The third era traditionally defined within the history of academic advising encompasses the 1970's to current times and is defined by Frost as an era of “Academic Advising as a Defined and Examined Activity” (2000, p.4). This era began the tradition of the examination and comparison of academic advising between universities and the shedding of the idea that academic advising is purely a function of scheduling and selecting courses (Kuhn, 2008). The 1970's saw the first conference of the National Academic Advising Association (NACADA) and published research articles that began to conceptualize and initiate discussion about what it meant to "advise” with two foundational concepts of prescriptive and developmental advising (Crookston, 1972; O’Banion, 1972). Subsequent work in the 1980s examined administrative and organizational structures related to advising (Habley, 1983). A detailed description of these models follows this section. Finally, much of the work in the last two decades has focused on the practice, research, constructs, and assumptions that underlie the foundation of academic advising as an organized and examined activity (Kuhn, 2008). What are students learning through academic advising? How does advising and learning 
differ by institutional type, by year in school, by ethnicity and gender? What is the relationship between academic advising and student retention? Advisors and researchers across the country are examining these and other questions to help identify how advising can be more effective and impactful.

\section{Academic Advising Organizational Models}

Habley (1983) was the first to develop a taxonomy detailing the academic advising patterns found in higher education institutions at the time. He identified seven organizational models and later reported on the frequency of these models by size and type of institution by asking each respondent which one model "most closely described the overall organization of advising services on their campuses” (Habley, 1988, p. 19). Survey results were presented in his report, The Status and Future of Academic Advising. In addition to this initial survey in 1987, the same question related to the overall organization of advising services was surveyed in 1992, 1998, and again in 2003 (Habley, 2004). It should be noted that none of these surveys had an option for detailing multiple models that may be present on each campus. The seven academic advising organizational models Habley identifies are as follows:

\section{Faculty-Only Model}

In the Faculty-Only Model, all students are assigned to an instructional faculty member for advising. Most typically, the faculty member is assigned based on the student's chosen major. Unlike other models, this model is unique as the organizational model and delivery system are congruent. All of the other models may utilize a 
combination of faculty, professional staff, paraprofessionals, or even peers (Habley, 1983).

\section{Supplementary Advising Model}

In the Supplementary Advising Model, faculty continue to serve as the assigned advisors for students in the institution, however, in addition to the faculty advising, there is an office that serves an additional function. This office may serve as a central warehouse for advising information, a referral location for additional student support services, or a processing center for advising transactions or paperwork. All academic transactions continue to be the responsibility of the student's faculty advisor, but this central office may maintain structure, training, and support. Typically the supervision of faculty advisors is decentralized in this model.

\section{Split Advising Model}

In the Split Advising Model the initial advising of students is split between faculty in academic subunits and staff in a central advising office. A main advising office has jurisdiction over one subgroup of students, while faculty in academic subunits maintain jurisdiction over another subgroup of students. Perhaps the clearest example of this model is where an advising office has jurisdiction over students who have not yet declared a major, transferring that jurisdiction over to a faculty advisor once a student has declared a major. This same model is common for students who may have unique advising needs such as athletes, special populations, or nontraditional students. Typically, the advising office does not instigate academic transactions in this model; 
those transactions remain the in the jurisdiction of the assigned advisor in the academic subunit.

\section{Dual Advising Model}

In the Dual Advising Model, there is a shared responsibility for advising each student. Faculty members provide advising related to a student's academic major or discipline, and advising office staff provide advising that relates to a student's general education requirements, academic policies, registration, and other administrative referrals. There is typically a supervisor who manages the advising office staff who may have additional campus-wide responsibilities. In addition, if there are undecided students, they are typically advised in this central advising office.

\section{Total Intake Model}

In the Total Intake Model, initial advising responsibilities for all incoming students are assigned to an advising office. This initial advising office handles all advising transactions until a culminating event has occurred. These culminating events vary by institutions and can include the completion of a certain number of terms or credits, remaining in good academic standing, completing a certain subset of general education requirements, or satisfaction of a certain set of courses required for admission to an academic major. Once this culminating event has been satisfied, the student is then assigned to an academic subunit determined by the student's major. The initial intake advising office may have responsibility over academic advising, academic policy, or curricular instruction, or may solely be responsible for academic advising. Again this 
varies by institution. A director of dean according to the level of responsibility assigned to the office usually supervises the intake advising office.

\section{Satellite Model}

In the Satellite Model academic advising is coordinated and administered by academic subunits on campus. These academic subunits provide advising for a particular college or major and are typically located within close proximity to the units represented. Undecided students are typically advised by a particular subunit designated to handle undecided or transitioning students. Typically advising responsibilities shift from a satellite office to a specific faculty advisor once a student has reached a particular milestone in his or her chosen major.

\section{Self-Contained Model}

In the Self-Contained model, all advising from matriculation to graduation is handled in a centralized unit headed by a dean or director who is responsible for all of the advising functions that take place on the campus.

\section{Organizational Model Utilization}

Trends in Habley's organizational models were most recently documented in the Sixth National Survey on Academic Advising conducted by ACT (Habley, 2004). This particular survey included two-year public colleges, two-year private colleges, four-year public universities, and four-year private universities (n=3019)(p. 11). Across all institutions, the Split Model has continued as the most prominent model, however, its 
utilization has not increased since the 1998 survey (p. 18). Overall, the Faculty-Only Model decreased from 33\% in 1987 to 25\% in 2003 following a general trend towards shared responsibility for academic advising (p. 20). Perhaps more glaring are the changes evident at four-year public universities. The Split Model has grown in usage from 36\% in 1987 to 46\% in 2003, while the Faculty Only or Supplementary Models have dropped significantly from 51\% in 1987 to 22\% in 2003 (p. 20). The student caseloads in advising are being transferred in many cases from faculty to full-time professional advisors.

Pardee (2000) took the initial work by Habley (1983) and further defined the grouping of these models as decentralized, centralized, and shared. The decentralized models consist of Habley’s faculty-only and satellite models, centralized consists of only the self-contained model, while the four remaining models identified by Habley fall into the shared category. Pardee defines the centralized model as one where both professional and faculty advisors are housed in one academic or administrative unit. The decentralized model is one in which both the professional and faculty advisors are located in their respective academic departments. Finally, the shared model is one in which some advisors meet with students in a central advising center, while others advise students based on the student's undergraduate major (Pardee, 2004). 


\section{Advising Delivery Structures in Relation to Student Satisfaction, Learning, and Retention}

Limited research has been conducted on the relationship between how advising is delivered and student outcomes such as student satisfaction with advising, student learning outcomes associated with advising, and student retention. Recent work by Smith and Allen (2012) identified a relationship between frequency of advising and advising learning outcomes as well as overall satisfaction with advising, namely the more frequently a student sees an advisor, the greater the learning, after accounting for other confounding variables. Limited research has been conducted on "who” delivers academic advising in relation to satisfaction with advising, advising learning outcomes, and student retention.

In 2007, a longitudinal study was conducted at a public university in the Southeastern United States that examined the effectiveness of the faculty advising delivery systems and the professional advising delivery systems as perceived by sophomore and senior level students (Kennedy-Dudley, 2007) The study examined student perceptions of academic advising experiences within two delivery systems reported from 1999 to 2002. Students were surveyed once as sophomores and then again as seniors. The two systems analyzed were "faculty advising” provided by doctoral faculty with teaching duties and advising responsibilities, and "professional advising" provided by employees in a centralized advising center who work full-time as professional advisors. The survey instrument was primarily examining student 
satisfaction with academic advising. The analysis consisted of linear correlation analyses, independent samples $t$ tests, and correlated samples $t$ tests estimating the relationships between outcome variables and predictor variables. A factorial analysis of variance was utilized to estimate the unique effect of each predictor (Kennedy-Dudley, 2007, pp. 55-57). Overall findings were that students were significantly more satisfied with advising during their senior year than during their sophomore year. In addition, the study found that students who were advised by professional academic advisors were more satisfied with the advising experience than those who were advised by faculty. Although statistically significant, the effect size was minimal. An additional finding from this study was that women were more likely than men to have been advised by a professional advisor.

Another study was conducted in 2004 at Arizona State University designed to determine if there is a relationship between student satisfaction and academic advising delivery model utilizing the framework developed by Habley (1983) (Avants, 2004). Two surveys were conducted, one that asked administrators to identify the most appropriate advising model as defined by Habley, and a second survey focused on student satisfaction with advising under the identified model. A random sample of 1200 students was taken in the fall of 2000 and again in the spring of 2001 (pp. 8-9). The only independent variables examined in this study were academic level, gender, and academic advising organizational model. The analysis was completed using Chi-Square and ANOVA procedures. The study failed to identify statistical significance related to satisfaction with any one advising model, but did identify the Satellite Model (Habley, 
1983) as having the highest level of satisfaction among respondents. The Satellite Model features advising offices that are maintained and controlled within academic subunits on a campus, such as all students with majors within a particular school or College (Avants, 2004, p. 22).

A study at Florida State University in 2004 also examined several factors related to academic advising, specifically where students were most and least satisfied with academic advising and which advising delivery system was the most preferred by students (Smith, 2004). The study had two samples, the first focused on roughly 4,000 undergraduates during the 2000 and 2001 academic year, and the second focused on a subset of students who were first-year students those years. The study looked at departing and returning students and used Tinto’s (1975) conceptual framework as the basis of analysis for examining future enrollment behavior as well as academic and social integration. The investigation utilized post-hoc methodology and relied upon multiple data sources including student satisfaction survey data, academic performance data, and student enrollment records. Statistical methodologies involved descriptive statistics, oneway ANOVA, independent samples $t$ test, stepwise discriminant analysis, and canonical correlation procedures (Smith, 2004, p. 47).

The most significant findings from this study were the statistically significant differences identified between student satisfaction with advising received from faculty advisors, professional advisors, and peer advisors (the three categories identified in this research question) across all students (p. 72). Students were most satisfied with the 
advising they received from professional advisors $(\mathrm{M}=1.94, \mathrm{~N}=1492, \mathrm{SD}=.54)$, followed by the advising received from faculty advisors $(\mathrm{M}=2.12, \mathrm{~N}=627, \mathrm{SD}=.63)$, and were least satisfied with the advising they received from peer advisors $(\mathrm{M}=2.41$, $\mathrm{N}=146, \mathrm{SD}=.70)($ Smith, 2004, p. 72). A second finding from this study was that there was no statistically significant difference in advising perception between returning and departing students (p. 74).

The majority of the studies that examine advising delivery models have focused on student satisfaction with the advising process. In addition, most of these studies have been in association with doctoral dissertations and not contributed through peer reviewed, published research studies.

\section{Research Gap}

The studies previously noted focused exclusively on student satisfaction with advising in relation to various academic advising delivery models, or in the case of Smith and Allen (2012) on the frequency of advising in relation to student satisfaction with advising and advising learning outcomes, or what has been termed in the literature as “quality academic advising.” One significant research gap exists; an examination of academic advising delivery structures in relation to measures of student satisfaction with advising, student learning outcomes associated with advising, and student retention.

Miller (in press) posits examining advising delivery structures from an approach that involves (1) who is advised, (2) who advises, (3) where advising is done, and (4) how advising responsibilities are divided. Is there a relationship between these various 
academic advising delivery variables and student satisfaction with advising, academic advising learning outcomes, and student retention? In particular, how do these variables impact first-year students at our four-year public institutions; those at highest risk for attrition (ACT, 2010)? Prior research has shown student satisfaction to be a key factor in student retention, but little research has been done on academic advising related to how and where advising is delivered. Given the dramatic change in "who” delivers advising at our public institutions (Habley, 2004) it is essential that we know if "who" delivers advising has a relationship to student satisfaction with advising, student learning outcomes associated with advising, and ultimately to student retention. With this information, institutions can more effectively and efficiently organize academic advising delivery models that have a better chance of contributing to student success.

\section{Summary and Conclusion}

The first chapter posited a need for further research regarding academic advising delivery models in relation to student satisfaction with advising, student learning associated with academic advising, and ultimately student retention that may be associated with academic advising. With a better understanding of the relationships between academic delivery models, student satisfaction with academic advising, learning that occurs through advising encounters, and ultimately relationships that may exist between academic advising and student retention, we have a better chance of creating advising structures that enhance the productivity and efficiency of, and satisfaction with academic advising. 
This chapter examined 1) key institutional factors traditionally associated with student retention, 2) literature exploring associations between academic advising and retention, 3) past research on student satisfaction and student satisfaction with advising, 4) historical and contemporary theories related to student learning and academic advising, 5) the historical background and current transitions related to academic advising delivery models, and 6) potential links that may exist between academic advising delivery models and student satisfaction with advising, student learning related to academic advising, and student retention.

The next chapter proposes a research study and methodology to examine student satisfaction with advising, student-learning outcomes associated with advising, and student retention under various advising delivery structures at a particular public fouryear institution in the Pacific Northwest. 


\section{Chapter 3}

\section{Research Design and Procedures}

The purpose of this study was to examine the relationship between various academic advising delivery variables and student advising learning outcomes, student satisfaction with advising, and student retention. In particular, this study asked if (a) who advises students, (b) where students are advised, (c) how frequently students are required to see an advisor, (d) how frequently students actually see an advisor, and (e) how “mandatory” academic advising is implemented, is related to advising satisfaction, advising learning outcomes, and student retention. This chapter outlines the research design, participant information, measures used, procedures, and data analyses techniques.

This study used data collected in 2010 and 2011 under the auspices of a research collaborative lead by Janine Allen and Cathleen Smith, both faculty members at Portland State University. Data were collected from five public universities, two private universities, and two community colleges in Oregon that were members of the research collaborative. The institutional research boards either at the member institution or at Portland State University approved the research protocols used to collect data that involved human subjects. One source of data for this study was survey responses collected in the spring of 2010 and 2011 from students enrolled in the nine institutions that were members of the collaborative. All fully admitted students at the universities and all students enrolled in credit-bearing classes at the community colleges were invited to participate in the survey. 
The second source of information came from data collected in 2011 from interviews with advising administrators in the academic units of the study institution as a component of the greater research collaborative. During the interviews, advising administrators were asked to identify who advises students, where students are advised, how often students are required to see an advisor, and how "mandatory” advising is implemented within each academic unit. This particular study utilized survey responses from students at one of the universities, the "study institution" - a land grant university classified as a Carnegie Research University with “very high” research activity.

\section{Participants}

The study institution was a land-grant university located in the northwestern United States. The institution has approximately 22,000 students, $82 \%$ of those students are undergraduates, and $70 \%$ are under the age of 25 . The institution is located in a city of approximately 60,000 residents and is the largest employer in the area.

Undergraduates are distributed among the nine academic colleges at the institution, the largest two colleges being the College of Engineering and the College of Liberal Arts. Female students represent approximately $47 \%$ of the undergraduate population and the predominant ethnicity of the students is white, representing $70 \%$ of institution undergraduates (Oregon University System, 2011). Of the 18,245 students at the study institution who in the spring of 2011 were invited to participate in the survey, 4,026 students did so resulting in a response rate of $22.1 \%$. 
From this sample, a subsample consisting of first-time freshmen (students who enrolled in the university with no post high school college credit) was selected for examination. The study university requires that students see an advisor, and receive what is known as a personal identification number (PIN) to register for coursework. By selecting this institution for further review, a more robust analysis of satisfaction and learning associated with advising can be performed as most students have participated in the academic advising process. The study also focused on first-year students as first-year college students are at highest risk for attrition (ACT, 2010). It should be noted that due to the survey being administered during winter quarter, students who left the study institution before this time were not included in the survey sample.

Participants in the study represented all nine academic colleges present at the study institution. Table 1 compares the survey sample population (those first-time freshmen that completed the survey instrument) to all first-time freshmen at the study institution at the time of survey administration on select descriptive demographic data measures.

Table 1

Demographic Data of First-year Freshmen Surveyed versus First-year Student Population

Measure Survey Sample Population

$\begin{array}{lll}\text { Participants } & 628 & 3624\end{array}$ 
Female

White

High School mean GPA

Mean SAT Math

Mean SAT Verbal
$58 \%$

$72 \%$

3.65

568

552
$47 \%$

$70 \%$

3.51

548

528

The students who participated in the survey represented $17.3 \%$ of all first-time

freshmen at the study institution. Female survey respondents were slightly

overrepresented in the survey sample and mean high school GPAs and SAT scores were higher in the sample than the population. White student response rate and the corresponding non-White response rate were representative of the overall first-time freshmen student population.

\section{Instrument - Inventory of Academic Advising Functions (Student Version)}

Measures for this study came from a survey instrument developed by Smith and Allen (2006), the Inventory of Academic Advising Functions-Student Version (see Appendix A). The survey was adapted slightly for the study institution, for example, the name of the institution was used, and response options for questions that asked student where they got their advising were actual places at the institution. The survey asked students about the importance of and their satisfaction with academic advising, where and how often they get academic advising, and their advising learning. In addition, the survey included measures that have been linked to retention (retention proxies) in the literature. 
In addition to asking students where and how often they received academic advising, the survey asked students to rate their satisfaction with 12 advising functions (nested within five domains) that Smith and Allen (2006) found had been consistently identified as essential to the advising role: integration, referral, information, individuation, and shared responsibility. Table 2 lists each of the 12 advising functions with its corresponding variable name. For each function, participants were asked to rate their satisfaction with the advising they receive on each function ("How satisfied are you with the advising you receive on this function?”) using six point Likert-type scales anchored on each end of the scale, where scale point $1=$ "not satisfied" and scale point $6=$ "very satisfied.”

Table 2

Academic Advising Functions and Variable Names

Variable Name Academic Advising Functions

Integration Functions

Overall Connect Advising that helps students connect their academic, career, and life goals

Major Connect Advising that helps students choose among courses in the major that connect their academic, career, and life goals

Gen Ed Connect Advising that assists students with choosing among the various general education options that connect their academic, career, and life goals

Degree Connect Advising that assists students with deciding what kind of degree to pursue (Bachelor of Science, Bachelor of Arts) in order to connect their academic, career, and life goals

Out-of-Class

Advising that assists students with choosing out-of-class activities Connect (e.g., part-time employment, internships or practicum, participation in clubs or organizations) that connect their academic, career, and 
life goals

\section{Referral Functions}

Referral Academic When students need it, referral to campus resources that address academic problems (e.g., math or science tutoring, writing, disability accommodation, testing anxiety)

Referral Non- $\quad$ When students need it, referral to campus resources that address Academic non-academic problems (e.g., childcare, financial, physical and mental health)

\section{Information Functions}

How Things Work Assisting students with understanding how things work at this university (e.g., understanding timelines, policies, and procedures with regard to registration, financial aid, grading, graduation, petition and appeals, etc.)

Accurate Information Ability to give students accurate information about degree requirements

\section{Individuation Functions}

Skills Abilities

Interests

Taking into account students' skills, abilities, and interests in helping them choose courses

Known as Individual Knowing the student as an individual

Shared Responsibility Function

Shared Responsibility Encouraging students to assume responsibility for their education by helping them develop planning, problem-solving, and decisionmaking skills

The survey also included eight statements that represented advising learning outcomes that Smith and Allen (2012) found were associated with receiving academic advising. Table 3 lists each of the learning outcomes and its corresponding variable name. Students were asked to rate their level of agreement with the learning outcomes 
using anchored six point Likert-type scales, where scale point 1 = “strongly disagree” and scale point 6 = "strongly agree."

Table 3

Advising Learning Outcomes and Variable Names

Variable Name

Knows

Requirements

Knows Resources

Understands How

Things Work

Understands

Connections

Has Educational

Plan

Has Significant

Relationship

Values Advisor-

Advisee

Relationship

Supports Mandatory Advising
Advising Learning Outcome

I know what requirements (e.g., major, general education, other university requirements) I must fulfill in order to earn my degree

When I have a problem, I know where at name of institution I can go to get help

I understand how things work at name of institution (timelines, policies, and procedures with regard to registration, financial aid, grading, graduation, petition and appeals, etc.)

I understand how my academic choices at name of institution connect to my career and life goals

I have a plan to achieve my educational goals

I have had at least one relationship with a faculty or staff member at name of institution that has had a significant and positive influence on me

It is important to develop an advisor-advisee relationship with someone on campus

There should be mandatory academic advising for students 
Students’ survey responses have been paired with their demographic and enrollment data on the institution's student information system (Banner SIS). By using students' majors listed in Banner SIS, it was possible to pair the kind of advising delivery mode the student has experienced with survey responses and retention.

\section{Measures - Advising Delivery Models}

During the winter of 2011, as a component of the larger research collaborative, interviews were conducted by the researcher with advising administrators in each of the nine academic colleges at the study institution to determine "who" delivers advising to students, "where” that advising is delivered, "how often” students are required to see advisors in particular majors, and how each particular unit implements the institutional requirement of "mandatory” advising. These interviews were conducted in accordance with the protocol set up with the study university’s Institutional Research Board for the implementation of the Inventory of Academic Advising Functions- Student Version (Smith \& Allen, 2006) survey. Interviewees were asked open-ended questions related to the questions noted above and later categorized into subcategories. Based on the responses, first-year students from the study institution were then classified by major and categorized according to (1) who does advising, (2) where students are advised, (3) how frequently students are required to be advised, and (4) how units implement "mandatory" advising. 
The "who" does advising component was based on the most common structures at the selected land-grand institution. With this particular institution, the following subcategories were examined:

(a) professional advisors where advising is a primary role ${ }^{2}$,

(b) faculty advisors with advising listed as one of several responsibilities within their job description, and

(c) advising provided by student peers.

The "where" students are advised was again based on the most common structures at the selected land-grant institution. With the particular institution, the following subcategories were examined:

(a) advising center centralized by college within the institution,

(b) advising center centralized by school or major within the institution, or

(c) decentralized advising that occurs in individual staff or faculty offices.

The next advising delivery variable category examined was the frequency in which a student is required to meet with an advisor in his/her particular major. Data for this category was compiled from interviews conducted by the researcher with advising administrators in each of the individual academic units. With this particular institution, the following subcategories were examined:

\footnotetext{
${ }^{2}$ Senior instructors with advising as a primary role were categorized as professional advisors in this study.
} 
(a) students required to meet with an advisor once per year,

(b) students required to meet with an advisor once per term.

The student-reported "frequency of advising" was also based on the most common structures for first-year students at the selected land-grant institution. The frequency of advising was determined directly from the self-reported frequency of advising on the Inventory of Academic Advising Functions- Student Version (Smith \& Allen, 2006), rather than from structured interviews with advising administrators. With this particular institution, the following subcategories were examined:

(a) not currently receiving advising,

(b) receiving advising once per year,

(c) receiving advising more than once per year.

Finally, the manner in which academic units implement "mandatory" advising was examined. Although all students at this particular land-grant institution are required to see an advisor to receive a registration PIN at least once per year, the manner in which students receive this PIN varies by academic unit and was further examined as follows:

(d) PIN received directly from assigned academic advisor, or

(e) PIN received by an advisor after attending a group process, or

(f) PIN received after participating in peer-led advising process. 


\section{Data Collection Procedures}

Students were sent an email from the Associate Provost for Academic Affairs at the study institution inviting them to participate in the web-based survey that could be accessed through an embedded link in the email message. The elements of informed consent were included in the email message where the purpose of the survey was described to the students, and students were advised that their responses would be kept confidential, their participation was voluntary, and that participation in the survey would not impact their relationship with the university. Two weeks after the initial email, a follow-up email was sent to the students who had not yet taken the survey, and two weeks later a second and final follow-up email was sent to the students who had still not taken the survey. See Appendix B for the text of the emails. Students at the study institution were not offered an incentive as institutional policy at the institution prohibited the use of incentives for students to participate in research.

Once the survey was closed, researchers Dr. Janine Allen and Dr. Cathleen Smith gathered survey responses from those who participated, transferred data to the Statistical Package for Social Sciences (SPSS) and then deleted students’ names and email addresses per institutional research board (IRB) protocol on file. Only the data reference number was paired with the students' survey responses. In addition, the original files provided by the institutional research office containing the names and email addresses of students invited to participate, were destroyed per IRB-approved protocol. 
The data reference numbers were sent to institutional research personnel at the study institution for use in providing demographic and enrollment data on the students who participated in the survey. See Appendix C for a list of demographic data provided. Each year since the survey was administered institutional research personnel at the study institution use the data reference number to provide additional continuing enrollment and graduation data to the research collaborative.

Approval from the Portland State University’s Human Subjects Research Review Committee (HSRRC), received in December 2012, determined that a human subjects’ review was not required because the data already existed. Upon the HSRRC determination that a review was not required, a file containing data on the participants who meet the criteria specified above (i.e., first-year students at the one selected public institution that does mandate academic advising) was provided to the researcher. The file contained no identifying information that could link data back to individual participants.

\section{Data Analysis}

This particular study examined three main subsets of data, namely, satisfaction with advising, advising learning outcomes, and student retention. These data subsets were examined based on variables defined in Chapter One, "who” is delivering advising, "where” advising is delivered, "how frequently" students are required to see an advisor, “how frequently” students reported seeing an advisor, and how "mandatory” advising is implemented. The student sample used for this analysis was from the one public institution in the collaborative research group that mandates yearly advising (at a 
minimum) for all students. This analysis looked at first-year students who enrolled at the institution after completing high school; students transferring from another institution were excluded from this analysis. In essence, this research was designed to determine if there is a variation in student satisfaction with advising, advising learning outcomes, or student retention that can be explained on the basis of academic advising delivery model variables. An analysis of covariance (ANCOVA) was used to control for other variables that have been empirically or conceptually associated with advising satisfaction, learning, or student retention. Prior research on these data has identified confounding variables that will need to be accounted for in these analyses (Avants, 2004; Kennedy-Dudley, 2007; Pascarella \& Terenzini, 2005; Schreiner, 2009; Schroeder, 2012; Smith \& Allen, 2006, 2012; Smith, 2004).

Prior research identifies three confounding variables related to student satisfaction with advising that are relevant to this analysis. The Inventory of Academic Advising Functions- Student Version (Smith \& Allen, 2006) identified race, in particular, White versus non-White as being a factor in two of the advising functions. Gender is a second variable identified in prior research as impacting student satisfaction with advising (Avants, 2004; Kennedy-Dudley, 2007; Schroeder, 2012). Finally, first-generation status (whether at least one parent had a bachelor's degree) has been identified as a factor in prior studies on student satisfaction (Schroeder, 2012) as well as an important factor in student success in college (Pascarella \& Terenzini, 2005). 
Two confounding variables were conceptually hypothesized to relate to advising learning outcomes in this analysis, namely student grade point average (GPA) and the size of a student's major department. Minimal research has been conducted specifically related to advising learning outcomes per se, but related empirical work on student success in college does suggest that those students with higher GPAs do learn more (Pascarella \& Terenzini, 2005). In addition, it can be hypothesized that students in smaller major departments with fewer students would have greater overall access to faculty and advising than would those in larger majors with many students. Furthermore, Hemwall and Trachte (2003) posit that small colleges produce more learning.

Finally, empirical and conceptual data tied to student retention suggest three primary confounding variables tied with student retention, particularly first-year to second-year retention. Student GPA has been shown over the years to be a variable that has the most significant relationship with student retention (Pascarella \& Terenzini, 2005). In addition financial need is prevalent in research as a significant factor tied with student retention (Astin, 1993; Pascarella \& Terenzini, 2005). For this research financial need was indicated by whether or not a student was eligible to receive a Pell grant at the study institution. The third confounding variable utilized in the analysis of student retention was first-generation status (whether at least one parent had a bachelor's degree). Studies have identified first-generation status as being a factor that negatively impacts student retention (Ishitani, 2006; Riehl, 1994). 
The ANCOVA analysis is ideally suited to allow for the removal of known confounding variables. One primary benefit of using ANCOVA is that it allows for stricter experimental control by taking into account the confounding variables and provides a more refined measure of the experimental manipulation when compared to other general linear models (Field, 2009). Essentially, ANCOVA provides greater power to detect group differences and precision of those estimates when group differences are found.

A primary assumption of ANCOVA is homogeneity of slope meaning that covariates and dependent variables do not differ across levels of the independent variables (Field, 2009). Preliminary analyses of homogeneity of slope indicated:

- For satisfaction ratings, significant interactions between the covariates and independent variables on 10 of the 195 (5\%) of the models tested. The $n^{2}$ (partial eta squared) associate of each significant interaction ranges from .009 to .018 accounting for less than $2 \%$ of the variance in the models.

- For learning outcome ratings, significant interactions between the covariates and independent variables on 11 of the $80(13 \%)$ of the models tested. The $n^{2}$ (partial eta squared) associate of each significant interaction ranges from .011 to .020 accounting for less than $2 \%$ of the variance in the models.

- For retention measures, significant interactions between the covariates and independent variables on 1 of the $16(6 \%)$ of the models tested. The $n^{2}$ 
(partial eta squared) associate of the significant interaction was .012 accounting for less than $2 \%$ of the variance in the models.

The researcher acknowledges that, given the number of tests that were run, the chances of type I error, which occurs when a statistical test identifies a significant relationship when in actuality one does not exist, increase. In such case the Bonferroni approach to correct for type I errors might have been in order. However, given the paucity of research on this topic, the somewhat less conservative Sidak correction procedure was used to control for type I errors across all comparisons.

\section{Data Subsets}

There were three data subsets examined as part of this analysis: student satisfaction with advising, academic advising learning outcomes, and student retention (first-year to second year). These data subsets were examined by the specific advising delivery variables of (a) who advises students, (b) where students are advised, (c) how frequently students are required to see an advisor, (d) how frequently students actually see an advisor, and (e) how "mandatory" academic advising is implemented.

The first data subset examined in this study was first year students' satisfaction with the advising they receive on the 12 academic advising functions. One-way analyses of covariance (ANCOVA) were used to evaluate if student satisfaction with advising varied by the five specific advising delivery variables. The mean satisfaction ratings were examined across all 12 academic advising functions for each of the delivery variables noted (See Table 2 for a detailed description of the academic advising 
functions). The ANCOVA was used to control for the confounding variables of gender (male/female), ethnicity (White/non-White) and first-generation status (whether at least one parent had a bachelor's degree).

The second data subset examined in this study was academic advising learning outcomes for first-year students. One-way analyses of covariance (ANCOVA) were used to evaluate if academic advising learning outcomes varied by the five specific advising delivery variables. The mean learning outcome ratings were examined across all eight learning outcomes for each of the delivery variables noted (See Table 3 for a list of learning outcome variables). The ANCOVA was used to control for the confounding variables of grade point average (GPA) and the size of students' majors.

The final data subset examined in this study was student retention (first-year to second year). One-way analyses of covariance (ANCOVA) were used to evaluate if firstyear student retention (as measured by re-enrollment the subsequent fall term) varied by the five specific advising delivery variables. The ANCOVA was used to control for confounding variables of first-generation status (whether at least one parent had a bachelor's degree), financial need (eligible/not eligible for a Pell grant at the study institution), and institutional GPA. Students were categorized as either "retained" or “not-retained” for purposes of these analyses. 


\section{Chapter 4}

\section{Results and Analysis of Data}

The purpose of this study was to determine if there is a relationship between the academic advising delivery variables of (a) who advises students, (b) where students are advised, (c) how frequently students are required to see an advisor, (d) how frequently students actually see an advisor, (e) how "mandatory” academic advising is implemented, and student satisfaction with advising, advising learning outcomes, and/or student retention.

This study examined student satisfaction with advising, advising learning outcomes, and student retention across five advising delivery variables. This chapter presents the results of the data analyses for each research question posed in the study.

\section{Research Question One - Who Advises}

1. Is there a relationship between who advises first-year students and
a. Student satisfaction with advising?
b. Academic advising learning outcomes?
c. Student retention (first-year to second-year)?

Students were assigned to one of three groups according to who in the academic unit of the student's major delivers advising to first-year students. Referred to here as the “who advises” groups, these groups included students who were advised by either (a) professional advisors where advising is a primary role, (b) faculty advisors with advising 
listed as one of several responsibilities such as teaching and research, or (c) peer undergraduate advisors. Approximately $75 \%$ of the students who completed the survey were advised by professional advisors, approximately $20 \%$ by faculty advisors, and approximately $5 \%$ by peer advisors.

\section{Who Advises Students in Relation to Student Satisfaction with Advising}

Table 4 presents the means and standard deviations of the satisfaction scores on each of the advising functions for each "who advises” grouping. Student mean satisfaction ratings on the advising functions ranged from 3.13 to 4.57 on a 6-point anchored Likert-type scale (see Table 2 for a list of all advising functions). For all three groups, the advising functions with the lowest overall mean were Out of Class Connect and Known as Individual. The advising function with the highest overall mean was Accurate Information for all three groups.

Table 4 also presents the results of the one-way analyses of covariance (ANCOVA) used to determine if the mean satisfaction ratings differed by "who advises" the student, controlling for the covariates of gender (male/female), ethnicity (White/nonWhite) and first-generation status (whether at least one parent had a bachelor's degree). The results showed that satisfaction ratings on Overall Advising Satisfaction and on 5 of the 12 advising functions varied by “who" provided advising to students ( $p<.05$ on each function).

The subscripts in Table 4 identify the results of individual post-hoc analyses using the Sidak correction where $p<.05$. On Overall Advising Satisfaction, students in the 
group advised by professional advisors rated their satisfaction as higher than those students in groups advised by either faculty advisors or peer advisors. No significant difference was found between the Overall Advising Satisfaction ratings of students in the group advised by faculty and the group advised by peers.

Students in the advised by professional advisors group were more satisfied with advising received on 4 of the 5 integration functions (Overall Connect, Major Connect, Gen Ed Connect, Degree Connect) than students in the advised by faculty group. On these 4 integration functions there were no statistically significant differences found between students in the group advised by professional advisors and students in the group advised by peer advisors. No statistically significant differences were found between satisfaction ratings of students in the group advised by faculty advisors and those in the group advised by peer advisors on any of the 12 advising functions. On the function Skills, Abilities, Interests the post-hoc results of the Sidak correction for multiple comparisons showed no difference between the three groups despite an overall statistical significance of the ANCOVA on this function. There were no statistically significant group differences found on the satisfaction ratings of Out of Class Connect, Referral Academic, Referral Non-Academic, How Things Work, Accurate Information, Known as Individual, and Shared Responsibility functions. The effect size, $\eta^{2}$ (partial eta squared), for the statistically significant group difference on the satisfaction ratings of the advising functions ranged from .013 to .027 . 
Table 4

Satisfaction Ratings on Advising Functions: By Who Advises - Numbers, Means, and Standard Deviations of Satisfaction ratings for Each Group, and ANCOVA Results

\begin{tabular}{|c|c|c|c|c|c|c|c|}
\hline \multirow[t]{2}{*}{ Advising Function } & \multicolumn{2}{|c|}{$\begin{array}{l}\text { Professional } \\
\text { Advisors }\end{array}$} & \multicolumn{2}{|c|}{ Faculty Advisors } & \multicolumn{2}{|c|}{ Peer Advisors } & \multirow[b]{2}{*}{ Results of ANCOVAs } \\
\hline & $n$ & $M(S D)$ & $n$ & $M(S D)$ & $n$ & $M(S D)$ & \\
\hline Overall Advising Satisfaction & 441 & $4.34_{a}(1.33)$ & 122 & $3.95_{b}(1.34)$ & 20 & $3.55_{b}(1.28)$ & $F(2,577)=6.59, M S E=1.79, p=.001, \eta^{2}=.022$ \\
\hline \multicolumn{8}{|l|}{ Integration } \\
\hline Overall Connect & 418 & $4.29_{a}(1.30)$ & 115 & $3.92_{\mathrm{b}}(1.40)$ & 18 & $3.83_{\mathrm{ab}}(1.04)$ & $F(2,545)=4.31, M S E=1.71, p=.014, \eta^{2}=.016$ \\
\hline Major Connect & 418 & $4.35_{a}(1.28)$ & 115 & $3.97_{b}(1.34)$ & 18 & $3.94_{\mathrm{ab}}(1.11)$ & $F(2,545)=4.77, M S E=1.66, p=.009, \eta^{2}=.017$ \\
\hline Gen Ed Connect & 411 & $4.25_{a}(1.29)$ & 114 & $3.71_{\mathrm{b}}(1.39)$ & 18 & $3.83_{\mathrm{ab}}(1.43)$ & $F(2,537)=7.36, M S E=1.75, p=.001, \eta^{2}=.027$ \\
\hline Degree Connect & 406 & $4.24_{\mathrm{a}}(1.31)$ & 111 & $3.86_{\mathrm{b}}(1.45)$ & 17 & $3.71_{\mathrm{ab}}(1.16)$ & $F(2,528)=4.34, M S E=1.79, p=.014, \eta^{2}=.016$ \\
\hline Out-of-Class Connect & 402 & $3.64(1.43)$ & 112 & $3.42(1.43)$ & 18 & $3.33(1.46)$ & $F(2,526)=1.25, M S E=2.04, p=.288, \eta^{2}=.005$ \\
\hline \multicolumn{8}{|l|}{ Referral } \\
\hline Referral Academic & 397 & $4.17(1.35)$ & 111 & $4.18(1.36)$ & 17 & $3.82(1.43)$ & $F(2,519)=0.44, M S E=1.84, p=.647, \eta^{2}=.002$ \\
\hline Referral Non-Academic & 391 & $4.00(1.36)$ & 110 & $3.82(1.36)$ & 17 & $4.12(1.05)$ & $F(2,512)=0.95, M S E=1.83, p=.387, \eta^{2}=.004$ \\
\hline \multicolumn{8}{|l|}{ Information } \\
\hline How Things Work & 397 & $4.03(1.36)$ & 110 & $3.73(1.34)$ & 17 & $3.76(1.25)$ & $F(2,518)=2.23, M S E=1.84, p=.108, \eta^{2}=.009$ \\
\hline Accurate Information & 402 & $4.57(1.30)$ & 112 & $4.35(1.38)$ & 16 & $4.19(1.42)$ & $F(2,524)=1.82, M S E=1.76, p=.163, \eta^{2}=.007$ \\
\hline
\end{tabular}




\begin{tabular}{|c|c|c|c|c|c|c|c|}
\hline Individuation & & & & & & & \\
\hline Skills, Abilities, Interests & 396 & $4.13_{\mathrm{a}}(1.35)$ & 110 & $3.79_{\mathrm{a}}(1.34)$ & 16 & $3.63_{\mathrm{a}}(1.46)$ & $F(2,516)=3.33, M S E=1.84, p^{*}=.037, \eta^{2}=.013$ \\
\hline Known as Individual & 396 & $3.78(1.52)$ & 111 & $3.51(1.52)$ & 16 & $3.13(1.67)$ & $F(2,517)=2.42, M S E=2.31, p=.090, \eta^{2}=.009$ \\
\hline Shared Responsibility & & & & & & & \\
\hline Shared Responsibility & 390 & $4.21(1.29)$ & 110 & $3.91(1.35)$ & 16 & $3.81(1.33)$ & $F(2,510)=2.68, M S E=1.70, p=.070, \eta^{2}=.010$ \\
\hline
\end{tabular}

Note. Ratings were made on 6-point scales (1 = not satisfied, 6 = very satisfied). Covariates: White/non-White, gender, first generation (parent did/did not earn bachelor's degree). Within each row, means with different subscripts differ at the $p<.05$ minimally using the Sidak corrections for multiple comparisons.

* Although the results of the ANCOVA were statistically significant, the results of the post-hoc analysis using the Sidak correction for multiple comparisons showed no difference between the three groups. 


\section{Who Advises Students in Relation to Academic Advising Learning Outcomes}

Table 5 presents the means and standard deviations of the learning outcome scores for each "who advises” group. Student mean scores ranged from 3.55 to 5.36 on a 6-point anchored Likert-type learning scale (see Table 3 for a list of all advising learning outcomes). The learning outcome with the lowest mean across all groups was Has Significant Relationship, while the learning outcome with the highest mean for all three groups was Has Educational Plan.

Table 5 also presents the results of the one-way analyses of covariance (ANCOVA) used to determine if the mean learning outcome ratings differed by "who advises" the student, controlling for the covariates of size of major (number of students in a given major), and student GPA. The results showed that ratings on four of the eight learning outcomes varied by “who” provided advising to students $(p<.05$ on each outcome). The groups differed in their scores on Understands Connections, Has Educational Plan, Values Advisor-Advisee Relationship, and Supports Mandatory Advising.

The subscripts in Table 5 identify the results of individual post-hoc analyses using the Sidak correction where $p<.05$. On the learning outcome Understands Connections students in the group advised by professional advisors scored higher than students in groups advised by either faculty advisors or peer advisors. On the outcomes Has Educational Plan and Values Advisor-Advisee Relationship, students in the group advised by professional advisors scored higher than students in the group advised by faculty 
advisors, but the scores of these two groups did not differ from those of the group advised by peers. On the outcome Supports Mandatory Advising the Sidak correction for multiple comparisons showed no difference between the three groups despite overall statistical significance on this function. There were no statistically significant differences found between the group advised by faculty advisors and the group advised by peer advisors on any of the learning outcomes. There were no statistically significant group differences noted on the learning outcomes Knows Requirements, Knows Resources, Understands How Things Work, or Has Significant Relationship. The effect size, $\eta^{2}$ (partial eta squared), for the statistically significant learning outcomes ranged from .013 to .030 . 
Table 5

Learning Outcomes: By Who Advises - Numbers, Means, and Standard Deviations of Learning Outcome Scores for Each Group, and ANCOVA Results

\begin{tabular}{|c|c|c|c|c|c|c|c|}
\hline Learning Outcome & Prof & sional Faculty & & Faculty & & Peer & \\
\hline & $n$ & $M(S D)$ & $n$ & $M(S D)$ & $n$ & $M(S D)$ & Results of ANCOVAs \\
\hline Knows Requirements & 412 & $4.73(1.14)$ & 116 & $4.62(1.29)$ & 18 & $4.44(1.38)$ & $F(2,541)=1.99, M S E=1.38, p=.138, \eta^{2}=.007$ \\
\hline Knows Resources & 410 & $4.32(1.30)$ & 116 & $4.18(1.22)$ & 19 & $3.58(1.35)$ & $F(2,540)=2.91, M S E=1.66, p=.055, \eta^{2}=.011$ \\
\hline $\begin{array}{l}\text { Understands How Things } \\
\text { Work }\end{array}$ & 411 & $4.28(1.18)$ & 116 & $4.09(1.31)$ & 18 & $3.89(1.49)$ & $F(2,540)=1.66, M S E=1.49, p=.190, \eta^{2}=.006$ \\
\hline Understands Connections & 407 & $5.02_{a}(1.01)$ & 114 & $4.70_{b}(1.11)$ & 18 & $4.39_{\mathrm{b}}(0.92)$ & $F(2,534)=8.31, M S E=1.05, p=.000, \eta^{2}=.030$ \\
\hline Has Educational Plan & 442 & $5.36_{a}(0.85)$ & 122 & $5.14_{\mathrm{b}}(1.22)$ & 20 & $5.15_{\mathrm{ab}}(0.99)$ & $F(2,579)=5.28, M S E=0.83, p=.005, \eta^{2}=.018$ \\
\hline Has Significant Relationship & 440 & $3.67(1.53)$ & 122 & $3.69(1.47)$ & 20 & 3.55 (1.79) & $F(2,577)=0.10, M S E=2.34, p=.904, \eta^{2}=.000$ \\
\hline $\begin{array}{l}\text { Values Advisor-Advisee } \\
\text { Relationship }\end{array}$ & 412 & $5.14_{a}(1.03)$ & 117 & $4.85_{b}(1.18)$ & 18 & $5.28_{\mathrm{ab}}(0.83)$ & $F(2,542)=7.18, M S E=1.10, p=.001, \eta^{2}=.026$ \\
\hline $\begin{array}{l}\text { Supports Mandatory } \\
\text { Advising }\end{array}$ & 412 & $4.43_{\mathrm{a}}(1.44)$ & 117 & $4.24_{a}(1.54)$ & 18 & $4.89_{a}(1.23)$ & $\begin{array}{l}F(2,542)=3.56, M S E=2.10,{ }^{*} p=.029, \eta^{2}= \\
.013\end{array}$ \\
\hline
\end{tabular}

Note. Ratings were made on 6-point scales $(1=$ strongly disagree, 6 = strongly agree $)$. Covariates: size of major, GPA. Within each row, means with different subscripts differ at the $p<.05$ minimally using the Sidak corrections for multiple comparisons.

* Although the results of the ANCOVA were statistically significant, the results of the post-hoc analysis using the Sidak correction for multiple comparisons showed no difference between the three groups. 


\section{Who Advises in Relation to Student Retention (First-Year to Second-Year)}

Table 6 presents the means and standard deviations of the retention (first-year to second-year) indicators for each "who advises” group. For this analysis students were coded with a " 1 ” if they were retained from first-year to second-year and a " 2 " if not retained from the first-year to the second-year. Table 6 also presents a one-way analysis of covariance (ANCOVA) used to determine if the retention of the groups differed by “who advises,” controlling for the covariates of student GPA, financial need (eligible/not eligible for Pell grant), and first-generation status (whether at least one parent had a bachelor's degree).

The results of the ANCOVA showed that students in the group advised by peer advisors were retained at a lower rate than students in either the group advised by professional advisors or the group advised by faculty advisors. There were no statistically significant differences found between the group advised by faculty advisors and the group advised by professional advisors. The subscripts in Table 6 identify the results of individual post-hoc analyses using the Sidak correction where $p<.05$. The effect size, $\eta^{2}$ (partial eta squared), for the statistically significant result was .023. 
Table 6

Retention First-year to Second-year: By Who Advises - Numbers, Means, and Standard Deviations of Retention Results for Each Group, and ANCOVA Results

\begin{tabular}{|l|l|l|l|l|l|l|l|}
\hline Retention & \multicolumn{2}{|l|}{ By Professional Faculty } & \multicolumn{2}{|c|}{ By Faculty } & \multicolumn{2}{c|}{ By Peer } & \\
\hline & $n$ & $M(S D)$ & $n$ & $M(S D)$ & $n$ & $M(S D)$ & Results of ANCOVA \\
\hline Retained as of year 2 & 442 & $1.11_{\mathrm{a}}(0.31)$ & 122 & $1.07_{\mathrm{a}}(0.26)$ & 20 & $1.35_{\mathrm{b}}(0.49)$ & $F(2,578)=6.92, M S E=0.88, p=.001, \eta^{2}=.023$ \\
\hline
\end{tabular}

Note. Scale: 1 = student returned for second year, 2= student did not return for second year. Covariates: GPA, financial need (eligible/not eligible for Pell grant), first generation (parent did/did not earn bachelor's degree). Within each row, means with different subscripts differ at the $p<.05$ minimally using the Sidak corrections for multiple comparisons. 


\section{Research Question Two - Where Advised}

2. Is there a relationship between where first-year students are advised and
a. Student satisfaction with advising?
b. Academic advising learning outcomes?
c. Student retention (first-year to second-year)?

Students were assigned to one of three groups based on where first-year students are advised for their given majors. Referred to here as the "where advised” groups, these groups include students who are advised either (a) centrally by academic college, (b) centrally by major within a college, or (c) in a decentralized location.

\section{Where Students are Advised in Relation to Student Satisfaction with Advising}

Table 7 presents the means and standard deviations of the satisfaction scores on each of the advising functions for each "where advised" grouping. Student mean satisfaction ratings on the advising functions ranged from 3.53 to 4.61 on a 6-point anchored Likert-Type scale (see Table 2 for a list of all advising functions). The advising delivery functions with the lowest overall means were Out of Class Connect and Known as Individual. The advising delivery function with the highest overall mean for all three groups was Accurate Information.

Table 7 also presents the results of a one-way analysis of covariance (ANCOVA) used to determine if the mean satisfaction ratings of the groups differed by where students were advised, controlling for the covariates of gender (male/female), ethnicity 
(White/non-White) and first-generation status (whether at least one parent had a bachelor's degree). The results showed that satisfaction ratings on 3 of the 12 advising functions varied by where students were advised ( $p<.05$ on each function).

The subscripts in Table 7 identify the results of individual post-hoc analyses using the Sidak correction where $p<.05$. On the function Major Connect students in the group advised centrally by college were more satisfied than students in the group advised in a decentralized location. No statistically significant differences were found on Major Connect between satisfaction ratings of students in the group advised centrally by major and students advised in a decentralized location, or between students in the group advised centrally by college and students in the group advised centrally by major. On the function Gen Ed Connect students in the group advised centrally by college were more satisfied than students in the group advised centrally by major or students in the group advised in a decentralized location. No statistically significant differences were found on Gen Ed Connect between students in the group advised centrally by major and students in the group advised in a decentralized location. On the function Skills, Abilities, Interests the post-hoc results of the Sidak correction for multiple comparisons showed no difference between the three groups despite an overall statistical significance of the ANCOVA on this function. There were no statistically significant group differences found on the satisfaction ratings of Overall Advising Satisfaction, Overall Connect, Degree Connect, Out of Class Connect, Referral Academic, Referral Non-Academic, How Things Work, Accurate Information, Known as Individual, or Shared Responsibility 
functions. The effect size, $\eta^{2}$ (partial eta squared), for the statistically significant group difference on the satisfaction ratings of the advising functions ranged from .012 to .032. 
Table 7

Satisfaction Ratings on Advising Functions: By Where Advised - Numbers, Means, and Standard Deviations of Satisfaction ratings of Each Group, and ANCOVA Results

\begin{tabular}{|c|c|c|c|c|c|c|c|}
\hline \multirow[t]{2}{*}{ Advising Function } & \multicolumn{2}{|c|}{$\begin{array}{l}\text { Centralized by } \\
\text { College }\end{array}$} & \multicolumn{2}{|c|}{$\begin{array}{l}\text { Centralized by } \\
\text { Major or School }\end{array}$} & \multicolumn{2}{|c|}{ Decentralized } & \\
\hline & $n$ & $M(S D)$ & $n$ & $M(S D)$ & $n$ & $M(S D)$ & Results of ANCOVAs \\
\hline Overall Advising Satisfaction & 149 & $4.35(1.24)$ & 286 & $4.22(1.39)$ & 148 & $4.13(1.37)$ & $F(2,577)=1.23, M S E=1.82, p=.294, \eta^{2}=.004$ \\
\hline \multicolumn{8}{|l|}{ Integration } \\
\hline Overall Connect & 142 & $4.35(1.24)$ & 269 & $4.20(1.32)$ & 140 & $4.06(1.38)$ & $F(2,545)=1.78, M S E=1.73, p=.170, \eta^{2}=.006$ \\
\hline Major Connect & 142 & $4.49 \mathrm{a}(1.15)$ & 269 & $4.22_{\mathrm{ab}}(1.31)$ & 140 & $4.10_{b}(1.37)$ & $F(2,545)=3.76, M S E=1.66, p=.024, \eta^{2}=.014$ \\
\hline Gen Ed Connect & 141 & $4.50_{a}(1.15)$ & 263 & $4.08_{b}(1.36)$ & 139 & $3.81_{b}(1.39)$ & $F(2,537)=8.90, M S E=1.74, p=.000, \eta^{2}=.032$ \\
\hline Degree Connect & 138 & $4.26(1.16)$ & 259 & $4.13(1.39)$ & 137 & $4.06(1.43)$ & $F(2,528)=0.91, M S E=1.81, p=.405, \eta^{2}=.003$ \\
\hline Out-of-Class Connect & 136 & $3.56(1.30)$ & 259 & $3.63(1.46)$ & 137 & $3.53(1.49)$ & $F(2,526)=0.23, M S E=2.05, p=.796, \eta^{2}=.001$ \\
\hline \multicolumn{8}{|l|}{ Referral } \\
\hline Referral Academic & 134 & $4.16(1.34)$ & 256 & $4.09(1.35)$ & 135 & $4.29(1.39)$ & $F(2,519)=1.09, M S E=1.83, p=.338, \eta^{2}=.004$ \\
\hline Referral Non-Academic & 133 & $3.96(1.34)$ & 251 & $4.01(1.36)$ & 134 & $3.89(1.36)$ & $F(2,512)=0.35, M S E=1.84, p=.703, \eta^{2}=.001$ \\
\hline \multicolumn{8}{|l|}{ Information } \\
\hline How Things Work & 135 & $4.09(1.15)$ & 256 & $3.93(1.44)$ & 133 & $3.88(1.38)$ & $F(2,518)=0.88, M S E=1.85, p=.415, \eta^{2}=.003$ \\
\hline Accurate Information & 135 & $4.61(1.18)$ & 259 & $4.51(1.39)$ & 136 & $4.43(1.34)$ & $F(2,524)=0.71, M S E=1.77, p=.495, \eta^{2}=.003$ \\
\hline
\end{tabular}




\begin{tabular}{|c|l|l|l|l|l|l|l|}
\hline Individuation & & & & & & & \\
\hline Skills, Abilities, Interests & 133 & $4.28_{\mathrm{a}}(1.28)$ & 255 & $3.98_{\mathrm{a}}(1.40)$ & 134 & $3.92_{\mathrm{a}}(1.35)$ & $\begin{array}{l}F(2,516)=3.12, \mathrm{MSE}=1.84, p^{*}=.045, \eta^{2}= \\
.012\end{array}$ \\
\hline Known as Individual & 133 & $3.80(1.39)$ & 255 & $3.64(1.57)$ & 135 & $3.73(1.58)$ & $F(2,517)=0.72, M S E=2.33, p=.489, \eta^{2}=.003$ \\
\hline Shared Responsibility & & & & & & & \\
\hline Shared Responsibility & 132 & $4.17(1.22)$ & 250 & $4.14(1.32)$ & 134 & $4.07(1.36)$ & $F(2,510)=0.21, M S E=1.71, p=.809, \eta^{2}=.001$ \\
\hline
\end{tabular}

Note. Ratings were made on 6-point scales ( 1 = not satisfied, 6 = very satisfied). Covariates: White/non-White, gender, first generation (parent

$\mathrm{did} /$ did not earn bachelor's degree). Within each row, means with different subscripts differ at the $p<.05$ minimally using the Sidak correction for multiple comparisons.

* Although the results of the ANCOVA were statistically significant, the results of the post-hoc analysis using the Sidak correction for multiple comparisons showed no difference between the three groups. 


\section{Where Students are Advised in Relation to Advising Learning Outcomes}

Table 8 presents the means and standard deviations of the learning outcome scores for each "where advised” group. Student mean scores ranged from 3.56 to 5.41 on a 6-point anchored Likert-type learning scale (see Table 3 for a list of all advising learning outcomes). The learning outcome with the lowest mean across all groups was Has Significant Relationship while the learning outcome with the highest overall mean for all three groups was Has Educational Plan.

Table 8 also presents the results of a one-way analysis of covariance (ANCOVA) used to determine if the mean learning outcome ratings differed by "where advised," controlling for the covariates of size of major (number of students in a given major), and student GPA. The results showed that ratings on one of the eight learning outcomes varied by where students were advised ( $p<.05$ on each outcome) and one outcome approached statistical significance $(p=.050)$. The groups differed in their scores on Has Educational Plan.

The subscripts in Table 8 identify the results of individual post-hoc analyses using the Sidak correction where $p<.05$. On the learning outcome Has Educational Plan students in the group advised centrally by major scored higher than students in the group advised in a decentralized location. There were no statistically significant differences found between the group advised centrally by college and the group advised centrally by major, or between the group advised centrally by college and the group advised in a decentralized location. There were no statistically significant differences noted on the 
learning outcomes Knows Requirements, Knows Resources, Understands How Things Work, Understands Connections, Has Significant Relationship, Values Advisor-Advisee Relationship or Supports Mandatory Advising. The effect size, $\eta^{2}$ (partial eta squared), for the statistically significant learning outcomes ranged from .011 to .014. 
Table 8

Learning Outcomes: By Where Advised - Numbers, Means, and Standard Deviations of Learning Outcome Scores for Each Group, and ANCOVA Results

\begin{tabular}{|c|c|c|c|c|c|c|c|}
\hline \multirow[t]{2}{*}{ Learning Outcome } & \multicolumn{2}{|c|}{ Central by College } & \multicolumn{2}{|c|}{$\begin{array}{l}\text { Centralized by } \\
\text { Major or School }\end{array}$} & \multicolumn{2}{|c|}{ Decentralized } & \\
\hline & $n$ & $M(S D)$ & $n$ & $M(S D)$ & $n$ & $M(S D)$ & Results of ANCOVAs \\
\hline Knows Requirements & 139 & 4.54 (1.19) & 266 & $4.77(1.13)$ & 141 & $4.72(1.26)$ & $F(2,541)=1.55, M S E=1.38, p=.214, \eta^{2}=.006$ \\
\hline Knows Resources & 138 & $4.33(1.30)$ & 266 & $4.20(1.31)$ & 141 & $4.31(1.25)$ & $F(2,540)=0.85, M S E=1.67, p=.427, \eta^{2}=.003$ \\
\hline $\begin{array}{l}\text { Understands How Things } \\
\text { Work }\end{array}$ & 138 & $4.19(1.13)$ & 266 & $4.27(1.22)$ & 141 & $4.18(1.31)$ & $F(2,540)=0.67, M S E=1.50, p=.514, \eta^{2}=.002$ \\
\hline Understands Connections & 137 & $4.94(0.99)$ & 263 & $4.97(1.01)$ & 139 & $4.84(1.14)$ & $F(2,534)=0.96, M S E=1.08, p=.385, \eta^{2}=.004$ \\
\hline Has Educational Plan & 150 & $5.25_{\mathrm{ab}}(0.94)$ & 286 & $5.41_{\mathrm{a}}(0.81)$ & 148 & $5.18_{b}(1.08)$ & $F(2,579)=4.23, M S E=0.83, p=.015, \eta^{2}=.014$ \\
\hline $\begin{array}{l}\text { Has Significant } \\
\text { Relationship }\end{array}$ & 149 & $3.75(1.63)$ & 285 & $3.56(1.49)$ & 148 & $3.80(1.49)$ & $F(2,577)=1.44, M S E=2.33, p=.237, \eta^{2}=.005$ \\
\hline $\begin{array}{l}\text { Values Advisor-Advisee } \\
\text { Relationship }\end{array}$ & 140 & $5.14(0.97)$ & 266 & $5.09(1.05)$ & 141 & $5.01(1.16)$ & $F(2,542)=3.01, M S E=1.12, p=.050, \eta^{2}=.011$ \\
\hline $\begin{array}{l}\text { Supports Mandatory } \\
\text { Advising }\end{array}$ & 140 & $4.36(1.47)$ & 265 & $4.48(1.40)$ & 142 & $4.32(1.56)$ & $F(2,542)=1.91, M S E=2.11, p=.149, \eta^{2}=.007$ \\
\hline
\end{tabular}

Note. Ratings were made on 6-point scales ( 1 = strongly disagree, 6 = strongly agree). Covariates: size of major, GPA. Within each row, means with different subscripts differ at the $p<.05$ minimally using the Sidak correction for multiple comparisons. 


\section{Where Students are Advised in Relation to Retention (First-Year to Second-Year)}

Table 9 presents the means and standard deviations of the retention (first-year to second-year) indicators for each "where advised” grouping. For this analysis students were coded with a " 1 ” if they were retained from the first-year to the second-year and a "2” if not retained to the second-year. Table 6 also presents a one-way analysis of covariance (ANCOVA) used to determine if the mean retention of the groups differed by “where advised,” controlling for the covariates of student GPA, financial need (eligible/not eligible for Pell grant), and first-generation status (whether at least one parent had a bachelor's degree).

The results of the ANCOVA indicate no significant group differences in retention for first-year students based upon where a student was advised. 
Table 9

Retention First-Year to Second-Year: By Where Advised - Numbers, Means, and Standard Deviations of Retention Results for Each Group, and ANCOVA Results

\begin{tabular}{|l|l|l|l|l|l|l|l|}
\hline Retention & \multicolumn{2}{|c|}{$\begin{array}{c}\text { Centralized by } \\
\text { College }\end{array}$} & \multicolumn{2}{|c|}{$\begin{array}{c}\text { Centralized by } \\
\text { Major/School }\end{array}$} & \multicolumn{2}{|c|}{ Decentralized } & \\
\hline & $n$ & $M(S D)$ & $n$ & $M(S D)$ & $n$ & $M(S D)$ & Results of ANCOVAs \\
\hline Retained as of year 2 & 149 & $1.11(0.32)$ & 287 & $1.13(0.33)$ & 148 & $1.08(0.27)$ & $F(2,578)=0.30, M S E=0.09, p=.744, \eta^{2}=.001$ \\
\hline
\end{tabular}

Note. Scale: 1 = student returned for second year, 2 = student did not return for second year. Covariates: GPA, financial need (eligible/not eligible

for Pell grant), first generation (parent did/did not earn bachelor’s degree). 


\section{Research Question Three - Required Frequency of Advising}

3. Is there a relationship between how frequently first-year students are required to see an advisor and
a. Student satisfaction with advising?
b. Academic advising learning outcomes?
c. Student retention (first-year to second-year)?

Students were assigned to one of two groups based upon how often first-year students are required to be advised in their given majors. Referred to here as "required frequency” groups, students are required to meet with their advisor a minimum of (a) once per term, or (b) once per year dependent on their chosen academic major.

\section{Required Frequency of Advising in Relation to Student Satisfaction with Advising}

Table 10 presents the means and standard deviations of the satisfaction scores on each of the advising functions for each "required frequency” advising group. Student mean satisfaction ratings on the advising functions ranged between 3.45 and 4.56 on a 6point anchored Likert-type satisfaction scale (see Table 2 for a list of all advising functions). The advising functions with the lowest overall mean for both groups were Out of Class Connect and Known as Individual. The advising function with the highest overall mean for both groups was Accurate Information.

Table 10 also presents a one-way analysis of covariance (ANCOVA) used to determine if the mean satisfaction ratings of the groups differed by the "required 
frequency” of advising, controlling for the covariates of gender (male/female), ethnicity (White/non-White), and first-generation status (whether at least one parent had a bachelor's degree). The results showed that satisfaction ratings on 1 of the 12 advising functions varied by "required frequency" ( $p<.05$ on each function). The subscripts in Table 10 identify the results of the individual post-hoc analyses using the Sidak correction where $p<.05$. On the function Known as Individual, students in group requiring advising only once per year were more satisfied than students in the group requiring advising once per term. The effect size, $\eta^{2}$ (partial eta squared), for this statistically significant function was .009. There were no statistically significant group differences found on the satisfaction ratings of Overall Advising Satisfaction, Overall Connect, Major Connect, Gen Ed Connect, Degree Connect, Out of Class Connect, Referral Academic, Referral Non-Academic, How Things Work, Accurate Information, Skills Abilities Interests, or Shared Responsibility. 
Table 10

Satisfaction Ratings on Advising Functions: By Required Advising Frequency - Numbers, Means, and Standard Deviations of Satisfaction Ratings for Each Group, and ANCOVA results

\begin{tabular}{|c|c|c|c|c|c|}
\hline \multirow[t]{2}{*}{ Advising Function } & \multicolumn{2}{|c|}{ Once per Year } & \multicolumn{2}{|c|}{ Once per Term } & \\
\hline & $n$ & $M(S D)$ & $n$ & $M(S D)$ & Results of ANCOVAs \\
\hline Overall Advising Satisfaction & 399 & $4.21(1.40)$ & 184 & $4.27(1.23)$ & $F(1,578)=0.03, M S E=1.82, p=.858, \eta^{2}=.000$ \\
\hline \multicolumn{6}{|l|}{ Integration } \\
\hline Overall Connect & 370 & $4.20(1.37)$ & 181 & $4.20(1.22)$ & $F(1,546)=0.08, M S E=1.74, p=.779, \eta^{2}=.000$ \\
\hline Major Connect & 370 & $4.29(1.33)$ & 181 & $4.19(1.22)$ & $F(1,546)=1.04, M S E=1.68, p=.307, \eta^{2}=.002$ \\
\hline Gen Ed Connect & 365 & $4.19(1.33)$ & 179 & $3.98(1.33)$ & $F(1,538)=1.83, M S E=1.78, p=.177, \eta^{2}=.003$ \\
\hline Degree Connect & 355 & $4.18(1.35)$ & 179 & $4.07(1.33)$ & $F(1,529)=1.32, M S E=1.81, p=.250, \eta^{2}=.002$ \\
\hline Out-of-Class Connect & 357 & $3.65(1.46)$ & 175 & $3.45(1.36)$ & $F(1,527)=2.80, M S E=2.04, p=.095, \eta^{2}=.005$ \\
\hline \multicolumn{6}{|l|}{ Referral } \\
\hline Referral Academic & 353 & $4.18(1.37)$ & 172 & $4.12(1.33)$ & $F(1,520)=0.79, M S E=1.84, p=.376, \eta^{2}=.002$ \\
\hline Referral Non-Academic & 349 & $4.02(1.36)$ & 169 & $3.86(1.33)$ & $F(1,513)=2.13, M S E=1.83, p=.145, \eta^{2}=.004$ \\
\hline \multicolumn{6}{|l|}{ Information } \\
\hline How Things Work & 352 & $4.01(1.32)$ & 172 & $3.84(1.43)$ & $F(1,519)=1.82, M S E=1.85, p=.178, \eta^{2}=.003$ \\
\hline Accurate Information & 352 & $4.56(1.35)$ & 178 & $4.43(1.28)$ & $F(1,525)=1.46, M S E=1.77, p=.227, \eta^{2}=.003$ \\
\hline Individuation & & & & & \\
\hline
\end{tabular}




\begin{tabular}{|c|c|c|c|c|c|}
\hline Skills, Abilities, Interests & 349 & $4.08(1.37)$ & 173 & $3.96(1.34)$ & $F(1,517)=1.51, M S E=1.86, p=.220, \eta^{2}=.003$ \\
\hline Known as Individual & 349 & $3.77_{\mathrm{a}}(1.55)$ & 174 & $3.57_{\mathrm{b}}(1.48)$ & $F(1,518)=4.71, M S E=2.31, p=.030, \eta^{2}=.009$ \\
\hline Shared Responsibility & & & & & \\
\hline Shared Responsibility & 347 & $4.14(1.30)$ & 169 & $4.10(1.32)$ & $F(1,511)=0.36, M S E=1.71, p=.550, \eta^{2}=.001$ \\
\hline
\end{tabular}

Note. Ratings were made on 6-point scales ( 1 = not satisfied, 6 = very satisfied). Covariates: White/non-White, gender, first generation (parent did/did not earn bachelor's degree). Within each row, means with different subscripts differ at the $p<.05$ minimally using the Sidak corrections for multiple comparisons. 


\section{Required Frequency of Advising in Relation to Advising Learning Outcomes}

Table 11 presents the means and standard deviations of the learning outcome scores for each "required frequency" group. Student mean responses ranged between 3.36 and 5.39 on a 6-point anchored Likert-type learning scale (see Table 3 for a list of all advising learning outcomes). The learning outcome with the lowest mean across both groups was Has Significant Relationship while the highest mean for both groups was Has Educational Plan.

Table 11 also presents the results of the one-way analysis of covariance (ANCOVA) used to determine if the mean learning outcome ratings of the groups differed by “required frequency," controlling for the covariates of size of major (number of students in a given major), and student GPA. The results showed that ratings on five of the eight learning outcomes varied by "required frequency" of advising ( $p<.05$ on each function). The groups differed in their scores on Knows Requirements, Understands Connections, Has Educational Plan, Has Significant Relationship, and Values AdvisorAdvisee Relationship.

The subscripts in Table 11 identify the results of individual post-hoc analyses using the Sidak correction where $p<.05$. On all five of the eight learning outcomes with significant variances, students in the group advised once per year reported learning more than students in the group where advising is required once per term. There were no statistically significant group differences noted on the learning outcomes Knows Resources, Understands How Things Work, or Supports Mandatory Advising. The effect 
size, $\eta^{2}$ (partial eta squared), for the statistically significant learning outcomes ranged from .016 to .037 . 
Table 11

Learning Outcomes: By Required Advising Frequency - Numbers, Means, and Standard Deviations of Learning Outcome Scores for Each Group, and ANCOVA Results

\begin{tabular}{|l|l|l|l|l|l|}
\hline Learning Outcome & \multicolumn{2}{|c|}{ Once per Year } & \multicolumn{2}{|c|}{ Once Per Term } & \\
\hline & $n$ & $M(S D)$ & $n$ & $M(S D)$ & Results of ANCOVAs \\
\hline Knows Requirements & 372 & $4.80_{\mathrm{a}}(1.16)$ & 174 & $4.48_{\mathrm{b}}(1.21)$ & $F(1,542)=9.42, M S E=1.37, p=.002, \eta^{2}=.017$ \\
\hline Knows Resources & 371 & $4.26(1.32)$ & 174 & $4.26(1.24)$ & $F(1,541)=0.04, M S E=1.67, p=.841, \eta^{2}=.000$ \\
\hline Understands How Things Work & 371 & $4.29(1.22)$ & 174 & $4.10(1.21)$ & $F(1,541)=2.63, M S E=1.49, p=.105, \eta^{2}=.005$ \\
\hline Understands Connections & 367 & $5.04_{\mathrm{a}}(1.03)$ & 172 & $4.69_{\mathrm{b}}(1.03)$ & $F(1,535)=14.27, M S E=1.05, p=.000, \eta^{2}=.026$ \\
\hline Has Educational Plan & 399 & $5.39_{\mathrm{a}}(0.90)$ & 185 & $5.15_{\mathrm{b}}(0.95)$ & $F(1,580)=9.17, M S E=0.83, p=.003, \eta^{2}=.016$ \\
\hline Has Significant Relationship & 397 & $3.82_{\mathrm{a}}(1.53)$ & 185 & $3.36_{\mathrm{b}}(1.47)$ & $F(1,578)=11.86, M S E=2.29, p=.001, \eta^{2}=.020$ \\
\hline $\begin{array}{l}\text { Values Advisor-Advisee } \\
\text { Relationship }\end{array}$ & 372 & $5.22_{\mathrm{a}}(0.97)$ & 175 & $4.80_{\mathrm{b}}(1.19)$ & $F(1,543)=20.98, M S E=1.08, p=.000, \eta^{2}=.037$ \\
\hline Supports Mandatory Advising & 372 & $4.48(1.41)$ & 175 & $4.26(1.56)$ & $F(1,543)=3.81, M S E=2.11, p=.051, \eta^{2}=.007$ \\
\hline
\end{tabular}

Note. Ratings were made on 6-point scales ( 1 = strongly disagree, 6 = strongly agree). Covariates: size of major, GPA. Within each row, means with different subscripts differ at the $p<.05$ minimally using the Sidak corrections for multiple comparisons. 


\section{Required Frequency of Advising in Relation to Retention (First-Year to Second- Year)}

Table 12 presents the means and standard deviations of the retention (first-year to second-year) indicators for each "required frequency” group. For this analysis students were coded with a " 1 " if they were retained from the first-year to second-year and a " 2 " if not retained from the first-year to the second-year. Table 12 also presents a one-way analysis of covariance (ANCOVA) used to determine if retention of the groups differed by “required frequency," controlling for the covariates of student GPA, financial need (eligible/not eligible for Pell grant), and first-generation status (whether at least one parent had a bachelor’s degree).

The results indicated no significant group differences in retention for first-year students based upon whether students are required to seek advising once per year or once per term. 
Table 12

Retention First-year to Second-year: By Required Advising Frequency - Numbers, Means, and Standard Deviations of Retention Results for Each Group, and ANCOVA Results

\begin{tabular}{|l|l|l|l|l|l|}
\hline Retention & \multicolumn{2}{|c|}{ Once Per Year } & \multicolumn{2}{|c|}{ Once Per Term } & \\
\hline & $n$ & $M(S D)$ & $n$ & $M(S D)$ & Results of ANCOVAs \\
\hline Retained as of year 2 & 399 & $1.12(0.33)$ & 185 & $1.09(0.28)$ & $F(1,579)=1.51, M S E=0.09, p=.220, \eta^{2}=.003$ \\
\hline
\end{tabular}

Note. Scale: 1 = student returned for second year, 2= student did not return for second year. Covariates: GPA, financial need (eligible/not eligible for Pell grant), first generation (parent did/did not earn bachelor’s degree) 


\section{Research Question Four - Self-Report Advising Frequency}

4. Is there a relationship between how frequently first-year students actually see an advisor and
a. Student satisfaction with advising?
b. Academic advising learning outcomes?
c. Student retention (first-year to second-year)?

Students were assigned to one of three groups based upon how often they selfreported getting academic advising on the Inventory of Academic Functions- Student Version (Smith \& Allen, 2006). Referred to here as the "self-report advising frequency" groups, these groups include students that are (a) not currently getting advising, (b) getting advising once per year, and (c) getting advising more than once per year. In contrast to the "required frequency" groups, this variable reflected actual reported advising visits versus mandated advising visits.

\section{Self-Report Advising Frequency in Relation to Student Satisfaction with Advising}

Table 13 presents the means and standard deviations of the satisfaction scores on each of the advising functions for each “self-report advising frequency” grouping. Approximately $88 \%$ of the first-year students completing the satisfaction questions selfreported seeing an advisor more than once per year while $6 \%$ of the students completing the satisfaction questions self-reported seeing an advisor once per year. An additional $6 \%$ of students self-reported that they were not currently seeking advising. Student mean 
satisfaction ratings on the advising functions ranged between 2.41 and 4.56 on a 6-point anchored Likert-type scale (see Table 2 for a list of all advising functions). Unlike other advising delivery variables, the three groups differed in functions rated as lowest or highest. The function with the highest mean across both groups that reported getting advising was Accurate Information, while the function with the highest mean for students not getting advising was Overall Connect. The function with the lowest mean for those students not getting advising and for those students getting advising more than once per year was Out-of-Class Connect, while the function with the lowest mean for students getting advising once per year was Known as Individual.

Table 13 also presents a one-way analysis of covariance (ANCOVA) used to determine if the mean satisfaction ratings of the groups differed on " self-report advising frequency,” controlling for the covariates of gender (male/female), ethnicity (White/nonWhite), and first-generation status (whether at least one parent had a bachelor's degree). The results showed that satisfaction ratings on 11 of the 12 advising functions varied by "self-report advising frequency" of advising ( $p<.05$ on each function).

The subscripts in Table 13 identify the results of the individual post-hoc analyses using the Sidak correction where $p<.05$. On the function Overall Advising Satisfaction students in the group getting advising more than once per year were more satisfied with their academic advising experience than those in the group not currently getting advising or those in the group getting advising once per year. No significant difference was found 
between the Overall Advising Satisfaction of students in the group advised once per year and those in the group not currently getting advising.

Those students in the group getting advising more than once per year were more satisfied than those in the group not currently getting advising or those in the group getting advising once per year on the functions Major Connect and Gen Ed Connect. On these two functions there were no statistically significant differences found between students in the group getting advising once per year and those in the group not currently getting advising.

Students in the group getting advising more than once per year were more satisfied than those in the group getting advising once per year on the functions Overall Connect; Skills, Abilities, Interests; Known as Individual; and Shared Responsibility. On these four functions there were no statistically significant differences found between students in the group getting advising once per year and those in the group not currently getting advising, nor between students in the group getting advising more than once per year and those in the group not currently getting advising.

Students in the group getting advising more than once per year were more satisfied than those in the group not currently getting advising on the advising functions Degree Connect and Accurate Information. On these two functions there were no statistically significant differences found between students in the group getting advising more than once per year and those in the group getting advising once per year, nor 
between students in the group getting advising once per year and the group not currently getting advising.

On the functions Out of Class Connect, Referral Academic, and How Things Work the post-hoc results of the Sidak correction for multiple comparisons showed no difference between the three groups despite an overall statistical significance of the ANCOVA on this function. There were no statistically significant group differences found on the satisfaction ratings of the function Referral Non-Academic. The effect size, $\eta^{2}$ (partial eta squared), for the statistically significant advising functions ranged from .015 to .080 . 
Table 13

Satisfaction Ratings on Advising Functions: By Self-Report Advising Frequency - Numbers, Means, and Standard Deviations of Satisfaction Ratings for Each Group, and ANCOVA results

\begin{tabular}{|c|c|c|c|c|c|c|c|}
\hline \multirow[t]{2}{*}{ Advising Function } & \multicolumn{2}{|c|}{$\begin{array}{l}\text { No Advice/Not } \\
\text { currently }\end{array}$} & \multicolumn{2}{|c|}{ Once per Year } & \multicolumn{2}{|c|}{$\begin{array}{c}\text { More than once per } \\
\text { year }\end{array}$} & \\
\hline & $n$ & $M(S D)$ & $n$ & $M(S D)$ & $n$ & $M(S D)$ & Results of ANCOVAs \\
\hline Overall Advising Satisfaction & 35 & $2.94_{b}(1.33)$ & 32 & $3.53_{\mathrm{b}}(1.39)$ & 515 & $4.36_{a}(1.29)$ & $F(2,576)=25.11, M S E=1.68, p=.000, \eta^{2}=.080$ \\
\hline \multicolumn{8}{|l|}{ Integration } \\
\hline Overall Connect & 9 & $3.78_{\mathrm{ab}}(1.72)$ & 31 & $3.55_{a}(1.52)$ & 510 & $4.25_{\mathrm{b}}(1.29)$ & $F(2,544)=5.07, M S E=1.71, p=.007, \eta^{2}=.018$ \\
\hline Major Connect & 9 & $3.11_{\mathrm{a}}(1.69)$ & 31 & $3.45_{\mathrm{ac}}(1.46)$ & 510 & $4.32_{b}(1.25)$ & $F(2,544)=10.75, M S E=1.62, p=.000, \eta^{2}=.038$ \\
\hline Gen Ed Connect & 9 & $2.89_{a}(1.54)$ & 29 & $3.41_{\mathrm{ac}}(1.35)$ & 504 & $4.18_{\mathrm{b}}(1.31)$ & $F(2,536)=8.34, M S E=1.74, p=.000, \eta^{2}=.030$ \\
\hline Degree Connect & 9 & $2.89_{a}(1.76)$ & 31 & $3.84_{\mathrm{ab}}(1.49)$ & 493 & $4.18_{\mathrm{b}}(1.31)$ & $F(2,527)=5.34, M S E=1.78, p=.005, \eta^{2}=.020$ \\
\hline Out-of-Class Connect & 9 & $2.67 \mathrm{a}(1.87)$ & 30 & $3.10_{a}(1.37)$ & 492 & $3.62_{\mathrm{a}}(1.41)$ & $F(2,525)=3.99, M S E=2.01, p^{*}=.019, \eta^{2}=.015$ \\
\hline \multicolumn{8}{|l|}{ Referral } \\
\hline Referral Academic & 9 & $3.33_{a}(1.50)$ & 27 & $3.63_{a}(1.42)$ & 488 & $4.20_{a}(1.34)$ & $F(2,518)=4.59, M S E=1.81, p^{*}=.011, \eta^{2}=.017$ \\
\hline Referral Non-Academic & 9 & $3.44(1.67)$ & 27 & $3.78(1.53)$ & 481 & $3.98(1.33)$ & $F(2,511)=1.09, M S E=1.83, p=.336, \eta^{2}=.004$ \\
\hline \multicolumn{8}{|l|}{ Information } \\
\hline How Things Work & 9 & $3.00_{a}(1.87)$ & 27 & $3.48_{a}(1.48)$ & 487 & $4.00_{a}(1.33)$ & $F(2,517)=4.08, M S E=1.83, p^{*}=.018, \eta^{2}=.016$ \\
\hline Accurate Information & 9 & $3.44_{a}(2.07)$ & 29 & $4.10_{\mathrm{ab}}(1.40)$ & 491 & $4.56_{a}(1.30)$ & $F(2,523)=4.75, M S E=1.74, p=.009, \eta^{2}=.018$ \\
\hline
\end{tabular}




\begin{tabular}{|c|l|l|l|l|l|l|l|}
\hline Individuation & & & & & & & \\
\hline Skills, Abilities, Interests & 9 & $3.44_{\mathrm{ab}}(2.07)$ & 28 & $3.32_{\mathrm{a}}(1.12)$ & 484 & $4.09_{\mathrm{b}}(1.35)$ & $F(2,515)=5.44, M S E=1.83, p=.005, \eta^{2}=.021$ \\
\hline Known as Individual & 9 & $3.33_{\mathrm{ab}}(1.66)$ & 27 & $2.41_{\mathrm{a}}(1.31)$ & 486 & $3.78_{\mathrm{b}}(1.51)$ & $F(2,516)=12.05, M S E=2.23, p=.000, \eta^{2}=.045$ \\
\hline Shared Responsibility & & & & & & & \\
\hline Shared Responsibility & 9 & $3.44_{\mathrm{ab}}(1.74)$ & 28 & $3.50_{\mathrm{a}}(1.37)$ & 478 & $4.18_{\mathrm{b}}(1.28)$ & $F(2,509)=5.25, M S E=1.68, p=.006, \eta^{2}=.020$ \\
\hline
\end{tabular}

Note. Ratings were made on 6-point scales ( 1 = not satisfied, 6 = very satisfied). Covariates: White/non-White, gender, first generation (parent did/did not earn bachelor's degree). Within each row, means with different subscripts differ at the $p<.05$ minimally using the Sidak corrections for multiple comparisons.

* Although the results of the ANCOVA were statistically significant, the results of the post-hoc analysis using the Sidak correction for multiple comparisons showed no difference between the three groups. 


\section{Self-Report Advising Frequency in Relation to Advising Learning Outcomes}

Table 14 presents the means and standard deviations of the learning outcome scores for each "self-report advising frequency” group. Student mean scores ranged from 2.60 to 5.44 on a 6-point anchored Likert-type learning scale (see Table 3 for a list of all advising learning outcomes). The outcome with the highest mean in the not currently advised group and the more than once per year group was Has Educational Plan, while the outcome with the lowest mean for both of these groups was Has Significant Relationship. The group getting advising once per year had the highest mean on the outcome Understands Connections and the lowest mean on the functions Knows Resources.

Table 14 also presents a one-way analysis of covariance (ANCOVA) used to determine if the mean learning outcome ratings of the groups differed by "self-report advising frequency," controlling for the covariates of size of major (number of students in a given major), and student GPA. The results of the ANCOVAs showed that ratings on seven of the eight learning outcomes varied by students' "self-report advising frequency" ( $p<.05$ on each function). The groups differed on their scores of Knows Requirements, Knows Resources, Understands How Things Work, Understands Connections, Has Significant Relationship, Values Advisor-Advisee Relationship, and Supports Mandatory Advising.

The subscripts in Table 14 identify the results of individual post-hoc analyses using the Sidak correction where $p<.05$. On the learning outcomes of Values Advisor- 
Advisee Relationship, Knows Requirements, Understands How Things Work, and Has Significant Relationship, students in the group getting advising more than once per year reported higher scores than those in the group not currently seeking advising. There were no statistically significant differences found between students in the group choosing to see an advisor more than once per year and students in the group choosing to seen an advisor once per year, nor between students in the group choosing to seen an advisor once per year and those in the group not currently seeking advising.

On the learning outcomes Understands Connections and Knows Resources, students in the group seeking advising more than once per year scored higher than students in the group not currently seeking advising. In addition, students in the group seeking advising once per year scored higher than students not currently seeking advising. There were no statistically significant differences found between those in the group seeking advising more than once per year and those in the group seeking advising once per year on these two learning outcomes.

On the learning outcome Supports Mandatory Advising, the post-hoc results of the Sidak correction for multiple comparisons showed no difference between the three groups despite an overall statistical significance of the ANCOVA on this function. There were no statistically significant group differences found on the outcome Has Education Plan. The effect size, $\eta^{2}$ (partial eta squared), for the statistically significant learning outcomes ranged from .013 to .069 . 
Table 14

Learning Outcomes: By Self-Report Advising Frequency - Numbers, Means, and Standard Deviations of Learning Outcome Scores for Each Group, and ANCOVA Results

\begin{tabular}{|c|c|c|c|c|c|c|c|}
\hline Learning Outcome & & $\begin{array}{l}\text { Advice/Not } \\
\text { currently }\end{array}$ & & ice per Year & & $\begin{array}{l}\text { e than Once } \\
\text { Per Year }\end{array}$ & \\
\hline & $n$ & $M(S D)$ & $n$ & $M(S D)$ & $n$ & $M(S D)$ & Results of ANCOVAs \\
\hline Knows Requirements & 34 & $3.82_{\mathrm{a}}(1.49)$ & 28 & $4.54_{\mathrm{ab}}(1.14)$ & 483 & $4.77_{b}(1.14)$ & $F(2,540)=9.82, M S E=1.34, p=.000, \eta^{2}=.035$ \\
\hline Knows Resources & 34 & $3.00_{a}(1.60)$ & 28 & $3.93_{\mathrm{b}}(1.44)$ & 482 & $4.37_{b}(1.21)$ & $F(2,539)=20.09, M S E=1.56, p=.000, \eta^{2}=.069$ \\
\hline $\begin{array}{l}\text { Understands How Things } \\
\text { Work }\end{array}$ & 34 & $3.50_{a}(1.54)$ & 28 & $4.04_{\mathrm{ab}}(1.37)$ & 482 & $4.29_{\mathrm{b}}(1.17)$ & $F(2,539)=7.19, M S E=1.46, p=.001, \eta^{2}=.026$ \\
\hline Understands Connections & 33 & $4.06 \mathrm{a}(1.46)$ & 28 & $5.07_{b}(0.77)$ & 477 & $4.98_{b}(1.00)$ & $F(2,533)=12.29, M S E=1.04, p=.000, \eta^{2}=.044$ \\
\hline Has Educational Plan & 36 & $5.17(1.40)$ & 32 & $5.44(0.72)$ & 515 & $5.31(0.89)$ & $F(2,578)=0.45, M S E=0.84, p=.635, \eta^{2}=.002$ \\
\hline $\begin{array}{l}\text { Has Significant } \\
\text { Relationship }\end{array}$ & 35 & $2.60_{\mathrm{a}}(1.54)$ & 32 & $3.31_{\mathrm{ab}}(1.53)$ & 514 & $3.77_{b}(1.50)$ & $F(2,576)=10.58, M S E=2.26, p=.000, \eta^{2}=.035$ \\
\hline $\begin{array}{l}\text { Values Advisor-Advisee } \\
\text { Relationship }\end{array}$ & 34 & $4.62_{\mathrm{a}}(1.16)$ & 27 & $4.93_{\mathrm{ab}}(1.30)$ & 485 & $5.12_{b}(1.03)$ & $F(2,541)=3.76, M S E=1.11, p=.024, \eta^{2}=.014$ \\
\hline $\begin{array}{l}\text { Supports Mandatory } \\
\text { Advising }\end{array}$ & 34 & $3.94_{a}(1.65)$ & 28 & $3.96_{a}(1.75)$ & 484 & $4.47_{a}(1.42)$ & $F(2,541)=3.62, M S E=2.10, p^{*}=.028, \eta^{2}=.013$ \\
\hline
\end{tabular}

Note. Ratings were made on 6-point scales (1 = strongly disagree, 6 = strongly agree). Covariates: size of major, GPA. Within each row, means with different subscripts differ at the $p<.05$ minimally using the Sidak corrections for multiple comparisons.

* Although the results of the ANCOVA were statistically significant, the results of the post-hoc analysis using the Sidak correction for multiple comparisons showed no difference between the three groups. 


\section{Self-Report Advising Frequency in Relation to Retention (First-Year to Second- Year)}

Table 15 presents the means and standard deviations of the retention (first-year to second-year) indicators for each "self-report advising frequency" group. For this analysis students were coded with a " 1 ” if they were retained from the first-year to the secondyear and a "2" if not retained from first-year to second-year. Table 15 also presents a one-way analysis of covariance (ANCOVA) used to determine if the mean retention of the groups differed by "self-report advising frequency," controlling for the covariates of student GPA, financial need (eligible/not eligible for Pell grant), and first-generation status (whether at least one parent had a bachelor's degree).

The results of the ANCOVA indicate no significant group differences in the retention of first-year students based "self-report advising frequency." 
Table 15

Retention First-Year to Second-Year: By Self-report Advising Frequency - Numbers, Means, and Standard Deviations of Retention Results for Each Group, and ANCOVA Results

\begin{tabular}{|l|l|l|l|l|l|l|l|}
\hline Retention & \multicolumn{2}{|c|}{$\begin{array}{c}\text { No Advice/Not } \\
\text { currently }\end{array}$} & \multicolumn{2}{|c|}{ Once Per Year } & \multicolumn{2}{|c|}{$\begin{array}{l}\text { Yore than Once per } \\
\text { Year }\end{array}$} & \\
\hline & $n$ & $M(S D)$ & $n$ & $M(S D)$ & $n$ & $M(S D)$ & Results of ANCOVAs \\
\hline Retained as of year 2 & 35 & $1.14(0.36)$ & 32 & $1.06(0.25)$ & 516 & $1.11(0.32)$ & $F(2,576)=0.27, M S E=0.09, p=.762, \eta^{2}=.001$ \\
\hline
\end{tabular}

Note. Scale: 1 = student returned for second year, 2= student did not return for second year. Covariates: GPA, financial need (eligible/not eligible

for Pell grant), first generation (parent did/did not earn bachelor’s degree). 


\section{Research Question Five - How “Mandatory” Advising is Implemented}

5. Is there a relationship between how "mandatory" advising is implemented and
a. Student satisfaction with advising?
b. Academic advising learning outcomes?
c. Student retention (first-year to second-year)?

Students at the study institution receive what is known as a registration "PIN" which is essentially a password that allows the students into the study institution's registration system. Students must enter this registration "PIN" before being allowed to register for any given academic period. Students were assigned to one of three groups according to how they receive their registration PIN. Referred to here as "PIN delivery" groups, these groups includes students who (a) receive a registration PIN directly from an advisor, (b) receive a registration PIN directly from an advisor after attending a group advising process, or (c) receive a registration PIN after attending a peer-led advising process.

\section{How “Mandatory” Advising is Implemented in Relation to Student Satisfaction with Advising}

Table 16 presents the means and standard deviations of the satisfaction scores on each of the advising functions for each of the "PIN delivery" groups. Approximately $90 \%$ of the first-year students completing the satisfaction questions were in the group that received a registration PIN directly from an advisor, 7\% of the students were in the group 
that received their registration PIN after group advising, and 3\% were in the group that received their registration PIN after a peer-led advising process. Student mean responses on the advising functions ranged between 3.13 and 4.55 on a 6-point anchored Likerttype satisfaction scale. The advising function with the highest mean for the group receiving a PIN in an individual advising appointment was Accurate Information, while the lowest mean for this group was Out of Class Connect. The function with the highest mean for the group receiving a PIN after a group-led process was Overall Connect while the lowest mean was Known as Individual. The function with the highest mean for the group receiving a PIN after a peer-led process was Accurate Information while the lowest mean was on the function Known as Individual.

Table 16 also presents a one-way analysis of covariance (ANCOVA) used to determine if the mean satisfaction ratings of the groups differed by "PIN delivery" group, controlling for the covariates of gender (male/female), ethnicity (White/non-White), and first-generation status (whether at least one parent had a bachelor's degree). The results showed that satisfaction ratings on 2 of the 12 advising functions varied by how students were receiving their registration PIN’s ( $p<.05$ on each function).

The subscripts in Table 16 identify the results of the individual post-hoc analyses using the Sidak correction where $p<.05$. On the advising function Known as Individual, students in the group that received their registration PIN directly from an advisor were more satisfied than students who received their PIN after a group advising process. No statistically significant differences were found between students who received their 
registration PIN directly from an advisor and those students who received their PIN after a peer-led advising process, nor between students that received their PIN in a group process compared to those that received their PIN after a peer-led advising process. On the function Skills, Abilities, Interests, the post-hoc results of the Sidak correction for multiple comparison showed no difference between the three groups despite an overall statistical significance of the ANCOVA on this function. There were no statistically significant group differences found on the satisfaction ratings of the functions Overall Advising Satisfaction, Overall Connect, Major Connect, Gen Ed Connect, Degree Connect, Out of Class Connect, Referral Academic, Referral Non-Academic, How Things Work, Accurate Information, or Shared Responsibility. The effect size, $\eta^{2}$ (partial eta squared), for the statistically significant advising functions ranged from .013 to .018. 
Table 16

Satisfaction Ratings on Advising Functions: By How PIN Delivered - Numbers, Means, and Standard Deviations of Satisfaction Ratings for Each Group, and ANCOVA Results

\begin{tabular}{|c|c|c|c|c|c|c|c|}
\hline \multirow[t]{2}{*}{ Advising Function } & \multicolumn{2}{|c|}{$\begin{array}{c}\text { By Advisor in } \\
\text { Individual Appt. }\end{array}$} & \multicolumn{2}{|c|}{$\begin{array}{l}\text { By Advisor in } \\
\text { Group Setting }\end{array}$} & \multicolumn{2}{|r|}{ By Peer } & \\
\hline & $n$ & $M(S D)$ & $n$ & $M(S D)$ & $n$ & $M(S D)$ & Results of ANCOVAs \\
\hline Overall Advising Satisfaction & 523 & $4.25(1.35)$ & 40 & $4.22(1.21)$ & 20 & $3.55(1.28)$ & $F(2,577)=2.47, M S E=1.81, p=.085, \eta^{2}=.008$ \\
\hline \multicolumn{8}{|l|}{ Integration } \\
\hline Overall Connect & 493 & $4.21(1.34)$ & 40 & $4.25(1.21)$ & 18 & $3.83(1.04)$ & $F(2,545)=0.60, M S E=1.73, p=.549, \eta^{2}=.002$ \\
\hline Major Connect & 493 & $4.28(1.31)$ & 40 & $4.08(1.16)$ & 18 & $3.94(1.11)$ & $F(2,545)=1.07, M S E=1.68, p=.344, \eta^{2}=.004$ \\
\hline Gen Ed Connect & 486 & $4.16(1.33)$ & 39 & $3.77(1.31)$ & 18 & $3.83(1.43)$ & $F(3,537)=1.70, M S E=1.78, p=.185, \eta^{2}=.006$ \\
\hline Degree Connect & 478 & $4.18(1.35)$ & 39 & $3.97(1.29)$ & 17 & $3.71(1.16)$ & $F(2,528)=1.38, M S E=1.81, p=.253, \eta^{2}=.005$ \\
\hline Out-of-Class Connect & 475 & $3.62(1.42)$ & 39 & $3.26(1.48)$ & 18 & $3.33(1.46)$ & $F(2,526)=1.53, M S E=2.04, p=.219, \eta^{2}=.006$ \\
\hline \multicolumn{8}{|l|}{ Referral } \\
\hline Referral Academic & 469 & $4.17(1.36)$ & 39 & $4.15(1.33)$ & 17 & $3.82(1.43)$ & $F(2,519)=0.47, M S E=1.84, p=.625, \eta^{2}=.002$ \\
\hline Referral Non-Academic & 462 & $3.97(1.35)$ & 39 & $3.82(1.45)$ & 17 & $4.12(1.05)$ & $F(2,512)=0.33, M S E=1.84, p=.608, \eta^{2}=.002$ \\
\hline \multicolumn{8}{|l|}{ Information } \\
\hline How Things Work & 469 & $4.00(1.33)$ & 38 & 3.55 (1.69) & 17 & $3.76(1.25)$ & $F(2,518)=1.99, M S E=1.84, p=.138, \eta^{2}=.008$ \\
\hline Accurate Information & 475 & $4.55(1.32)$ & 39 & $4.18(1.37)$ & 16 & $4.19(1.42)$ & $F(2,524)=2.08, M S E=1.76, p=.126, \eta^{2}=.008$ \\
\hline
\end{tabular}




\begin{tabular}{|c|l|l|l|l|l|l|l|}
\hline Individuation & & & & & & & \\
\hline Skills, Abilities, Interests & 469 & $4.09_{\mathrm{a}}(1.35)$ & 37 & $3.59_{\mathrm{a}}(1.36)$ & 16 & $3.63_{\mathrm{a}}(1.46)$ & $\begin{array}{l}F(2,516)=3.27, M S E=1.84, p^{*}=.039, \eta^{2}= \\
.013\end{array}$ \\
\hline Known as Individual & 468 & $3.77_{\mathrm{a}}(1.51)$ & 39 & $3.18_{\mathrm{b}}(1.55)$ & 16 & $3.13_{\mathrm{ab}}(1.67)$ & $F(2,517)=4.71, M S E=2.29, p=.009, \eta^{2}=.018$ \\
\hline Shared Responsibility & & & & & & & \\
\hline Shared Responsibility & 463 & $4.15(1.29)$ & 37 & $4.00(1.45)$ & 16 & $3.81(1.33)$ & $F(2,510)=0.76, M S E=1.71, p=.476, \eta^{2}=.003$ \\
\hline
\end{tabular}

Note. Ratings were made on 6-point scales (1 = not satisfied, 6 = very satisfied). Covariates: White/non-White, gender, first generation

(parent did/did not earn bachelor's degree). Within each row, means with different subscripts differ at the $p<.05$ minimally using the Sidak corrections for multiple comparisons.

* Although the results of the ANCOVA were statistically significant, the results of the post-hoc analysis using the Sidak correction for multiple comparisons showed no difference between the three groups. 


\section{How “Mandatory” Advising is Implemented in Relation to Advising Learning Outcomes}

Table 17 presents the means and standard deviations of the learning outcome scores for each "PIN delivery" group. Student mean responses ranged between 2.95 and 5.32 on a 6-point anchored likert-type learning scale (see Table 3 for a list of all advising learning outcomes). The learning outcome with the highest mean for the group receiving a PIN after an individual appointment as well as the group receiving a PIN after a groupled advising process was Has Educational Plan, while the learning outcome with the lowest mean for both groups was Has Significant Relationship. The learning outcome with the highest mean for the group receiving a PIN after a peer-led advising process was Values Advisor Advisee Relationship, while the outcome with the lowest mean was Knows Resources.

Table 17 also presents a one-way analyses of covariance (ANCOVA) used to determine if the mean learning outcome ratings of the groups differed by "PIN delivery" group, controlling for the covariates of size of major (number of students in a given major), and student GPA. The results showed that ratings on two of the eight learning outcomes varied by "PIN delivery" group ( $p<.05$ on each function). The groups differed in their scores on the outcomes Knows Resources, and Has Significant Relationship. 
The subscripts in Table 17 identify the results of individual post-hoc analyses using the Sidak correction where $p<.05$. On the learning outcome Knows Resources, students in the group that received their registration PINs directly from an advisor had higher scores than students in the group that received their registration PINs after a peerled advising process. There were no statistically significant differences found between the group where students received their registration PINs directly from advisors, and the group where students received their registration PINs after a group process, nor between students in the group that received their registration PIN after a group advising process, and those that received their registration PIN after a peer-led process on this outcome. On the learning outcome Has Significant Relationship, students in the group that received their PIN directly from an advisor reported higher scores than students in the group who received their PIN after a group advising process. There were no statistically significant differences found between the group where students received their registration PINs directly from advisors, and the group that received their registration PINs after a peer-led process, nor between those students in the group that received their registration PINs after a group advising process and those in the group that received their PINs after a peer-led process. There were no statistically significant group differences found on the outcomes Knows Requirements, Knows Resources, Understands How Things Work, Understands Connections, Has Educational Plan, Values Advisor-Advisee Relationship, or Supports Mandatory Advising. The effect size, $\eta^{2}$ (partial eta squared), for the statistically significant learning outcomes ranged from .016 to .017. 
Table 17

Learning Outcomes: By How PIN Delivered - Numbers, Means, and Standard Deviations of Learning Outcomes for Each Group, and ANCOVA Results

\begin{tabular}{|c|c|c|c|c|c|c|c|}
\hline \multirow[t]{2}{*}{ Learning Outcome } & \multicolumn{2}{|c|}{$\begin{array}{l}\text { By Advisor in } \\
\text { individual appt }\end{array}$} & \multicolumn{2}{|c|}{$\begin{array}{l}\text { By Advisor in } \\
\text { group setting }\end{array}$} & \multicolumn{2}{|r|}{ By Peer } & \\
\hline & $n$ & $M(S D)$ & $n$ & $M(S D)$ & $n$ & $M(S D)$ & Results of ANCOVAs \\
\hline Knows Requirements & 491 & $4.71(1.19)$ & 37 & $4.70(1.05)$ & 18 & $4.44(1.38)$ & $F(2,541)=0.40, M S E=1.39, p=.668, \eta^{2}=.001$ \\
\hline Knows Resources & 489 & $4.31_{\mathrm{a}}(1.28)$ & 37 & $3.92_{\mathrm{ab}}(1.26)$ & 19 & $3.58_{b}(1.35)$ & $F(2,540)=4.27, M S E=1.65, p=.014, \eta^{2}=.016$ \\
\hline Understands How Things Work & 490 & $4.25(1.22)$ & 37 & $4.11(1.08)$ & 18 & $3.89(1.49)$ & $F(2,540)=0.93, M S E=1.49, p=.396, \eta^{2}=.003$ \\
\hline Understands Connections & 485 & $4.96(1.04)$ & 36 & $4.81(1.04)$ & 18 & $4.39(0.92)$ & $F(2,534)=2.84, M S E=1.07, p=.059, \eta^{2}=.011$ \\
\hline Has Educational Plan & 524 & $5.32(0.93)$ & 40 & $5.27(0.78)$ & 20 & $5.15(0.99)$ & $F(2,579)=0.36, M S E=0.84, p=.701, \eta^{2}=.001$ \\
\hline Has Significant Relationship & 522 & $3.73_{a}(1.52)$ & 40 & $2.95_{b}(1.28)$ & 20 & $3.55_{\mathrm{ab}}(1.79)$ & $F(2,577)=5.08, M S E=2.30, p=.006, \eta^{2}=.017$ \\
\hline $\begin{array}{l}\text { Values Advisor-Advisee } \\
\text { Relationship }\end{array}$ & 492 & $5.09(1.06)$ & 37 & $4.86(1.21)$ & 18 & $5.28(0.83)$ & $F(2,542)=1.20, M S E=1.12, p=.302, \eta^{2}=.004$ \\
\hline Supports Mandatory Advising & 492 & $4.40(1.45)$ & 37 & $4.22(1.69)$ & 18 & $4.89(1.23)$ & $F(2,542)=1.39, M S E=2.11, p=.250, \eta^{2}=.005$ \\
\hline
\end{tabular}

Note. Ratings were made on 6-point scales ( 1 = strongly disagree, $6=$ strongly agree). Covariates: size of major, GPA. Within each row, means with different subscripts differ at the $p>.05$ minimally using the Sidak corrections for multiple comparisons. 


\section{How "Mandatory" Advising is Implemented in Relation to Retention (First-Year to Second-Year)}

Table 18 presents the means and standard deviations of the retention (first-year to second-year) indicators for each “PIN delivery” group. For this analysis students were coded with a " 1 " if they were retained from the first-year to the second-year and a " 2 " if not retained from first-year to the second-year. The subscript in Table 18 identifies the results of the individual post-hoc analyses using the Sidak correction where $p<.05$.

Table 18 also presents a one-way analysis of covariance (ANCOVA) used to determine if the retention of the groups differed by "PIN delivery” group, controlling for the covariates of student GPA, financial need (eligible/not eligible for Pell grant), and firstgeneration status (whether at least one parent had a bachelor's degree).

The results of the ANCOVA indicate that students in the group who received their registration PIN from a peer-led process were retained at a lower rate than students who received their registration PIN from either a group-led advising process or directly from an advisor. There were no statistically significant differences found between the group who received their registration PINs from an individual advisor and the group who received their registration PINs after a group advising process. The effect size, $\eta^{2}$ (partial eta squared), for the statistically significant result was .024. 
Table 18

Retention First-Year to Second-Year: By How PIN Delivered - Numbers, Means, and Standard Deviations of Retention Results for Each Group, and ANCOVA Results

\begin{tabular}{|l|l|l|l|l|l|l|l|}
\hline Retention & \multicolumn{2}{|c|}{$\begin{array}{c}\text { By Advisor in } \\
\text { Individual appt }\end{array}$} & \multicolumn{2}{|c|}{$\begin{array}{c}\text { By Advisor in group } \\
\text { setting }\end{array}$} & \multicolumn{2}{|c|}{ By Peer } & \\
\hline & $n$ & $M(S D)$ & $n$ & $M(S D)$ & $n$ & $M(S D)$ & Results of ANCOVAs \\
\hline Retained as of year 2 & 524 & $1.10_{\mathrm{a}}(0.31)$ & 40 & $1.08_{\mathrm{a}}(0.27)$ & 20 & $1.35_{\mathrm{b}}(0.49)$ & $F(2,578)=7.09, M S E=0.09, p=.001, \eta^{2}=.024$ \\
\hline
\end{tabular}

Note. Scale: 1 = student returned for second year, 2= student did not return for second year. Covariates: GPA, financial need (eligible/not eligible for Pell grant), first generation (parent did/did not earn bachelor's degree). Within each row, means with different subscripts differ at the $p<.05$ minimally using the Sidak correction for multiple comparisons. 


\section{Chapter 5}

\section{Discussion of Results, Limitations of Research, Implications for Practice, Suggestions for Future Research}

This study examined the relationship between the outcome of student satisfaction with advising, academic advising learning outcomes, and student retention and the academic advising delivery variables of (a) who advises students, (b) where students are advised, (c) how frequently students are required to see an advisor, (d) how frequently students actually see an advisor, and (e) how "mandatory" academic advising is implemented. Results related to each advising variable will be discussed in this chapter followed by limitations present in this research study, and implications for practice and future research.

\section{Research Questions}

This research addressed whether the manner in which advising is delivered to first year students is associated with advising learning outcomes, student satisfaction with advising, and/or student retention. In the study, first-year students were defined as students who began their study at an institution of higher education without earning college credit after graduating from high school. Students who earned college credit while still in high school (through advanced placement credit, enrollment in a community college, international baccalaureate, etc.) were considered first-time students in this study. Student retention, for this study, was defined as continuous enrollment from one 
academic year to the next academic year, or more simply put, a student returns for a subsequent fall semester or quarter.

The following research questions were explored in this study.

1. Is there a relationship between who advises first-year students and
d. Student satisfaction with advising?
e. Academic advising learning outcomes?
f. Student retention (first-year to second-year)?

2. Is there a relationship between where first-year students are advised and
a. Student satisfaction with advising?
b. Academic advising learning outcomes?
c. Student retention (first-year to second-year)?

3. Is there a relationship between how frequently first-year students are required to see an advisor and
a. Student satisfaction with advising?
b. Academic advising learning outcomes?
c. Student retention (first-year to second-year)?

4. Is there a relationship between how frequently first-year students actually see an advisor and
a. Student satisfaction with advising?
b. Academic advising learning outcomes?
c. Student retention (first-year to second-year)? 
5. Is there a relationship between how "mandatory" advising is implemented and
a. Student satisfaction with advising?
b. Academic advising learning outcomes?
c. Student retention (first-year to second-year)?

\section{Who Advises Students - Discussion of Results}

Students participating in the research at the study institution were either advised by professional advisors (75\%), faculty advisors (21\%), or peer advisors (4\%). Results of the study showed that who advises students does matter in student satisfaction, attainment of advising learning outcomes, and retention.

\section{Professional Advisors versus Faculty Advisors}

Students in the study who were advised by professional advisors were more satisfied overall with the advising they received than those students who were advised by faculty. These findings are consistent with prior research that has examined overall student satisfaction with advising in relation to who delivers advising (Kennedy-Dudley, 2007; Smith, 2004). In addition, students in the group advised by professional advisors were more satisfied than students in the group advised by faculty advisors on four of the five "integration" functions. Students advised by professional advisors were more satisfied with the advising they received that involved assisting them with connecting their educational, career, and life goals to each other as well as to choices of courses in the major, general education options, and the kind of degree to pursue. 
In addition, on several of the advising learning outcomes first-year students advised by professional advisors reported greater learning than the students advised by faculty advisors. Students in the former group were more likely to understand how their academic choices connect to career and life goals, have a plan to achieve their educational goals, and believe it is important to develop an advisor-advisee relationship with someone on campus.

The significant advising functions and learning outcomes that varied between professional advisors and faculty in this study would primarily be categorized as holistic; these functions and outcomes are focused on helping students integrate their educational, career, and life goals. There are several reasons why students may be more satisfied with the advising that they receive from professional advisors on these more holistic functions. First, professional advisors typically receive more training related to helping students make important connections between the curriculum and academic, career, and life goals, and typically are employed full-time in this capacity. Secondly, professional advisors tend to work with a broader spectrum of the curriculum; it is not unusual for them to advise for a variety of majors at the institution; faculty advisors rarely advise outside of their assigned academic specialty. Finally, professional advisors have chosen advising as a career path, or at minimum an occupation, meaning they have a commitment to student guidance as a profession.

Students did not distinguish between professional advisors and faculty advisors on what would typically be considered more prescriptive and referral-related advising 
functions and outcomes. Items such as providing accurate information to students, helping students understand university policies and procedures, connecting students to academic and non-academic resources, and the learning associated with these functions was not significantly different between groups. It may be that students are getting this information outside of specific advising engagements or even through online or printed materials. It may also be that as first-year students, the need has not yet arisen for some of these referral or informational items. Finally, what Smith and Allen (2006) would categorize as the functions and learning more steeped in developmental advising such as being known as an individual, encouraging student responsibility, and developing a significant relationship with faculty or staff did not vary between the group of students advised by faculty and the group advised by professional advisors. It may be that both professional advisors and faculty are doing an equal job on these functions. It may also be possible that first-year students have not been around the institution long enough to realistically develop these more personalized relationships with either professional advisors or faculty.

There were no differences noted between students advised by professional advisors and those students advised by faculty associated with student retention. Research associated with retention and advising has focused on either intensive advising interventions (Patrick et al., 1988; Seidman, 1991), quantity or quality of relationships with faculty or staff (Creamer, 1980; Grosset, 1991; Kuh et al., 2006; Nordquist, 1993), or student satisfaction with advising (Metzner, 1989; Schreiner, 2009; Schroeder, 2012). None of the research to date has indicated that being advised by a professional advisor or 
faculty advisor has a direct relationship to student retention, consistent with the findings of the present study.

\section{Peer Advisors versus Faculty and Professional Advisors}

Very few differences were found between the satisfaction ratings and learning outcome scores between those students advised by peers and those students advised by professional advisors or faculty advisors. Overall students were less satisfied with advising provided by peers when compared to advising provided by professional advisors. There was no difference found on overall advising satisfaction when examining advising provided by faculty versus advising provided by peers. On the learning outcome related to understanding how academic choices connect to career and life goals, students advised by peers were less satisfied than students advised by professional advisors or faculty. There were no other significant findings on any of the remaining advising functions or learning outcomes. The number of students advised by peers at the study institution was quite small (20 students) and may contribute to the lack of statistically significant differences.

One significant finding from this study was that students advised by peers were retained at a lower rate than those advised by either professional advisors or faculty advisors. The preponderance of literature touts the value of peer interactions, particularly related to student development in college (Astin, 1993). The National Academic Advising Association (NACADA) has even published a monograph that highlights what are presented as best practices in peer advising (Koring \& Campbell, 2005). 
Unfortunately, there are no studies that have examined the efficacy of peer advising in relation to student retention. Findings from this study would suggest that peer interaction within the context of providing academic advising is not as effective as peer interaction in other educational experiences and may indeed be detrimental to student success. Peers do not have the content knowledge that professional and faculty advisors possess, they are limited in authority to help students resolve problems, they have no working knowledge to put experience, curriculum, and goals in context, and, in many cases, students may not have confidence in what peers are recommending.

\section{Where Advised - Discussion of Results}

Students participating in the research at the study institution were either advised centrally by college (26\%), centrally by academic major (49\%), or in a decentralized location (25\%). At the study institution it is most common for faculty advising to take place in a decentralized location while professional advisors and peer advisors are typically located either centrally by major or centrally by college. Results of the study showed that where students are advised does matter in student satisfaction and advising learning. There were no significant findings related to student retention from year one to year two connected with where students are advised.

\section{Central by College versus Decentralized}

Results from the study indicated that first-year students advised centrally by college were more satisfied than first-year students advised in a decentralized location on the functions that help students connect general education and major coursework with 
academic, career, and life goals. At the study institution, all of the centralized by college advising centers utilize professional advisors as opposed to faculty or peer advisors. Given the full-time advising nature of professional advisors, these advisors may have a better understanding of how major and general education coursework is integrated in the curriculum when compared to faculty advisors or peer advisors. In addition, the geographic realities of centralized advising may be involved, meaning it is much easier to find a centralized advising center than a decentralized office.

\section{Central by Major versus Decentralized}

Students in the group advised centrally by major reported greater learning on the outcome related to having a plan to achieve their educational goals when compared to first-year students in the decentralized advising group. Many of the majors at the study institution utilize professional advisors in the "central by major" advising, and many of these advisors require that students come to advising meetings with an academic plan ranging from two terms to two years. These academic plans may be one reason for the variance in learning scores; however, students advised centrally by college typically have this same academic plan requirement. There was no difference found between the scores of students advised centrally by college and those advised in a decentralized location on this outcome.

\section{Central by College versus Central by Major}

Students advised centrally by college were more satisfied on advising that helps connect their general education requirements with their academic, career, and life goals 
than students advised centrally by major. As centralized advising centers house a variety of majors, the advisors generally have better training on how these general requirements can be utilized for exploratory purposes. In addition, as all of the advisors in centralized by college centers at the study institution are professional advisors, they typically have more training on the curriculum than those advisors who work with only one major.

\section{Required Frequency of Advising - Discussion of Results}

Students at the participating study institution were required, based upon the student's major, to meet with an advisor either once per year (68\%) or once per term (32\%). This choice of once per year or once per term is determined by the leadership of each College at the study institution. One would expect to see a positive relationship between required frequency of advising and satisfaction with advising given that students who develop significant relationships with faculty and staff have been shown more likely to persist in higher education (Astin, 1993; Pascarella \& Terenzini, 2005). This study had an interesting result that was not expected. Students in the group required to see an academic advisor once per term were less satisfied than students in the group required to see an academic advisor once per year on the advising function related to knowing the student as an individual. No other advising functions showed any significant results based on how frequently students are required to see an advisor. One would expect that a student required to see an advisor once per term would actually feel known as an individual more than a student who is only required to see an advisor once per year. One possible explanation for this result may be the actual time and content of the advising 
session. Students in majors requiring advising once per term may be limited to very short advising appointments which would not provide ample time for the student to feel known as an individual while students in majors with advising once per year may have longer sessions and may be able to cover more advising content tied with students' individual interests.

Even more surprising is that on five of the eight learning outcomes students reported learning more when they were in the group required to see an advisor once per year versus once per term. Students reported greater learning on knowing what requirements they need to fulfill their degree, on understanding how academic choices connect to career and life goals, on having a plan to achieve the students' educational goals, on having at least on significant relationship with a faculty or staff member at the institution, and on valuing the importance of developing an advisor-advisee relationship on campus. In addition, the outcome where students identify the importance of having mandatory advising approached statistical significance with a $p=.051$, indicating that students in the group advised once per year see this outcome as more important than those in the group advised once per term.

These results at first glance seem baffling, but when examined jointly with how often students are actually getting advising, the picture becomes clearer. What students are mandated to do by the institution and what they actually do related to advising encounters is much different. Although only $32 \%$ of students are required by the institution to see an advisor every term, over $88 \%$ of all students, regardless of the 
mandated advising structure, are seeing an advisor more than once per year. In other words, those students who are not mandated to seek advising every term are in essence seeking advising beyond what is required and are reporting greater learning as a result. This dynamic is discussed further in the next section on self-report advising frequency.

One additional explanation for these findings related to learning outcomes and frequency may derive from what students are learning outside of the actual advising appointment. Advisors in majors where advising is required only once per year are forced to use alternate methods to help students learn content normally covered in an advising appointment. Some of these alternate methods may include online curriculum planners, interactive advising guides, and electronic communication mediums. It may be that these alternate delivery methods are showing effectiveness for some students.

It is important not to discount the value of mandatory advising based upon these findings. Those students who were required to get advising once per term were less likely to report that they were not getting advising than those who were required to get advising only once per year (3.2\% versus 7.9\%). The mandated advising system forces students who would not normally seek advising on their own to do so.

No significant group retention differences were found from first to second year based upon required frequency of advising at the study institution. This finding would be expected for two reasons: (1) only 1 out of 12 advising functions varied by satisfaction on this variable, and (2) this variable examined mandated frequency of advising, not content, intensity, or duration of the advising appointment. Research has shown some connection 
between frequent, intrusive, and intentional advising with selected populations (Pascarella \& Terenzini, 2005), which is not the type of advising most students receive at the study institution.

\section{Self-Report Advising Frequency - Discussion of Results}

In addition to exploring required advising frequency, this research examined selfreported student advising frequency. Although a student may only be required by the institution to see an advisor once per year, in actuality, the student may be seeing an advisor more frequently. For this set of research questions, student responses were categorized based on the self-report advising frequency of more than once per year (88\%), once per year (6\%), and not currently receiving academic advising (6\%).

It is important to note that although $32 \%$ of the students surveyed are required by their major to see an advisor once per term, 88\% self-reported that they see an advisor more than once per year. Table 19 compares how often students are mandated to receive advising at the institution with how often students self-report actually getting advising at the institution. 
Table 19

Mandated frequency of advising at study institution versus student self-report frequency of advising

\begin{tabular}{cccc} 
& \multicolumn{3}{c}{$\begin{array}{c}\text { Self-Report Frequency } \\
\text { Once Per }\end{array}$} \\
Mandated Frequency & No Advising & Year & More than once per year \\
Once per Year & $7.90 \%$ & $4.40 \%$ & $87.70 \%$ \\
Once per Term & $3.20 \%$ & $8.60 \%$ & $88.20 \%$
\end{tabular}

Despite institutionally mandated advising, approximately 6\% of the surveyed students reported that they are not currently receiving academic advising. Satisfaction ratings on 11 of the 12 advising functions and seven of eight learning outcomes varied by student "self-report advising frequency." Students who chose to see an advisor more than once per year were more satisfied with advising and reported greater learning from their advising experiences.

\section{More than Once per Year}

On the function overall advising satisfaction it was clear that those students in the group seeking advising more than once per year were more satisfied than those students in the group seeking advising once per year or in the group not currently seeking advising. This was also true on the advising functions that assist students with identifying major and general university coursework that connects to academic, career, and life goals. Students in the group seeking advising more than once per year were also more satisfied with advisors taking into account student skills, interests, and abilities 
when helping them choose courses; they are more satisfied with feeling known as an individual in the advising process; they believe they have a partner in helping them develop planning, problem-solving, and decision-making skills. These results are in contrast to the group of students that only seek advising once per year.

Students getting advising more than once per year reported greater learning on developing an advisor-advisee relationship, knowing university requirements, understanding policies and how things work at the institution. They also report having more significant relationships with faculty and staff on campus when compared to those students not currently seeking advising.

It is important to note that the majority of students are only required to see an advisor once per year, indicating that most students are seeking additional advising appointments beyond what is required. It is quite possible that these additional visits are highly correlated with particular advising needs that students have during their first year in college. What is most important to the students may be better addressed in these elective visits. In addition, students seeking advising more than once per year report a higher level of connection with faculty and staff and place a higher value on the advisoradvisee relationship. Smith and Allen (2006, p. 56) noted that students consider all of the advising functions to be important to them, but do not always have a commensurate level of satisfaction reported. These elective advising visits may be one way for students to have these needs addressed outside of the prescribed advising frequency structure. The 
interesting dynamic between required advising frequency and self-report advising frequency will be addressed in the implications portion of this chapter.

\section{Once per Year versus Not Seeking Advising}

There were no significant group differences found between those students seeking advising once per year and those students not seeking advising on any of the advising functions. Only two significant differences were noted on the learning outcomes related to understanding how academic choices connect to career and life goals, and knowing where to go at the institution if a problem arises. On these two outcomes, students seeking advising once per year reported higher learning than those students not seeking advising. In contrast to students seeking advising multiple times per year, students in the once per year and not seeking advising groupings are essentially doing what is mandated by the institution. Not surprisingly, those students that are not utilizing advising have a lesser understanding of how their academics tie to academic, career, and life goals, and may not know where to go on campus if a problem should arise compared to those students that have met with an advisor at least once.

There were no significant findings associated with student retention from year one to year two based upon the frequency with which students were getting advising. Students seeking advising once per year (6\%), or not seeking advising (6\%), should be at highest risk for attrition in this study. It may well be that the frequency with which students see advisors needs to be combined with a measure of what happens within the advising appointment to have statistical relevance related to student retention. 


\section{How Mandatory Advising is Implemented - Discussion of Results}

The final advising delivery variable explored in this research involved how students received their advising registration PINs at the study institution. These registration PINs are required to “unlock” a student's ability to register. Students in a major with advising required once per term received a new registration PIN each term, while students in a major with advising required once per year received a registration PIN once per year. This variable explored how students received this PIN. Approximately $90 \%$ of the first-year students completing the satisfaction questions received their registration PIN directly from an advisor, 7\% of the students completing the satisfaction questions reported receiving their registration PIN after group advising, and 3\% reported receiving their registration PIN after a peer-led advising process. These percentages do not correspond directly to specific advising encounter percentages just as the manner in which a student receives a PIN does not necessarily correspond with an actual advising appointment or encounter.

\section{PIN from Advisor versus Group Led Process}

Findings indicated that students in the group who received their registration PIN directly from an advisor were more satisfied being known as an individual than those students who received their PIN after a group advising process. In addition, students who received their PIN from an advisor scored higher on the outcome of developing a meaningful and positive relationship with someone at the institution in comparison to those students who went through group advising. No other advising functions or learning 
outcomes varied between the two groups. These findings would indicate that some advising functions and learning may be appropriate for a group advising context; however, it should be noted that overall means for group-advised students were lower on 11 of 12 advising functions and on 8 out of 8 learning outcomes. The literature and prior research have focused heavily on this interaction between student and faculty as a part of the departure puzzle (Kuh, Kinzie, Buckley, Bridges, \& Hayek, 2006; Nordquist, 1993; Pascarella \& Terenzini, 1977, 1980, 2005;). Interaction with faculty and the level of concern that faculty had for students was identified by Pascarella and Terenzini (2005) as a significant contributor to identifying departing and persisting students. Although only one function and one outcome were identified as significant between individual versus group advising, they are both associated with retention proxies tied to prior research, meaning that the relationships developed in individual advising appointments may have benefits beyond the advising functions and learning outcomes.

\section{PIN from Peer}

There were no significant group differences identified on advising functions between those students that received their PIN from a peer advisor, a group-led advising process, or from an individual advisor. On the outcome related to knowing where to get help at the institution, students that received a PIN directly from an advisor reported higher learning than students that went through a peer-led advising process to get their PIN. Peer advisors may not be as well versed in campus resources when compared to professional or faculty advisors which may explain this finding. 
One significant and perhaps alarming finding did surface in relation to first-year to second-year student retention. Students in the group who received their registration PIN from a peer led advising process were retained at a lower rate than those students in groups who received their registration PIN in a group advising process or directly from an academic advisor. This finding is consistent with the results under the variable "who advises” where students advised by peers were retained at a lower rate than those advised by either faculty advisors or professional advisors. It is important to note that only 20 students in this study reported receiving a registration PIN during a peer led advising process, indicating that any possible inferences related to peer-advising would need further exploration in a larger study.

\section{Implications for Practice and Recommendations for Future Research}

\section{Who Advises}

There is some indication, based on this research, that several advising delivery variables play a role in student satisfaction with advising, advising learning outcomes, and potentially student retention. The most significant results from this study were related to who advises first-year students. First-year students in this study were more satisfied on several advising functions, and reported greater learning on several outcomes when advising was provided by professional advisors versus faculty or peer advisors. These findings are consistent with prior research indicating that students, in general, are more satisfied with advising provided by professional advisors (Kennedy-Dudley, 2007; Smith, 2004). It is important to note that faculty advisors have significant responsibilities 
outside of academic advising. In fact for most tenure and tenure-track faculty, academic advising may comprise less than $5 \%$ of their full-time equivalent job responsibilities (Habley, 2004). The demand for faculty to produce more research continues to rise, and academic advising is one faculty responsibility that may be suffering as a result (Milem, Berger, \& Dey, 2000). Given trends related to faculty workload, it may no longer be reasonable to expect tenure and tenure-track faculty to be able to devote time to academic advising for first-year students. This research supports the continued use of professional advisors to assist with first-year student advising, and suggests the need for further research on non-tenure track faculty (also known as fixed-term faculty or instructors) who have an equal split between teaching and advising first-year students.

Although student participant numbers were low related to peer advising, students in the group advised by peers were not retained at that same rate as those in groups advised by faculty or professional advisors. This finding should not be ignored. Defining the role most appropriate for peer advisors in relation to first-year students, along with how best to structure who delivers advising to first-year students, are topics that need further exploration. Many institutions are exploring the expanded use of peer advisors to either enhance or, in some institutions, replace advising responsibilities that used to be handled by professional or faculty advisors. A survey conducted in 2004 noted that $58 \%$ of respondents at public 4-year institutions had some type of undergraduate peer advising program on their campus (Habley, 2004). The financial benefits of using students to advise other students are self-evident and may be fueling much of the increased usage of peers in the advising process. This study would suggest the need for further research 
regarding the efficacy of peer advising programs, particularly in relation to student retention from first-year to second-year.

\section{Where Advised}

Where students are advised was significant in relation to advising satisfaction and advising learning outcome scores, although not to the extent of who advises students. Those students in the group advised centrally by college reported greater learning on outcomes associated with academic planning. In addition, students in the group advised centrally by college were more satisfied with understanding how their major coursework connects to their skills, interests, and abilities. This finding may be due to more standardized systems and processes present in a larger centralized advising locations, as well as staffs more versed in helping students to self-identify skills, interests, and abilities. Although this "where advised" variable has been explored in earlier research (Avants, 2004), continued exploration on this variable would add clarification to why students seem to have a preference for advising that is delivered centrally by college during their first year. Some institutions have created advising centers for first-year students that encompass all majors within one first-year center. Further research should explore student satisfaction with advising functions, advising learning outcomes, and first-year to second-year retention for institutions utilizing this more comprehensive approach. In addition, expanding research on this particular variable across both lower and upper division students may yield significantly different results and may even suggest a bi-modal approach. 


\section{Advising Frequency}

A fascinating interplay between advising delivery variables in this study was between how often first-year students are required to see an advisor, and how often they choose to see an advisor. Over $60 \%$ of first-year students in the group required to see their advisor once per year were choosing to see their advisor more than once per year and reported greater satisfaction with several advising functions and greater learning based on this chosen frequency. One hypothesis might be that the actual advising encounter may be different in a "required" versus a voluntary visit. In the "required each term” scenario the student is required to meet with the advisor, the advisor is required to meet with the student, and for the study institution the prime focus of the "required" advising session may simply be the delivery of a student registration PIN. This required session may be as limited as five minutes in duration and may simply involve "any questions?" followed by a "here is your PIN" statement. Contrast that scenario with one where a student is seeking advising for a particular reason, the advisor is not forced into a prescribed routine, and the advisor may have an expanded timeframe to work with a student. It would appear that the mandatory policy at the study institution is effectively sending a message to students that advising is important. The number of students that are seeking advising outside of what is mandated by the institution may indicate that advising needs that are not being adequately met during mandated sessions, or it may speak to the value and trust that students place on advising and their advisors. Either way, this study indicated that the more frequently students seek advising, the more satisfied they are with advising functions and the greater learning they report. 


\section{Advising delivery variables versus advising content}

Despite statistically significant results on several advising delivery variables in this study, the effect size of these variables was fairly low, meaning that between $1 \%$ and $8 \%$ of the variance in student satisfaction with advising and advising learning can be explained by various advising delivery variables. The most obvious conclusion from these results would be that what is happening within an advising appointment, and as a result of an advising appointment, is crucial to examine and may play a much larger role in student satisfaction with advising and advising learning than specific advising delivery variables. We know from prior research that there is not always agreement between what advising functions and advising learning faculty and students think is important (Allen \& Smith, 2008). The frequency with which students seek advising outside of what is mandated would also point towards specific advising needs not being met with established advising content and structures. It is essential that further research explore the efficacy of the actual advising content in relation to advising learning, academic planning, and time to degree.

The results of this study also indicate that students are more satisfied with advising and learn more when given the opportunity to seek advising beyond what is required by the institution on their own terms and based upon their own needs. One implication for practice may be conceptually structuring advising in such a way that students have a voice and role in what Laff (2006) describes as problem-based learning in an advising context. Finding a way to challenge students to identify what they know, 
identify what they need to know, and then help them develop ways to go about exploring these questions could align well with problem-based learning tools helpful to students elsewhere in the curriculum. Advisors can then be seen as resources and partners in problem-solving as opposed to gatekeepers.

It is important to note that the study institution mandated advising for all students. Future research should explore if similar findings are present at institutions that have a combination of mandatory and non-mandatory academic advising structures.

\section{Limitations}

There were several limitations in this study that may have impacted the results of the study and the methodology employed in evaluating the results. This section will explore the eight limitations specific to this study.

This particular study was structured to examine relationships between academic advising delivery variables. As this design was not experimental in nature, cause and effect cannot be determined, nor do the findings have predictive value.

A second limitation is that this study relied on self-report data which is not necessarily reflective of the students' actual experience, and may be impacted by maturation, meaning that the passage of time may be influencing the results.

A third limitation is that this study utilized a longitudinal design only in relation to student retention, and only for a one-year period. A more robust examination would follow students longitudinally throughout their years in higher education in relation to 
academic advising satisfaction, learning outcomes, and retention. The timeline for this analysis did not allow for a more in-depth longitudinal study.

A fourth limitation relates to the post-hoc analyses used in this study. The posthoc analyses from the ANCOVA results used the Sidak correction, known to be less conservative than the Bonferroni correction in identifying type I errors. Given the paucity of research on advising delivery variables, the Sidak correction was chosen based upon a greater power to detect group differences that may exist after accounting for known covariates utilized in the ANCOVA analyses, when compared to the Bonferroni correction. The probability of a Type I error in the study is extremely low.

A fifth limitation surrounds not utilizing a random sample selection process for student participants. Students self-selected survey participation and may have had opinions and views that are not reflective of the general student population. Participant demographic characteristics for this study indicated an overrepresentation of women and high achieving students. Research examining standardized test scores in relation to student retention indicate that higher standardized test scores (ACT and SAT) do correlate with greater persistence rates in college as well as higher first-term GPAs (Astin, 1993; Pascarella \& Terenzini, 2005). In addition, the retention rates for the selfselected survey respondents was higher than the general student population.

A sixth limitation is that this study was limited to first-year students at one particular institution at one particular point in time. Results may have been significantly different at another institutional type or in another geographic location. 
A seventh limitation in this study was the sample size of students advised by peers or who received registration PINs directly from peers. A limited number of majors participated in peer advising at the study institution, and the small response rate may have impacted the findings. Given statistically significant results showing a negative relationship between peer advising and retention, it may be that the low sample size masked additional statistically significant relationships tied with student satisfaction with advising functions, advising learning outcomes, and retention.

An eighth limitation relates to a unique category of faculty known at the study institution as senior instructors. These senior instructors are typically fixed term faculty where the majority of their time is spent either teaching or advising. Senior instructors rarely have a research assignment. For the purposes of this study these senior instructors were categorized as professional advisors as they have advising responsibilities significantly beyond that of tenured faculty. This study may have had different results had these senior instructors been identified and categorized, particularly related to the research questions related to who advises.

Finally, although several significant findings were found in this study, the effect sizes $n^{2}$ (partial eta squared) for the statistically significant group differences were fairly low ranging from .009 to .080 , meaning that each statistically significant variable accounted for between roughly $1 \%$ and $8 \%$ of the variance in the model that is not explained by other variables. When dealing with student satisfaction ratings, advising learning outcomes, and student retention, there will be a multitude of variables that will 
impact these three measures, but a higher percentage of explained variance in a model would be ideal.

\section{Conclusion}

This study explored the relationship between academic advising delivery variables associated with (a) who advises students, (b) where students are advised, (c) how frequently students are required to see an advisor, (d) how frequently students actually see and advisor, (e) how "mandatory" academic advising is implemented, and first-year student satisfaction with advising, first-year advising learning outcomes, and first-year student retention at a four-year public, high research activity institution located on the west coast.

The findings indicate that (a) who advises students, and (b) how frequently students choose to see an advisor are particularly noteworthy variables for first-year students in relation to student satisfaction with advising and attainment of certain advising learning outcomes. Students in the group advised by professional advisors were more satisfied on several functions and reported higher learning scores on several outcomes when compared to students in the groups advised by either faculty advisors or peer advisors. Students advised by peers were retained at a lower rate than students advised by professional advisors or faculty. This is an alarming finding that needs further exploration in future research studies.

Those students in the group that chose to meet with an advisor more than once per year were more satisfied on several advising functions, and reported higher learning 
scores than the group of students that chose to meet with an advisor only once per year, or not at all.

One important future consideration is not reflected in this study. This study explored delivery variables that have nothing to do with the actual content of what is happening in and as a result of an advising appointment. The advising delivery variables explored in this study are probably less important than the content of what happens in the advising appointment, what advising "assignments" or homework are completed in advance of or as a result of an advising appointment, and how student reflection and learning are constructed within the academic advising paradigm. Barr \& Tagg (1995) initiated conversations focused on student learning versus student instruction in the classroom. These same conversations are happening in the realm of academic advising (Hemwall \& Trachte, 1999, 2005; Kelley, 2008; Lowenstein, 2005; Smith \& Allen, 2012) and should continue in partnership with studies such as this one designed to explore the efficacy of certain advising delivery variables. Prior research has shown that intensive, focused and frequent student advising can have an impact on student satisfaction and in some cases retention (Grosset, 1991; Metzner, 1989; Seidman, 1991). The interplay between the learning that occurs in an advising appointment and the delivery variables explored in this study may be key in helping to define the not yet fully understood links between academic advising, academic advising functions, advising learning outcomes, and student retention, particularly for first-year students. 


\section{References}

ACT. (2010). What works in student retention? Fourth national survey: report for all colleges and universities. Iowa City, IA: Author.

Allen, J., \& Smith, C. (2008). Faculty and student perspectives on advising: Implications for student dissatisfaction. Journal of College Student Development, 49, 609-624. doi:10.1353/csd.0.0042

Allen, J., Smith, C., \& Muehleck, J. (2012). Advising pre- and post- transfer students: What is important to them. Manuscript submitted for publication, College of Education, Portland State University, Portland, OR.

Astin, A. (1977). Four critical years: Effects of college on beliefs, attitudes, and knowledge. San Francisco, CA: Jossey-Bass.

Astin, A. (1993). What matters in college? San Francisco, CA: Jossey-Bass.

Astin, A., Green, K., \& Korn, W. (1987). The American freshman: Twenty year trends, 1966-1985. Los Angeles, CA: Higher Education Research Institute. Retrieved from http://www.getcited.org/pub/102844281

Avants, L. (2004). Student satisfaction with academic advising organizational models in a multiversity (Unpublished doctoral dissertation). Arizona State University, Tempe, AZ.

Barr, R., \& Tagg, J. (1995). A new paradigm for undergraduate education. Change, 27(6), 13-25. doi:10.1080/00091383.1995.10544672 
Baum, S., \& Payea, K. (2004). Education pays 2004: The benefits of higher education for individual and society. Retrieved from http://citeseerx.ist.psu.edu/viewdoc/summary?doi=10.1.1.177.8261

Beal, P., \& Noel, L. (1980). What works in student retention: The report of a joint project of the American College Testing Program and the National Center for Higher Education Management Systems. American College Testing Program, Iowa City, IA. Retrieved from http://www.eric.ed.gov/ERICWebPortal/contentdelivery/servlet/ERICServlet?acc no=ED197635

Bean, J., \& Metzner, B. (1985). A conceptual model of nontraditional undergraduate student attrition. Review of Educational Research, 55, 485-540. doi:10.3102/00346543055004485

Beasley-Fielstein, L. (1986). Student perceptions of the developmental advisor-advisee relationship. NACADA Journal, 6(2), 107-117.

Bloom, B. (1956). Taxonomy of educational objectives, handbook 1: Cognitive domain. New York: Longmans Green.

Bound, J., Lovenheim, M., \& Turner, S. (2010). Why have college completion rates declined? An analysis of changing student preparation and collegiate resources. Applied Economics, 2, 129-157. doi:10.1257/app.2.3.129

Burton, J., \& Wellington, K. (1998). The O’Banion model of academic advising: An integrative approach. NACADA Journal, 18, 13-20. 
Carlstrom, A.(Ed.) (in press). NACADA Survey of Academic Advising (Monograph no.

25). Manhattan, KS: National Academic Advising Association.

Chapman, C., Laird, J., \& Kewal-Ramani, A. (2010). Trends in high school dropout and completion rates in the United States: 1972-2008. Washington, DC: National Center for Education Statistics, US Department of Education.

Chickering, A. (1969). Education and identity. San Francisco, CA: Jossey-Bass.

Chickering, A., \& Reisser, L. (1993). Education and identity. San Francisco, CA: JosseyBass Inc.

Chickering, A., Gamson, Z., \& Poulsen, S. (1987). Seven principles for good practice in undergraduate education. American Association for Higher Education Bulletin, 39(7), 3-7.

Creamer, D. (1980). Educational advising for student retention: An institutional perspective. Community College Review, 7(4), 11-18.

doi:10.1177/009155218000700402

Creamer, D. (2000). Use of theory in academic advising. In V. N. Gordon, \& W. R. Hadley (Eds.), Academic advising: A comprehensive handbook (pp. 18-34). San Francisco, CA: Jossey-Bass.

Crookston, B. (1972). An organizational model for student development. NASPA Journal, 10(1), 3-13.

Crookston, B. (1994). Classics revisited: A developmental view of academic advising as teaching. NACADA Journal, 14(2), 5. 
Day, J., Newburger, E., \& Bureau, U. (2002). The big payoff: Educational attainment and synthetic estimates of work-life earnings. Washington, DC: U.S. Dept. of Commerce, Economics and Statistics Administration, U.S. Census Bureau.

Dwyer, R., McCloud, L., \& Hodson, R. (2012). Debt and graduation from American universities. Social Forces, 90, 1133-1155. doi:10.1093/sf/sos072

Erikson, E. (1963). Childhood and society. New York, NY: W. W. Norton.

Field, A. (2009). Discovering statistics using SPSS. London, England: Sage.

Fink, L. (2003). Creating significant learning experiences: An integrated approach to designing college courses. San Francisco, CA: Jossey-Bass.

Freire, P. (1970). Pedagogy of the oppressed. New York, NY: Continuum.

Frost, S. (2000). Historical and philosophical foundations for academic advising. In In V. N. Gordon, \& W. R. Hadley (Eds.), Academic advising: A comprehensive handbook, (pp. 3-17), San Francisco, CA: Jossey-Bass.

Getzlaf, S., Sedlacek, G., Kearney, K., \& Blackwell, J. (1984). Two types of voluntary undergraduate attrition: Application of Tinto's model. Research in Higher Education, 20, 257-268. doi:10.1007/BF00983501

Gordon, V. N., Habley, W. R., \& Grites, T. J. (Eds.). (2008). Academic advising: A comprehensive handbook ( $2^{\text {nd }}$ ed.). San Francisco, CA: Jossey-Bass.

Gore, P., \& Metz, A. (2008). Advising for career and life planning. In V. N. Gordon, W. R. Habley, \& T. J. Grites (Eds.), Academic advising: A comprehensive handbook (2 ${ }^{\text {nd }}$ ed.), (pp. 103-117). San Francisco, CA: Jossey-Bass. 
Grosset, J. (1991). Patterns of integration, commitment, and characteristics and retention among younger and older students. Research in Higher Education, 32, 159-178. doi:10.1007/BF00974435

Guillén, C. (2010). Undergraduate academic advising and its relation to degree completion time (Unpublished doctoral dissertation). Humboldt State University, Arcata, CA.

Habley, W. R. (1981). Academic advisement: The critical link in student retention. NASPA Journal, 18, 45-50.

Habley, W. R. (1983). Organizational structures for academic advising: models and implications. Journal of College Student Personnel, 24, 535-540.

Habley, W. R. (1988). The status and future of academic advising: Problems and promise. Retrieved from http://www.eric.ed.gov/ERICWebPortal/contentdelivery/servlet/ERICServlet?acc no $=E D 346903$

Habley, W. R. (1994). Fire!(ready, aim): Is criticism of faculty advising warranted. NACADA Journal, 14(2), 25-31.

Habley, W. R. (2004). The status of academic advising: Findings from the ACT sixth national survey. National Academic Advising Association Monograph Series Number 10. Manhattan, KS: National Academic Advising Association.

Habley, W. R., \& McClanahan, R. (2004). What works in student retention? All survey colleges. Iowa City, IA: ACT. 
Hawkins, H. (1960). Pioneer: A history of the Johns Hopkins University, 1874-1889. Ithaca, NY: Cornell University.

Hemwall, M. K., \& Trachte, K. C. (1999). Learning at the core: Toward a new understanding of academic advising. NACADA Journal, 19(1), 5-11.

Hemwall, M. K., \& Trachte, K. C. (2003). Learning at the core: Theory and practice of academic advising in small colleges and universities. In M. K. Hemwall, \& K. C. Tachte (Eds.), Advising and Learning: Academic advising from the perspective of small colleges and universities (Monograph No. 8, pp. 13-19). Manhattan, KS: National Academic Advising Association.

Hemwall, M. K., \& Trachte, K. C. (2005). Academic advising as learning: 10 organizing principles. NACADA Journal, 25(2), 74.

Huggett, K. D. (2004). Advising in undergraduate honors programs: A learner-centered approach. NACADA Journal, 24(1-2), 75-87.

Ishitani, T. T. (2006). Studying attrition and degree completion behavior among firstgeneration college students in the United States. Journal of Higher Education, 77, 861-885. doi:10.1353/jhe.2006.0042

Kelley, B. (2008). Significant Learning, Significant Advising. NACADA Journal, 28(1), 19-28.

Kennedy-Dudley, P. (2007). Student perception's concerning centralized and faculty advising models: Utilization and perceived effectiveness at a university in the 
southeastern United States (Unpublished doctoral dissertation). Southeastern University, Lakeland, FL.

Kent State University. (1993). Survey results of 1993 graduates. Kent State University, Trumball Campus, Warren, $\mathrm{OH}$.

Keup, J. R., \& Stolzenberg, E. B. (2004). The 2003 your first college year survey: Exploring the academic and personal experiences of first-year students (Monograph No. 40). Columbia, SC: University of South Carolina, National Resource Center for The First-Year Experience and Students in Transition. Kirk-Kuwaye, M., \& Libarios, N. (2003). Expanding the prescriptive-developmental advising continuum: Using social constructivism as an advising approach for students from high relational groups. The Mentor: An Academic Advising Journal, 5(4). Retrieved from: http://dus.psu.edu/mentor/old/articles/031205mk.htm

Kohlberg, L. (1972). A cognitive-developmental approach to moral education. Humanist, 32(6), 13-16.

Koring, H., \& Campbell, S. (Eds). (2005). Peer advising: Intentional connections to support student learning (NACADA Monograph Series, no. 13). Manhattan, KS: National Academic Advising Association.

Kuh, G. D. (2008). Thinking DEEPly about academic advising and student engagement. Thinking, 29(2).

Kuh, G. D., Kinzie, J., Buckley, J. A., Bridges, B. K., \& Hayek, J. C. (2007). Piecing together the student success puzzle: Research, propositions, and recommendations. ASHE Higher Education Report, (32)5. 
Kuh, G. D., Kinzie, J., Schuh, J. H., \& Whitt, E. J. (2010). Student success in college: Creating conditions that matter. San Francisco: Jossey-Bass.

Kuhn, T. L. (2008). Historical foundations of academic advising. In V. N. Gordon, W. R. Habley, \& T. J. Grites (Eds.), Academic Advising: A Comprehensive Handbook (pp. 3-17). San Francisco, CA: Jossey-Bass.

Laff, N. S. (2006). Teachable moments: Advising as liberal learning. Liberal Education, 92(2), 36.

Light, R. J. (2001). Making the most of college: Students speak their minds. Boston, MA: Harvard University.

Low, L. (2000). Are college students satisfied? A national analysis of changing expectations. (New Agenda Series). Indianapolis, IN: USA Group. (ERIC Document no. ED451816).

Lowe, A., \& Toney, M. (2000). Academic advising: Views of the givers and takers. Journal of College Student Retention, 2(2), 93-108. doi:10.2190/D5FD-D0P8N7Q2-7DQ1

Lowenstein, M. (2000). Academic advising and the "logic" of the curriculum. The Mentor, 2(2). Retrieved from http://www.psu.edu/dus/mentor/000414ml.htm

Lowenstein, M. (2005). If advising is teaching, what do advisors teach? NACADA Journal, 25(2), 65-73.

Lyons, L. (1991). The integration of qualitative and quantitative research in a longitudinal retention study. In Association for Institutional Research Forum Paper. San Francisco, CA. 
Metzner, B. S. (1989). Perceived quality of academic advising: The effect on freshman attrition. American Educational Research Journal, 26, 422. doi:10.3102/00028312026003422

Milem, J. F., Berger, J. B., \& Dey E. L. (2000). Faculty time allocation: A study of change over 20 years. Journal of Higher Education, 71, 454-475. doi:10.2307/2649148

Miller, M. (in press). Structuring the conversation: Shifting to four dimensional advising models. In A. Carlstrom, 2011 national survey of academic advising. (Monograph No. 25). Manhattan, KS: National Academic Advising Association. Retrieved from: http://www.nacada.ksu.edu/Clearinghouse/AdvisingIssues/structureconversations.htm.

National Academic Advising Association. 2006. NACADA concept of academic advising. Retrieved from www.nacada.ksu.edu/Clearinghouse/ AdvisingIssues/Concept-Advising

National Center for Educational Statistics (2012). The condition of education undergraduate enrollment. Retrieved from: http://nces.ed.gov/programs/coe/indicator_hep.asp

Noel-Levitz, Inc. (2006). Five-year trend study: National student satisfaction report. Iowa City, IA: Author. 
Nordquist, E. D. (1993). Missing Opportunities: Drop-outs and a failure to find a mentor. Retrieved from http://eric.ed.gov/ERICWebPortal/recordDetail?accno=ED365253

O’Banion, T. (1972). An academic advising model. Junior College Journal, 42(6), 62-69.

Oregon University System. (2011). Oregon University System Enrollment Report. Retrieved from http://www.ous.edu/factreport/student

Pardee, C. F. (2000). Organizational models for academic advising. In V. N. Gordon, \& W. R. Habley (Eds.), Academic advising: a comprehensive handbook, (pp. 192209). San Francisco, CA: Jossey-Bass.

Pardee, C.F. (2004). Organizational structures for advising. Clearinghouse of Academic Advising [database online]. National Academic Advising Association. Retrieved from http://www.nacada.ksu.edu/Clearinghouse/AdvisingIssues/org_models.htm

Pascarella, E. T, \& Terenzini, P. T. (2005). How college affects students: A third decade of research (2nd ed.). San Francisco, CA: Jossey-Bass.

Pascarella, E. T., \& Terenzini, P. T. (1977). Patterns of student-faculty informal interaction beyond the classroom and voluntary freshman attrition. Journal of Higher Education, 48, 540-552. doi:10.2307/1981596

Pascarella, E. T., \& Terenzini, P. T. (1980). Predicting freshmen persistence and voluntary dropout decisions from a theoretical model. Journal of Higher Education, 51, 60-75. doi:10.2307/1981125 
Patrick, J., Furlow, J. W., \& Donovan, S. (1988). Using a comprehensive academic intervention program in the retention of high risk students. NACADA Journal, 8(1), 29-34.

Peterson, M., Wagner, J. A., \& Lamb, C. W. (2001). The role of advising in nonreturning students' perceptions of their university. Journal of Marketing for Higher Education, 10(3), 45-59. doi:10.1300/J050v10n03_03

Riehl, R. J. (1994). The academic preparation, aspirations, and first-year performance of first-generation students. College and University, 70, 14-19.

Roberts, J., \& Styron, R. (2009). Student satisfaction and persistence: Factors vital to student retention. Research in Higher Education Journal, 6, 1-18.

Schertzer, C., \& Schertzer, S. (2004). Student satisfaction and retention: a conceptual model. Journal of Marketing for Higher Education, 14, 79-91. doi:10.1300/J050v14n01_05

Schneider, M. (2010). Finishing the first lap: The cost of first year student attrition in America. American Institutes for Research. Retrieved from http://www.air.org/files/AIR_Schneider_Finishing_the_First_Lap_Oct101.pdf.

Schreiner, L. A. (2009). Linking student satisfaction and retention. Coralville, IA: NoelLevitz.

Schroeder, S. (2012). Undergraduate business student satisfaction with academic advising (Unpublished doctoral dissertation). University of Wisconsin, Madison, WI. 
Seidman, A. (1991). The evaluation of a pre/post admissions/counseling process at a suburban community college: impact on student satisfaction with the faculty and the institution, retention, and academic performance. College and University, 66, 223-232.

Smith, C., \& Allen, J. (2006). Essential functions of academic advising: What students want and get. NACADA Journal, 26(1), 56-66.

Smith, C., \& Allen, J. (2012). Does contact with advisors predict learning outcomes? A multi-institutional study. Manuscript submitted for publication.

Smith, J. S. (2002). First-year students perception of academic advisement: A qualitative study and reality check. NACADA Journal, 22(2), 39-49.

Smith, K. (2004). Perceptions of academic advising and freshman student retention: an application of Tinto's Model (Unpublished doctoral dissertation). Florida State University, Tallahassee, FL.

Tinto, V. (1975). Dropout from higher education: A theoretical synthesis of recent research. Review of Educational Research, 45, 89-125.

doi:10.3102/00346543045001089

Tinto, V. (1993). Leaving college: Rethinking the causes and cures of student attrition ( $2^{\text {nd }}$ ed.). Chicago, IL: University of Chicago.

Upcraft, M. L., \& Gardner, J. N. (1989). The freshman year experience. Helping students survive and succeed in college. San Francisco, CA: Jossey-Bass. 
Veysey, L. R. (1965). The emergence of the American university. Chicago, IL: University of Chicago.

World Bank Staff. (2010). Migration and Remittances Factbook 2010. Washington, DC: World Bank Publications.

Yarbrough, E. (2010). An examination of academic advising style preference in undergraduate students (Unpublished doctoral dissertation). Auburn University, Auburn, AL. 
Appendix A

\author{
Inventory of Academic Advising Functions \\ Student Version \\ (C) Cathleen L. Smith and Janine M. Allen
}

Instructions: Please answer the following questions according to your experiences at Name of Institution.

Which of the following best describes where at Name of Institution you get your PRIMARY academic advising, i.e., the advising you consider most central to your academic progress? (Choose one)
$\square$ I have not received academic advice from faculty or staff atName of Institution
$\square$ Adviser in my major department
$\square$ List include places at the institution where students might receive advising
$\square$ Other (please specify)

If you selected other, please specify

On average, how often do you get advice from your primary source of advising, i.e., the advising you consider most central to your academic progress?

$\square$ I'm not currently getting academic advice from faculty or staff at Name of

Institution

$\square$ At least once per term

$\square$ At least twice per year

$\square$ At least once per year 
How do you access your primary source of advising, i.e., the advising you consider most central to your academic progress?

$\square$ Phone

$\square$ Email

$\square$ In person

$\square \operatorname{Fax}$

Please select the circle that best describes where you get most of your information about classes to take to meet requirements.

$\square$ Adviser/Professor in my major department

$\square$ List include places at the institution where students might receive advising I

$\square$ Bulletin (University Catalog)

$\square$ Undergraduate Advising Website

$\square$ Departmental Website

$\square$ Friend(s)/Other Student(s)

$\square$ Family Member(s)

Overall, I am satisfied with the academic advising I receive at Name of Institution.

$\square 1$ Strongly Disagree

$\square 2$

$\square 3$

$\square 4$

$\square 5$

$\square 6$ Strongly Agree

It is important for me to graduate from college.

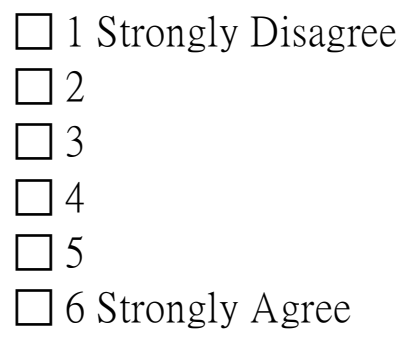

I am confident that I made the right decision in choosing to attend Name of Institution.

$\square 1$ Strongly Disagree 


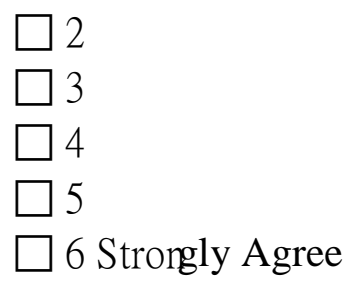

I have a plan to achieve my educational goals.

$\square 1$ Strongly Disagree

$\square 2$

$\square 3$

$\square 4$

$\square 5$

$\square 6$ Strongly Agree

I have had at least one relationship with a faculty or staff member at Name of Institution that has had a significant and positive influence on me.

$\square 1$ Strongly Disagree

$\square 2$

$\square 3$

$\square 4$

$\square 5$

$\square 6$ Strongly Agree

I plan to graduate from Name of Institution.

$\square 1$ Strongly Disagree

$\square 2$

$\square 3$

$\square 4$

$\square 5$

$\square 6$ Strongly Agree

Overall, I am satisfied with my educational experience at Name of Institution.

$\square 1$ Strongly Disagree

$\square 2$

$\square 3$

$\square 4$

$\square 5$

6 Strongly Agree 
Highest educational level of your parent(s)/guardian(s)

Parent Number One

$\square$ High Schooldegree or less, no college

$\square$ Some college, no degree

$\square$ Associate (2 year) degree

$\square$ Baccalaureate (e.g., BS or BA) degree or above

\section{Parent Number Two}

$\square$ Not applicable, I have only one parent

$\square$ High school degree or less, no college

$\square$ Some college, no degree

$\square$ Associate (2 year) degree

$\square$ Baccalaureate (e.g., BS or BA) degree or above

Does your family use a language other than English at home?

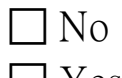

$\square$ Yes

In the space provided, please indicate the name(s) of the language(s), other than English, used in your home.

Have you ever been a foster child?

$\square$ No

$\square$ Yes

The following questions refer to various kinds of help that academic advisers might provide to students. Given your experience with your PRIMARY source of 
academic advising at Name of Institution, i.e., the advising you consider most central to your academic progress, make two ratings for each advising function.

a. its importance to you

b. your satisfaction with the advising you receive

Advising that helps students connect their academic, career, and life goals.

How important is this advising function to you?

$\square 1$ Not Important

$\square 2$

$\square 3$

$\square 4$

$\square 5$

$\square 6$ Very Important

How satisfied are you with the advising you receive on this function?

$\square 1$ Not Satisfied

$\square 2$

$\square 3$

$\square 4$

$\square 5$

$\square 6$ Very Satisfied

Advising that helps students choose among courses in their major that connect their academic, career, and life goals.

How important is this advising function to you?

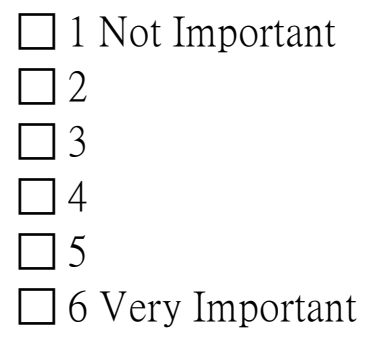


How satisfied are you with the advising you receive on this function?

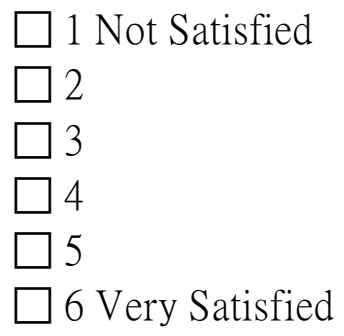

Advising that assists students with choosing among the various General Education options (e.g., examples unique to each institution) that connect their academic, career, and life goals.

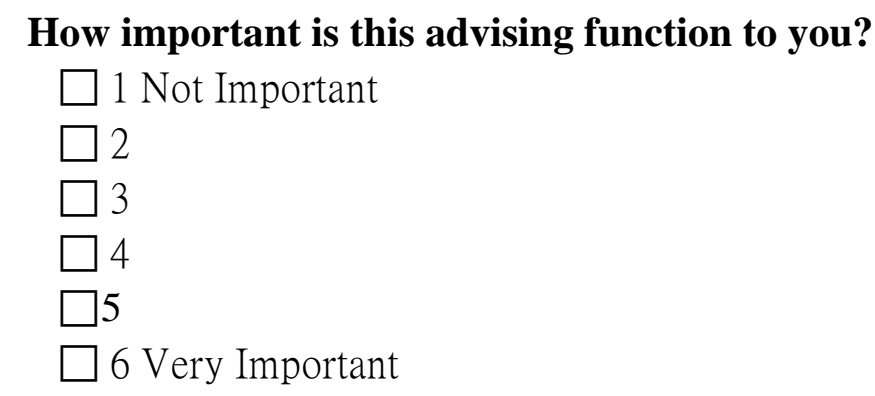

How satisfied are you with the advising you receive on this function?

$\square 1$ Not Satisfied

$\square 2$

$\square 3$

$\square 4$

$\square 5$

$\square 6$ Very Satisfied

Advising that assists students with deciding what kind of degree to pursue (Examples for Universities include: Bachelor of Science, Bachelor of Arts)

How important is this advising function to you?

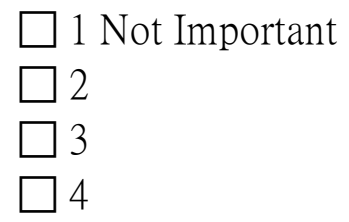


$\square 5$

$\square 6$ Very Important

How satisfied are you with the advising you receive on this function?

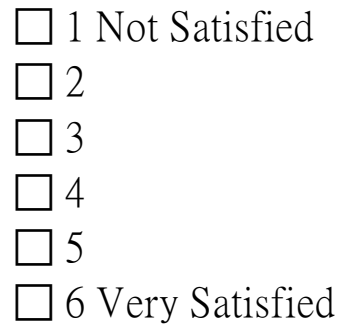

Advising that assists students with choosing out-of-class activities (e.g., part-time or summer employment, internships or practicum, participation in clubs or organizations) that connect their academic, career, and life goals.

How important is this advising function to you?

$\square 1$ Not Important

$\square 2$

$\square 3$

$\square 4$

$\square 5$

$\square 6$ Very Important

How satisfied are you with the advising you receive on this function?

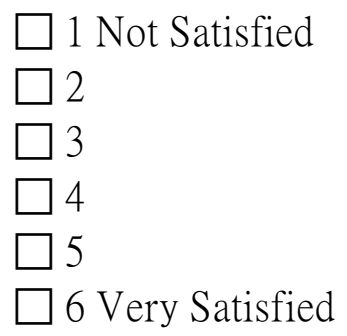

When students need it, referral to campus resources that address academic problems (e.g., math or science tutoring, writing, disability accommodation, test anxiety). 
How important is this advising function to you?

$\square 1$ Not Important
$\square 2$
$\square 3$
$\square 4$
$\square 5$
$\square 6$ Very Important

How satisfied are you with the advising you receive on this function?

$\square 1$ Not Satisfied

$\square 2$

$\square 3$

$\square 4$

$\square 5$

$\square 6$ Very Satisfied

When students need it, referral to campus resources that address non-academic problems (e.g., child-care, financial, physical and mental health).

How important is this advising function to you?

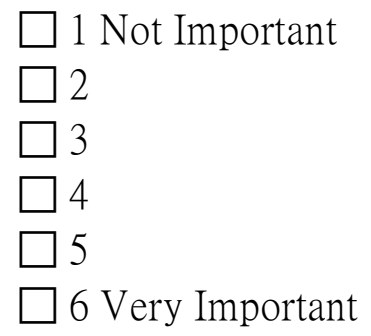

How satisfied are you with the advising you receive on this function?

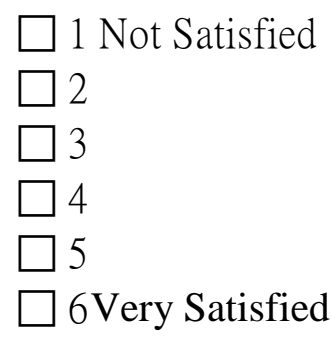

Assisting students with understanding how things work at Name of Institution 
(understanding timelines, policies, and procedures with regard to registration, financial aid, grading, graduation, petitions and appeals, etc.).

How important is this advising function to you?

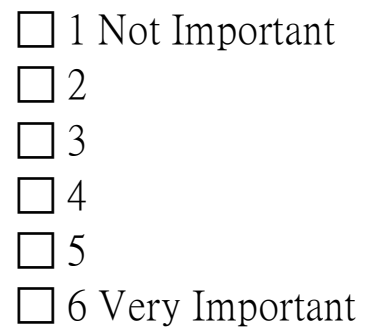

How satisfied are you with the advising you receive on this function?

$\square 1$ Not Satisfied

$\square 2$

$\square 3$

$\square 4$

$\square 5$

$\square 6$ Very Satisfied

Ability to give students accurate information about degree requirements.

How important is this advising function to you?

$\square 1$ Not Important

$\square 2$

$\square 3$

$\square 4$

$\square 5$

$\square 6$ Very Important

How satisfied are you with the advising you receive on this function?

$\square 1$ Not Satisfied

$\square 2$

$\square 3$

$\square 4$ 


\section{$\square 6$ Very Satisfied}

Taking into account students' skills, abilities, and interests in helping them choose courses.

How important is this advising function to you?

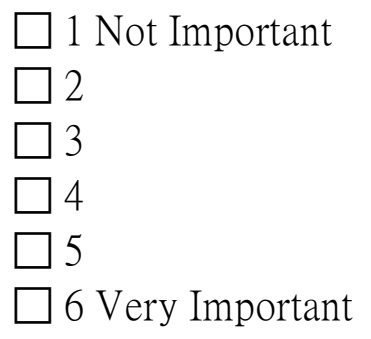

How satisfied are you with the advising you receive on this function?

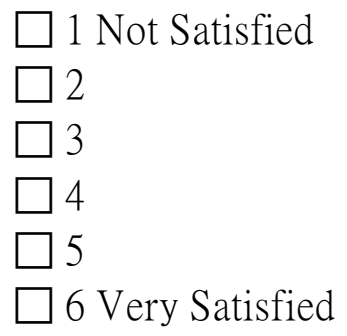

Knowing the student as an individual.

How important is this advising function to you?

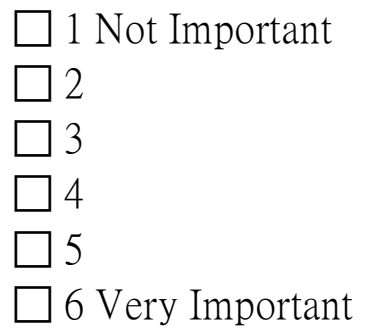

How satisfied are you with the advising you receive on this function?

$\square 1$ Not Satisfied

$\square 2$ 


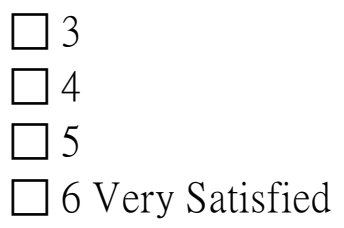

Encouraging students to assume responsibility for their education by helping them develop planning, problem-solving, and decision-making skills.

How important is this advising function to you?

$\square 1$ Not Important

$\square 2$

$\square 3$

$\square 4$

$\square 5$

$\square 6$ Very Important

How satisfied are you with the advising you receive on this function?

$\square 1$ Not Satisfied

$\square 2$

$\square 3$

$\square 4$

$\square 5$

$\square 6$ Very Satisfied

For the next series of questions, indicate your level of agreement.

It is important to develop an adviser/advisee relationship with someone on campus.

$\square 1$ Strongly Disagree

$\square 2$

$\square 3$

$\square 4$

$\square 5$

$\square 6$ Strongly Agree 
There should be mandatory academic advising for students.

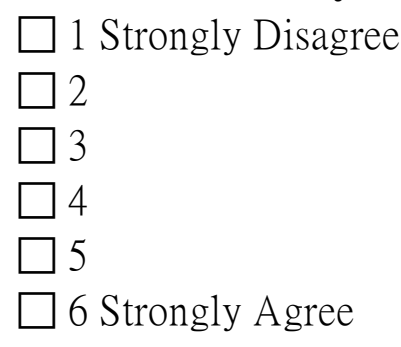

43) I know what requirements (e.g., major, general education, other university requirements) I must fulfill in order to earn my degree.

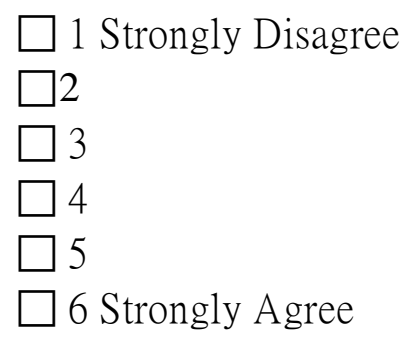

I understand how things work at Name of Institution (timelines, policies, and procedures with regard to registration, financial aid, grading, graduation, petition and appeals, etc.)

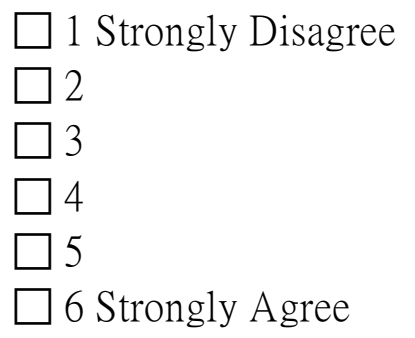

I understand how my academic choices at Name of Institution connect to my career and life goals.

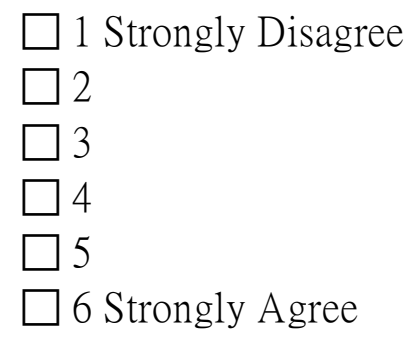

When I have a problem, I know where at Name of Institution I can go to get help. 


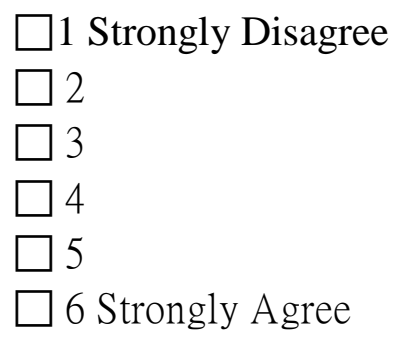

I have used the university's electronic degree audit system. If applicable.<smiles>[Mg][Mg]</smiles>

The electronic degree audit system is helpful in understanding academic requirements at Name of Institution and tracking progress toward my degree.

$\square 1$ Strongly Disagree

$\square 2$

$\square 3$

$\square 4$

$\square 5$

$\square 6$ Strongly Agree

I believe I have been accurately advised by faculty or staff at Name of Institution.

$\square$ Yes

$\square$ No

If no, what consequences resulted from the advising inaccuracy? (check all that apply)

$\square$ I have had to delay my graduation in order to take one or more additional classes.

$\square$ I have petitioned for an exception to an academic requirement.

$\square$ I have had to take one or more classes that I later discovered I didn't need (for universities students “to Graduate” was added).

$\square$ I took a course that did not transfer as I expected(An option for community college students)

$\square$ I was placed in a course for which I was unprepaed.

$\square$ Other (please specify) 
If you selected other, please specify

51) Please use the space below to comment about any aspect of advising at Name of institution: 
Appendix B

\section{Initial Email to Students Regarding Survey}

Subject: Academic Advising at Study Institution - We Need Your Input

Dear Study Institution Student:

Academic advising is important to students, and because you are a student at Study Institution, I want to hear about your experiences with advising. I am inviting you to complete a survey that will tell us what you think about academic advising at Study Institution. Your answers to these questions are crucial to our continued efforts to improve student experiences at Study Institution, and I hope you will participate in this research by taking the 12 minutes required to complete the survey. You can take the survey now through this link: Take the Survey.

Please be assured that the answers you provide will be kept confidential to the extent permitted by law. Special precautions have been established to protect the confidentiality of your responses by using an electronic system that will separate your survey responses from any personally identifiable information that could link your responses to you. Any information that is obtained in connection with this study that can be linked to you or identify you will be confidential. The answers you provide will be summarized along with the responses of other students so that your individual responses will never be identified in any report. There are no foreseeable risks to you as a participant in this project; nor are there any direct benefits. However, your participation is extremely valued.

Although your participation is entirely voluntary, I hope you will complete the survey. Your willingness or unwillingness to participate will not affect decisions involving course grades or other evaluations of your coursework, or your employment or relationship with Study Institution. You may choose not to participate and can skip any question or withdraw at any time.

If you have questions about your rights as a participant in this research project, please contact Study Institution Institutional Review Board (IRB) Human Protections Administrator at (XXX) XXX-XXXX or by email at IRB@studyinstitution. If you have questions about the study itself, please contact the Study Administrator at (XXX) XXX- 
XXXX or studyadministrator@studyinstitution.edu.

Thank you for telling us what we are doing well with academic advising and where we need to improve. You can take the survey now through this link: Take the Survey.

Sincerely,

Study Administrator

\section{Follow Up Email to Students}

Subject: Tell us about academic advising at Study Institution

Dear Study Institution Student:

A short time ago, I invited you to answer some questions related to academic advising and your experiences at Study Institution. As a Study Institution student, your answers to these questions are crucial to our continued efforts to improve academic advising at Study Institution, and I hope you will participate in this research by taking the 12 minutes required to complete the survey. You can take the survey now through this link: Take the Survey.

Please be assured that the answers you provide will be kept confidential to the extent permitted by law. Special precautions have been established to protect the confidentiality of your responses by using an electronic system that will separate your survey responses from any personally identifiable information that could link your responses to you. Any information that is obtained in connection with this study that can be linked to you or identify you will be confidential. The answers you provide will be summarized along with the responses of other students so that your individual responses will never be identified in any report. There are no foreseeable risks to you as a participant in this project; nor are there any direct benefits. However, your participation is extremely valued.

Although your participation is entirely voluntary, I hope you will complete the survey. Your willingness or unwillingness to participate will not affect decisions 
involving course grades or other evaluations of your coursework, or your employment or relationship with Study Institution. You may choose not to participate and can skip any question or withdraw at any time.

If you have questions about your rights as a participant in this research project, please contact Study Institution Institutional Review Board (IRB) Human Protections Administrator at (XXX) XXX-XXXX or by email at IRB@studyinstitution.edu. If you have questions about the study itself, please contact Study Administrator at (XXX) XXXXXXX or Studyadministrator@studyinstitution.edu.

Thank you for telling us what we are doing well with academic advising and where we need to improve. You can take the survey now through this link: Take the Survey.

Sincerely,

Study Administrator

\section{Second follow up email to students}

Subject: Academic Advising: Your opinion matters

Dear Study Administrator Student:

I know this is a busy time of the year, but your opinion as a Study Institution student matters to me and other decision makers at Study Institution. That is why I am asking you once again to complete a survey about academic advising and your experiences at Study Institution. You can take the survey by clicking here (add link).

Your answers to these questions are crucial to our continued efforts to improve the student experience at Study Institution, and I hope you will participate in the research by taking the 12 minutes required to answer the questions. This survey will be open until (Insert date and time). There is still time to let your opinions be heard by clicking here (add link).

Please be assured that the answers you provide will be kept confidential to the extent permitted by law. Special precautions have been established to protect the confidentiality of your responses by using an electronic system that will separate your survey responses from any personally identifiable information that could link your responses to you. Any 
information that is obtained in connection with this study that can be linked to you or identify you will be confidential. The answers you provide will be summarized along with the responses of other students so that your individual responses will never be identified in any report. There are no foreseeable risks to you as a participant in this project; nor are there any direct benefits. However, your participation is extremely valued.

Although your participation is entirely voluntary, I hope you will complete the survey. Your willingness or unwillingness to participate will not affect decisions involving course grades or other evaluations of your coursework, or your employment or relationship with Study Institution. You may choose not to participate and can skip any question or withdraw at any time.

If you have questions about your rights as a participant in this research project, please contact Study Institution Institutional Review Board (IRB) Human Protections Administrator at (XXX) XXX-XXXX or by email at IRB@studyinstitution.edu. If you have questions about the study itself, please contact Study Administrator at (XXX) XXXXXXX or Studyadministrator@studyinstitution.edu.

Thank you for telling us what we are doing well with academic advising and where we need to improve. You can take the survey now through this link: Take the Survey.

Sincerely,

Study Administrator 
Appendix C

Student Demographic and Enrollment Data and Definitions from Student Information Systems (SIS) and Survey

\begin{tabular}{|c|c|}
\hline Variable Name & Description \\
\hline \multicolumn{2}{|c|}{ Initial Data from SIS on all Participants } \\
\hline Data Reference number & Number assigned to each participant \\
\hline Gender & Male, female \\
\hline \multicolumn{2}{|l|}{ Race/Ethnicity } \\
\hline \multicolumn{2}{|l|}{ Date of Birth } \\
\hline Citizenship & US citizen or non-US citizen \\
\hline Visa & Type of visa \\
\hline EFC & Expected Family Contribution for Financial Aid \\
\hline Pell & Amount of Pell grant received \\
\hline $\begin{array}{l}\text { High School Graduation } \\
\text { date }\end{array}$ & Year student graduated from high school \\
\hline actc & ACT Composite \\
\hline satm & SAT Math \\
\hline satv & SAT Verbal \\
\hline \multicolumn{2}{|l|}{ High school GPA } \\
\hline Class level & $\begin{array}{l}\text { Freshmen, sophomore, junior, senior during term in which } \\
\text { the survey is administered }\end{array}$ \\
\hline Major_1 & $\begin{array}{l}\text { Student's major in the term in which the survey is } \\
\text { administered }\end{array}$ \\
\hline Admission Term & $\begin{array}{l}\text { Term for which the student was first admitted and/or } \\
\text { enrolled }\end{array}$ \\
\hline
\end{tabular}




\begin{tabular}{|c|c|}
\hline Educational Source & $\begin{array}{l}\text { The type of institution that the student was last enrolled in } \\
\text { prior to enrolling in the study institution, e.g., Oregon high } \\
\text { school, other high school, community college, other four } \\
\text { year institution, GED, international high school, } \\
\text { international four year institution }\end{array}$ \\
\hline Source Institution & $\begin{array}{l}\text { Name of the most recent institution attended prior to } \\
\text { enrollment at the institution }\end{array}$ \\
\hline Admission type & $\begin{array}{l}\text { What is used to determine the admission status of the } \\
\text { student - GED, New freshman from h. s., New freshman } \\
\text { from h. s. w/ college credit, transfer frosh, transfer soph, } \\
\text { transfer junior, transfer senior }\end{array}$ \\
\hline Major & Major at the time the student took the survey \\
\hline Term hrs & Hours completed in fall 2010 \\
\hline Term gpa & Fall 2010 GPA \\
\hline Cum ins hrs & $\begin{array}{l}\text { Cumulative Hours completed at institution at the time the } \\
\text { student took the survey }\end{array}$ \\
\hline Cum ins gpa & $\begin{array}{l}\text { Cumulative Institutional GPA at the time the student took } \\
\text { the survey }\end{array}$ \\
\hline Cum gpa & $\begin{array}{l}\text { Cumulative GPA including transfer and institution GPA at } \\
\text { the time the student took the survey }\end{array}$ \\
\hline Cum hrs & $\begin{array}{l}\text { Cumulative hours including transfer and institution hours at } \\
\text { the time the student took the survey }\end{array}$ \\
\hline Acadstat & $\begin{array}{l}\text { Academic standing, e.g., good standing, academic } \\
\text { probation, at the time the student took the survey }\end{array}$ \\
\hline \multicolumn{2}{|c|}{ Follow-up Data from SIS } \\
\hline Enrollment & Is the student still enrolled in subsequent fall term \\
\hline Major & Student's major in the subsequent fall term \\
\hline Cum GPA & For in the subsequent fall term \\
\hline
\end{tabular}




\begin{tabular}{|l|l|}
\hline Cum Hours & For in the subsequent fall term \\
\hline Graduation Date & $\begin{array}{l}\text { If the student has graduated, term in which the degree was } \\
\text { awarded }\end{array}$ \\
\hline Graduation Major & $\begin{array}{l}\text { If the student has graduated, the major in which the degree } \\
\text { was awarded }\end{array}$ \\
\hline Demographic Data from the Survey \\
\hline Parent Education & To determine first generation college student status \\
\hline Language Spoken at Home & \\
\hline $\begin{array}{l}\text { Former Foster Youth } \\
\text { Status }\end{array}$ &
\end{tabular}

